\title{
Hybridisation in the brown alga Carpophyllum: \\ Investigating morphology, distribution and wave exposure
}

By

Fiona Jean Hodge

\begin{abstract}
A thesis
Submitted to the Victoria University of Wellington

In part fulfilment of the requirements for the degree of

Master of Science

in Marine Biology
\end{abstract}

Victoria University of Wellington

2009 
"There are known knowns. There are things we know that we know. There are known unknowns. That is to say, there are things that we now know we don't know. But there are also unknown unknowns. There are things we do not know we don't know."

- Donald Rumsfeld 


\begin{abstract}
Hybridisation can result in new hybrid lineages, parental species extinctions, the transfer of adaptations, or the merging of parental lineages. Subsequently hybridisation has important implications for the species involved. Hybridisation has recently been confirmed between the Fucalean brown algae Carpophyllum angustifolium and Carpophyllum maschalocarpum using the ITS2 marker. This study conducted a detailed morphometric analysis combined with molecular data to investigate morphology distribution and exposure at two sites on the East Cape. Hybridisation was also morphologically investigated at Leigh, where the previous work had been unable to resolve hybrids using the ITS2 marker.
\end{abstract}

Carpophyllum angustifolium, C. maschalocarpum and their hybrids had distinct and intermediate morphologies, and could be identified by stipe width alone. Individuals with hybrid genotypes with distinctive C. angustifolium morphotypes were also found, which suggests asymmetrical introgression is occurring. Some aspects of $C$. angustifolium and C. maschalocarpum morphology were found to be correlated with wave exposure. In the more exposed zones $C$. angustifolium individuals were longer, while C. maschalocarpum individuals were shorter, had thinner stipes and less frequent vesicle presence. There were also non-significant trends of $C$. maschalocarpum individuals having thinner lamina, and lower branch presence in higher wave exposures. The distributions of C. angustifolium, C. maschalocarpum and their hybrids were found to be correlated with exposure. Carpophyllum angustifolium was distributed only in the relatively exposed zones, while $C$. maschalocarpum was distributed mainly in the more sheltered zones. Hybrids were distributed in intermediate exposure zones where both parental species were present. 
The hybrid distributions could be a reflection of environmental selection or of the parental contact zone. Morphological evidence was found for hybridisation at Leigh, although there were differences between the morphologies of East Cape and Leigh clusters of $C$. angustifolium and hybrids. These differences could be due to environmental differences, genetic differentiation or different levels of introgression between the two locations. The general findings in this study support the existing literature on hybridisation, which mainly comes from terrestrial plant and animal species complexes. 


\section{Acknowledgements}

Many people have given their time, advice and assistance to me during the production of this thesis. Firstly thanks to Joe Zuccarello for his constant patience and guidance. Thanks also to Joe Buchanan for his advice on all things Carpophyllum, and supply of helpful papers and grammar tips.

Tracey Taylor, Jen Van der Veur, and Aaron Packard came away with me as field assistants and risked life and limb getting the Carpophyllum off rocks, in spite of treacherous seas, rocks and barnacles. Richard Taylor facilitated my field work at Leigh. Neville Higgison built me a set of dynamometers, and helped solve the attachment problems. Carlos Lehnebach provided statistical assistance. The Phycology Lab Group, Plant Club, and KK702 all provided a place to sound out ideas, as well as support and encouragement.

Thanks to my parents for the car, freezer space, and ongoing support. My brother David toiled over my drafts, and provided some amazing advice on structure and semi-colons. Bart Ludbrook provided assistance with physics.

I am grateful for the financial support from the VUW MSc by thesis Scholarship, Alison Morton Scholarship, Kathleen Stewart Scholarship and the New Zealand Postgraduate Study Abroad award. 


\section{Table of Contents}

Abstract

Acknowledgements $\quad \mathrm{V}$

Table of Contents vi

Chapter 1: General Introduction $\quad 1$

Chapter 2: Morphological differences between Carpophyllum 9

angustifolium $\times$ Carpophyllum maschalocarpum hybrids and their parents

2.1 Abstract 9

2.2 Introduction 9

2.3 Methods

Sampling locations $\quad 13$

Sampling 13

Morphometrics 14

Genetic analysis $\quad 14$

Morphometric data analysis 16

2.4 Results $\quad 18$

ITS2 sequences and morphological identification $\quad 18$

Morphology of clusters 18

$\begin{array}{ll}\text { Comparing morphologies } & 21\end{array}$

2.5 Discussion 24

Chapter 3: Wave exposure and morphology in Carpophyllum 29

angustifolium and Carpophyllum maschalocarpum

$\begin{array}{ll}3.1 \text { Abstract } & 29\end{array}$

3.2 Introduction $\quad 29$

3.3 Methods 32

Sampling locations $\quad 32$

Assessing wave exposure $\quad 33$

Morphometrics $\quad 35$

$\begin{array}{ll}\text { Data analysis } & 37\end{array}$ 
3.4 Results 38

Wave exposure and morphology 38

Site effect $\quad 42$

3.5 Discussion 42

Chapter 4: Distribution of C. angustifolium, C. maschalocarpum, and 48 their hybrids with regard to wave exposure

4.1 Abstract 48

4.2 Introduction 49

4.3 Methods 52

Sampling locations 52

Assessing wave exposure $\quad 53$

Sampling $\quad 54$

Laboratory analysis $\quad 55$

Data analysis $\quad 56$

4.4 Results $\quad 56$

Distribution of parent species $\quad 56$

Distribution of hybrids $\quad 57$

Site differences $\quad 58$

$\begin{array}{ll}\text { 4.5 Discussion } & 58\end{array}$

Chapter 5: Morphological evidence of hybridisation in Carpophyllum 63 angustifolium and Carpophyllum maschalocarpum populations from Leigh

5.3 Methods 66

Sampling locations $\quad 66$

$\begin{array}{ll}\text { Sampling } & 67\end{array}$

Morphometrics $\quad 68$

$\begin{array}{ll}\text { Data analysis } & 69\end{array}$

$\begin{array}{ll}5.4 \text { Results } & 70\end{array}$

$\begin{array}{ll}\text { Leigh morphologies } & 70\end{array}$

$\begin{array}{ll}5.5 \text { Discussion } & 73\end{array}$ 
$\begin{array}{ll}\text { Chapter 6: General Discussion } & 77\end{array}$

Morphology 77

Morphology and wave exposure $\quad 78$

Distribution $\quad 79$

Hybridisation at Leigh $\quad 80$

Limitations of this study $\quad 82$

Future directions $\quad 82$

Conclusion $\quad 83$

$\begin{array}{lr}\text { References } & 84\end{array}$

Appendix 1: Cluster tree of all morphologically identified individuals 93 from the East Cape

Appendix 2: Herbarium specimens $\quad 94$ 


\section{Chapter 1: General Introduction}

Hybridisation occurs when two species crossbreed to produce offspring. It is a common and important evolutionary process. Hybrids have been identified in a broad range of ecosystems and species, from irises in Louisiana (Emms \& Arnold, 1997) to Cichlid fish in Lake Victoria (Crapon de Caprona \& Fritzsch, 1984). It is estimated that $25 \%$ of plant species, and $10 \%$ of animal species are currently hybridising in the wild (Mallet, 2005).

Biodiversity can be significantly affected by hybridisation (Seehausen, 2004). Hybridisation can result in new hybrid lineages, parental species extinctions, or the merging of parental lineages. Introgression, the backcrossing of hybrids with parental species, can occur and can be common (Rieseberg, 1998). Introgression can affect parental genetic diversity by transferring genetic adaptations between parent species (Seehausen, 2004). Consequently hybridisation has important implications for the conservation and management of biodiversity. In New Zealand hybridisation and introgression affect the genetic integrity and conservation of the black stilt, Himantopus novaezelandiae (Greene, 1999), and the hen and chicken fern, Asplenium bulbiferum, (Perrie et al., 2005). Hybridisation and introgression have also been hypothesised to stimulate invasiveness in exotic species (Ellstrand \& Schierenbeck, 2000).

Hybridisation is interesting to study for a variety of reasons. Taxonomically it challenges existing species concepts, definitions, and boundaries. It also offers opportunities to investigate evolution and speciation processes in the wild. Hypotheses surrounding fitness and environmental selection can be explored with the 
novel hybrid phenotypes and genotypes (Campbell \& Waser, 2001; Fritz, 1999; Johansen-Morris \& Latta, 2008). The mix of parental genes within hybrids allows investigation of co-adapted gene complexes (Baack \& Rieseberg, 2007; Landry et al., 2007; Landry et al., 2005), and cytoplasm-nuclear DNA interactions (Fishman \& Willis, 2006; Levin, 2002; Sambatti et al., 2008).

The development of molecular markers has allowed more rigorous identification of hybridisation and introgression than traditional morphometric techniques (Rieseberg, 1998). Molecular markers have revealed hybrids between highly plastic or cryptic taxa (e.g. in fungi Kauserud et al., 2007), as well as hybrids with parental morphologies (Lihova et al., 2007). Introgression can also be identified and quantified with molecular markers (Chen et al., 2004; Coyer et al., 2007; Hardig et al., 2000; Wallace et al., 2004). Molecular techniques use species level variation in nuclear, chloroplast, or mitochondrial DNA markers with the assumption that species specific markers from both parental species will be found in the hybrids (Hegarty \& Hiscock, 2005). The consensus in the literature is that combining morphological and molecular data is optimal for investigating hybrid systems (Lihova et al., 2007; Repplinger et al., 2007; Tiebre et al., 2007).

Research into most hybrid systems now begins with identifying and confirming hybridisation using morphological and molecular tools (e.g. Coyer et al., 2002a). Following this the phenotypes of hybrids and parental species are documented to generate hypotheses about the distribution and results of hybridised genomes (Thorsson et al., 2007). A practical outcome of this documentation of phenotypes is the development of morphological traits for field identification. Hybrids usually have 
intermediate morphologies to the parental species which reflect their mixed genotype (Coyer et al., 2002a; Estabrook et al., 1996; Wilson, 1992). However, the morphology of hybrids can be similar to, or even more extreme than, the parental species (Coyer et al., 2002a; Rieseberg \& Ellstrand, 1993; Seehausen, 2004). Morphologically distinguishing hybrids from parental species can be difficult due to intra-specific variation and phenotypic plasticity (Mathieson et al., 1981; Rieseberg \& Ellstrand, 1993; Scott \& Hardy, 1994). Documenting the morphology of hybrids and parental species can be further complicated by introgression, which can result in a continuum of morphologies between the parental species (Albert et al., 1997).

The distribution of hybrids is particularly intriguing. Hybrids tend to have unusual zoned distributions (Rieseberg, 1998). Hybrids are often found in intermediate environments from the parental species, but can also occur in marginal or novel environments (Arnold, 1997; Coyer et al., 2006; Scott \& Hardy, 1994). These distributions have been explained by a range of models that each place differing importance on the relative roles of endogenous hybrid fitness, environmentally dependent fitness, and dispersal limitations. These include the evolutionary novelty model (Arnold, 1997), the tension zone model (Barton \& Hewett, 1985), the mosaic hybrid zone model (Harrison, 1986), and the bounded hybrid superiority model (Moore, 1977). Determining patterns of hybrid distribution relative to environmental parameters is an important first step to establishing the role of environmental selection (Rieseberg, 1998). There is generally support for the distribution of hybrids being environmentally dependent (Fritsche \& Kaltz, 2000; Harrison, 1993; Wang et al., 1997). This is a reflection of the relative fitness of hybrids in certain environments (Arnold \& Hodges, 1995; Fritsche \& Kaltz, 2000; Wang et al., 1997). 
Hybridisation research has disproportionately focused on vascular plants and animals. A recent literature review on hybridisation investigated plants and animals only (Mallet, 2005). The vast majority of research into hybridisation is done in terrestrial habitats (Gardner, 1997). Despite this the level of hybridisation in marine taxa is thought to be equivalent to terrestrial taxa (Gardner, 1997). Hybridisation has been identified in a range of marine taxa including mussels, and algae (Coyer et al., 2007; Schneider et al., 2005). Hybridisation occurs in the brown macro-algae, phylum Phaeophyta, kingdom Chromista (e.g. Coyer et al., 2002a; Lewis \& Neushul, 1995; Wallace et al., 2004). Investigations of hybridisation in Phaeophyceae can provide insights from a taxonomically and ecologically distinct study system.

Phaeophyceae provide exciting, but challenging, study organisms for the investigation of hybrid morphology and distribution. Phaeophyceae are extremely plastic, which can make hybridisation morphologically difficult to identify (Scott \& Hardy, 1994). Phaeophyceae are the dominant primary producers in temperate intertidal and subtidal ecosystems, and are often important ecological components of their local habitats (Graham \& Wilcox, 2000). Intertidal and subtidal habitats are interesting to study environmental selection in as they have large environmental variation over small spatial scales (Nybakken \& Bertness, 2004).

Exposure to water motion has been found to have particularly significant effects on the distribution and morphology of local macroalgae biota in the shallow subtidal (Engelen et al., 2005; Johnson \& Koehl, 1994; Tuya \& Haroun, 2006). Water motion around macroalgae affects nutrient acquisition and creates mechanical fatigue (Hurd, 
2000; Mach et al., 2007). It can also result in the loss of biomass or dislodgement of entire individuals, which creates selection pressures (Hurd, 2000; Kawamata, 2001). The effects of wave exposure on different morphologies has been relatively well studied; flexible, streamlined and strong macroalgae fare best in high wave exposures (Puijalon \& Bornette, 2004; Stewart, 2006; Thomsen et al., 2004; Wernberg \& Thomsen, 2005). Consequently interesting comparisons can be made on the effects of wave exposure between novel hybrid and parental pheonotypes in Phaeophyceae.

The vast majority of work investigating hybridisation within Phaeophyceae has been done in the order Fucales (Billard et al., 2005; Coyer et al., 2002a; Lewis, 1996; Wallace et al., 2004). Hybridisation between Fucus species has been observed and investigated morphologically since the 1850 s (Thuret, 1854). Fucalean algae are useful organisms to study hybridisation in for a number of reasons. Firstly they are abundant and often ecologically dominant in easily accessible intertidal and high subtidal habitats (Graham \& Wilcox, 2000). Secondly there is a good baseline of information on their life history, reproduction, and ecology (e.g. see review by Chapman, 1995). Thirdly Fucales have a diplontic life cycle with only one free living multicellular phase (Chapman, 1995). This simple life cycle makes considering fitness and the effects of selection much easier. Dispersal capacity in Fucales is limited, due to their large non-motile eggs, allowing study into hybridisation to occur at small spatial scales (Chapman, 1995; Schiel, 1980). Almost all of the study into hybridisation in Fucalean algae has been on the intertidal genus Fucus in the Northern Hemisphere (e.g. Billard et al., 2005; Coyer et al., 2002a; Wallace et al., 2004). The dominance of Fucalean algae in the high subtidal is considered one of the 
unusual aspects of New Zealand's algal flora; this provides a novel Fucalean study system (Schiel, 1990).

Carpophyllum angustifolium J. Agardh and Carpophyllum maschalocarpum Turner (Sargassaceae) are two Fucalean species which dominate high subtidal habitats in New Zealand (Schiel, 1990). The two species have different morphologies. Carpophyllum angustifolium is streamlined and flexible with strong aggregating holdfasts. Carpophyllum maschalocarpum is much less streamlined with large laminae, wide flat stipes, and often bearing vesicles (Adams, 1994; Dromgoole, 1965; Lindauer et al., 1961). The parental species distribution are thought to be structured by wave exposure with $C$. angustifolium in more exposed areas, and $C$. maschalocarpum in more sheltered areas (Adams, 1994; Dromgoole, 1965; Lindauer et al., 1961). Individuals with morphology intermediate to $C$. angustifolium and $C$. maschalocarpum have been observed since at least the early 1960s (Lindauer et al., 1961). These individuals were long hypothesised to be hybrids (Dromgoole, 1973; Lindauer et al., 1961), however no work was done to verify this hypothesis until recently (Buchanan, unpubl. data).

Recent molecular work confirmed several of these individuals with intermediate morphologies to be hybrids (Buchanan, unpubl. data). The internal transcribed spacer (ITS) sequence used to confirm the putative hybrids is one of the most widely used sequences in plant evolutionary studies (Feliner \& Rossello, 2007). ITS is a biparentally inherited nuclear DNA marker; hybrids are the ITS heterozygotes where parental species have distinct ITS sequences (Coyer et al., 2002b). Carpophyllum angustifolium and C. maschalocarpum in the East Cape populations each have a 
single distinct ITS2 ribotype, which allows ITS2 based detection of hybrids (Buchanan, unpubl. data). However multiple ITS2 ribotypes were found in more northern C. angustifolium and C. maschalocarpum populations - some of which were shared (Buchanan, unpubl.). Consequently ITS2 alone cannot resolve hybrids in northern populations.

The presence of shared ribotypes in northern populations could be due to introgression. Vesicles, conceptacles, eggs and sperm have been found on $C$. angustifolium $\times$ C. maschalocarpum hybrids which suggests they could be fertile (Buchanan \& Hodge, unpubl. data). These potentially fertile hybrids were found when both parental species were also fertile, which suggests the potential for introgression.

The aim of this thesis is to combine morphological and molecular tools to investigate Carpophyllum angustifolium, Carpophyllum maschalocarpum, and in particular their hybrids. In Chapter 2 the morphological differences between genetically identified $C$. angustifolium, C. maschalocarpum, and their hybrids will be explored. Are the three groups morphologically distinct? Do the hybrids have intermediate morphology? Is there evidence of introgression? Chapter 3 will investigate whether the morphology of $C$. angustifolium and C. maschalocarpum vary by wave exposure. Does the morphology of C. angustifolium and C. maschalocarpum individuals change in areas of different wave exposure? Is the relationship between wave exposure and morphology the same in both species? In Chapter 4 the distribution of parental species and hybrids with relation to each other and wave exposure will be analysed. Are the distributions of $C$. angustifolium and C. maschalocarpum correlated with 
wave exposure? Do the hybrids occur in novel environments from the parental species? Are the hybrids in intermediate wave exposure environments relative to the parents? Finally in Chapter 5 Carpophyllum morphology will be compared between individuals from Leigh and the East Cape. Is hybridisation also occurring at Leigh? Is there evidence of extensive introgression?

It should be noted that the following chapters are written as independent scientific papers, and consequently there is some repetition of core ideas and methodology. 


\section{Chapter 2: Morphological differences between Carpophyllum angustifolium $\times$ Carpophyllum maschalocarpum hybrids and their parents}

\subsection{Abstract}

Hybridisation is an important evolutionary process, which can have significant effects on biodiversity. Hybridisation tends to produce morphologies intermediate to the parent species. Most species of macroalgae in the class Phaeophyceae have highly plastic morphologies, which makes species identifications based on morphology difficult - particularly if hybridisation is occurring. Recent work using the molecular marker ITS2 has confirmed hybridisation between Carpophyllum angustifolium and C. maschalocarpum on the East Cape of New Zealand. In the present study, morphological differences were investigated between $C$. angustifolium, C. maschalocarpum and their hybrids from East Cape populations. It was found that the hybrids had an intermediate morphology to the parent species. Stipe width clearly differentiated hybrids from the parent species and was the best single character for identification. Some individuals with $C$. angustifolium morphology had hybrid ITS2 ribotypes suggesting backcrossing between the hybrids and $C$. angustifolium.

\subsection{Introduction}

Hybridisation is an important evolutionary process that brings together diverged genetic lineages, through the crossing of two genetically distinct species. Hybridisation challenges our species definitions and provides insight into speciation 
processes (Seehausen, 2004). It also produces unique hybrid morphologies. Hybrids are generally expected to have intermediate morphologies reflecting their mixed genotype, but may also have morphologies similar to, novel from, or more extreme than the parental species (Coyer et al., 2002a; Lihova et al., 2007; Seehausen, 2004). Identification of hybrids based on morphology can be difficult due to the large degree of intra-specific variation and phenotypic plasticity present in many taxa (Rieseberg \& Ellstrand, 1993; Scott \& Hardy, 1994). Furthermore, morphological intermediacy does not always indicate hybrids and may reflect patterns of plasticity or environmental variation (Mathieson et al., 1981).

Introgression, the backcrossing of hybrids with parental species, can result in a continuum of morphologies between the parental species (Albert et al., 1997). Introgression has been described as the most common outcome of hybridisation (Rieseberg, 1998). Introgression is of great evolutionary significance as it can result in the transfer of adaptations between species (Seehausen, 2004). Other potential outcomes of introgression include the strengthening of reproductive barriers and further divergence of the parental species, or the development of new hybrid lineages (Grant et al., 2004; Lihova et al., 2007; Seehausen, 2004).

The Phaeophyceae, brown macroalgae, are a morphologically diverse group. Individuals range from microscopic filaments to the more familiar large conspicuous fleshy seaweeds (Graham \& Wilcox, 2000; Phillips, 2007). Even within species there is great morphological variation, due to phenotypic plasticity and environmental selection (Mathieson et al., 1981). Despite this variability, putative Fucalean hybrids have been observed in wild populations since the 1850s (and references within 
Mathieson et al., 1981; Thuret, 1854). More recently genetic methods have been used to confirm and identify hybrids (Coyer et al., 2007; Wallace et al., 2004).

New Zealand has a distinct brown algal flora, with high levels of endemism (Nelson, 1994). The dominance of Fucalean algae in the shallow subtidal is considered one of the more unusual aspects of the flora (Schiel, 1990). Fucalean algae in the Northern Hemisphere dominate the intertidal, and subsequently have been relatively well studied (Chapman, 1995). The vast majority of research into hybridisation in Phaeophyceae is on the Northern Hemisphere Fucalean genus Fucus (Billard et al., 2005b; Chapman, 1995; Coyer et al., 2006b; Mathieson et al., 1981; Wallace et al., 2004). Research into hybridisation has revealed hybrids with intermediate morphologies, and in some cases evidence of introgression has been reported (Billard et al., 2005b; Coyer et al., 2002a; Mathieson et al., 2006; Wallace et al., 2004). Little work has been done on hybridisation in Fucales outside of Fucus, despite the well documented abundance, diversity and ecological importance of other genera in the Southern Hemisphere (Clayton, 1984).

In north-eastern New Zealand two species of Fucales, Fam. Sargassaceae, form dominant stands in the high subtidal: Carpophyllum maschalocarpum Turner and Carpophyllum angustifolium J. Agardh (Dromgoole, 1973; Schiel, 1988; Schiel, 1990). Based on intermediate morphotypes it has been hypothesised that hybridisation is occurring between the two species (Dromgoole, 1973). Recent molecular work using the internal transcribed spacer 2 (ITS2) region supported this hypothesis (Buchanan, unpubl. data). The ITS2 sequence is part of the ribosomal region in the nuclear DNA, and it is one of the most widely used sequences in plant 
evolutionary studies (Feliner \& Rossello, 2007). ITS2 is a bi-parentally inherited marker, which is distinct between $C$. angustifolium and C. maschalocarpum in the East Cape populations of New Zealand (Buchanan, unpubl. data). Coyer et al. (2002b) showed that artificially produced $F_{1}$ hybrids of two Fucus species with distinct ITS ribotypes, were all heterozygous in ITS. The work on Carpophyllum by Buchanan (unpubl. data) found all putative hybrids, based on cursory identification of morphology, to be ITS2 heterozygotes.

ITS has low functional constraint, and highly constrained flanking genes which allow universal primers to be produced (Alvarez \& Wendel, 2003). ITS is multi-copy, and homogenisation of the multiple ITS sequences can occur, meaning that only recent hybridisation is revealed (Alvarez \& Wendel, 2003). Introgressed and $F_{2}$ individuals will not necessarily have heterozygous ITS2 ribotypes. Combining ITS and morphometric data could allow non-subjective identification of individuals, and help determine the presence of introgression and $\mathrm{F}_{2}$ hybrids within a population.

This study aims to combine ITS2 identification and morphometric analysis to investigate the morphology of $C$. angustifolium, C. maschalocarpum, and their hybrids. Three questions will be addressed. Firstly are the parental species morphologically distinct? Secondly can hybrids be morphologically distinguished from the parental species? Finally are the hybrids morphologically intermediate to the parent species? 


\subsection{Methods}

\section{Sampling locations}

Samples were collected from two sites on the East Cape of the North Island of New Zealand, where $C$. angustifolium $\times C$. maschalocarpum hybrids were known to occur (Fig.1). The two sites are both within the greater Whanarua Bay, which faces northwest and contains a number of smaller sandy bays separated by large rocky islands. The first site is located at the south-eastern end of Maraehako Bay ( $\mathrm{S} 37^{\circ} 40.4^{\prime}$ E177 ${ }^{\circ}$ $\left.47.8^{\prime}\right)$. The second site was located at Uncles Bay (S37 $\left.40.0^{\prime} \mathrm{E} 177^{\circ} 48.0^{\prime}\right)$, which is the adjacent bay to the north-east. The two sites are approximately $500 \mathrm{~m}$ apart, and are separated by Motu Kaimeanui Island and two deep inlets. Sampling was conducted during the 2007-2008 summer.

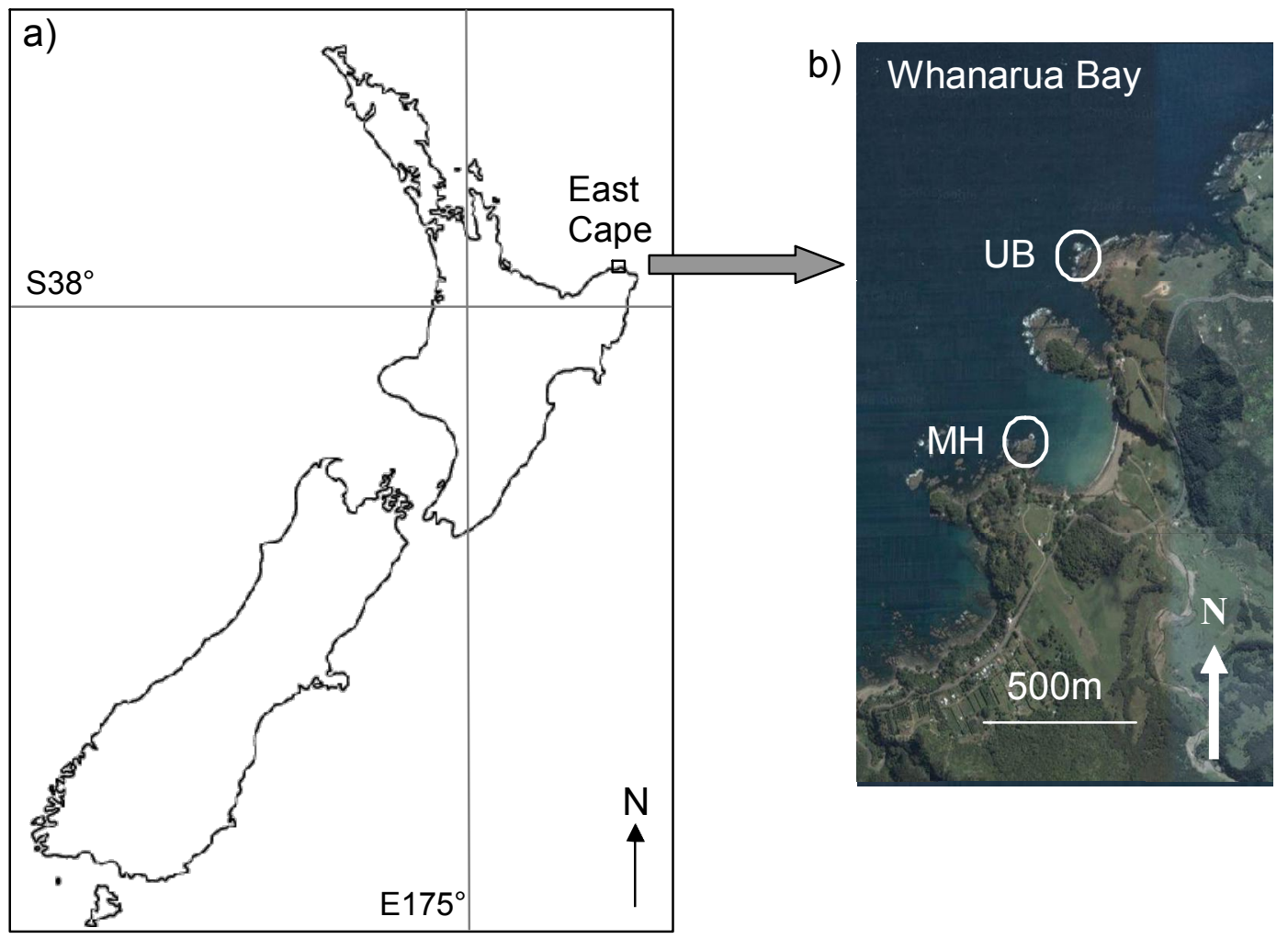

Figure 1: The location of sampling a) on the East Cape of the North Island of New Zealand, and b) the two sites in the greater Whanarua Bay: Maraehako Bay (MH) and Uncles Bay (UB) (Google Earth 5.0). 


\section{Sampling}

Transect lines were laid along rock walls in the high subtidal, and quadrat locations were selected randomly from the top $0.5 \mathrm{~m}$ of Carpophyllum depth distribution. Quadrats were rejected if the rock face was not vertical, fewer than three individuals were present, or if the quadrat was less than $0.5 \mathrm{~m}$ from a previously sampled quadrat. All Carpophyllum individuals with holdfasts inside the $20 \mathrm{~cm}$ by $20 \mathrm{~cm}$ quadrats were collected. Sixty-nine quadrats were sampled in the two sites, with 280 C. angustifolium, 152 C. maschalocarpum and 32 hybrid adults collected in total. Collected material was frozen at $-4^{\circ} \mathrm{C}$ within a week of collection, and thawed in seawater prior to morphometric analysis.

\section{Morphometrics}

Adults greater than $20 \mathrm{~cm}$ were morphologically identified and cleared of epiphytes, and measured using digital callipers. Only those individuals with complete haptera were used in morphometrics so as to avoid pseudo-replication (i.e. the doubling up of measurements from the same individual). Individuals were measured using digital callipers and a metre rule. A small section of lamina was removed from each individual after processing and placed into a labelled centrifuge tube with silica gel for later genetic analysis.

The morphometric characteristics selected for measurement were stipe width and thickness; and lamina length, width and thickness (Fig. 2). This study focused on the stipe and lamina characteristics of the primary axis (defined as the dominant axis which arises directly from the holdfast). The stipe and lamina measurements were taken from approximately $5,10,15$, and $20 \mathrm{~cm}$ from the tip of the axis. Lamina length was measured from the edge of the stipe where the lamina forms to its tip. 
Lamina and stipe width were measured at the widest point, perpendicular to an imagined mid-line. Stipe and lamina thickness was measured at the thickest point. In some places herbivory had altered the morphology of the stipe and lamina; these could be detected by sudden and distinct changes in lamina or stipe outline. Measurements of stipe and lamina that were affected by herbivory were excluded, and if possible replaced by measurements from the nearest intact equivalent within 3 $\mathrm{cm}$. The total length of the individual, presence of vesicles longer than $8 \mathrm{~mm}$, and presence of secondary branches longer than $20 \mathrm{~cm}$ were also recorded.

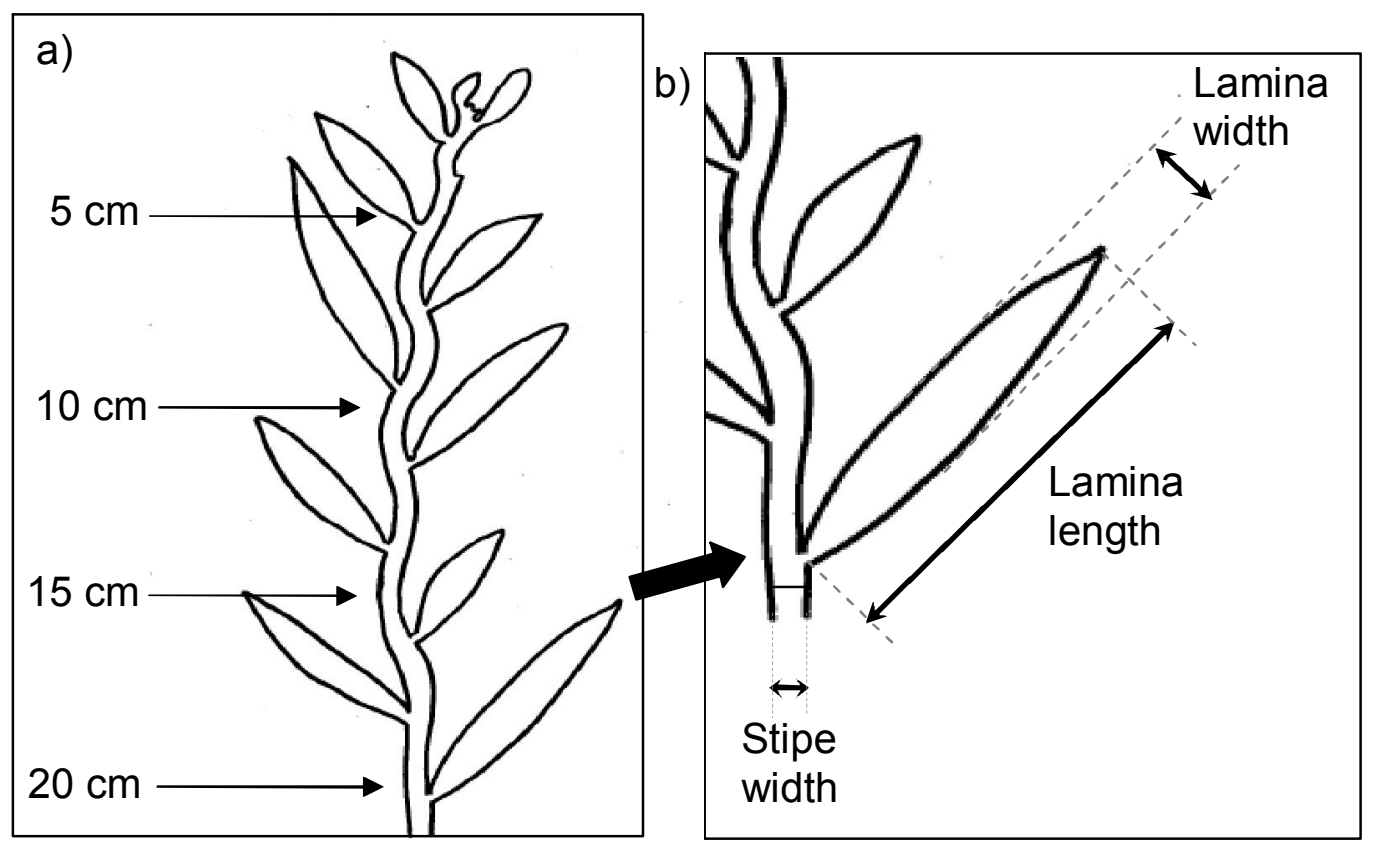

Figure 2: The location of the measurements taken from each individual are shown with arrows on a stylised axis. Stipe width, lamina length and width are illustrated at $20 \mathrm{~cm}$ from the apex.

Digital images for the C. angustifolium (\#2572, Botanical Museum Lund) and $C$. maschalocarpum (\#000562635, The Natural History Museum, London Department of Botany) type specimens were obtained and measurements of lamina length, lamina width and stipe width were taken where possible. 


\section{Genetic Analysis}

Validity of the morphological identification for the hybrids and parental species were checked by genetically identifying a randomly selected sub-sample. Individuals with unusual morphological characteristics were also checked genetically.

DNA was extracted from approximately $3 \mathrm{mg}$ of dry tissue using a CTAB extraction protocol (Zuccarello \& Lokhorst, 2005). The tissue was ground in $500 \mu \mathrm{L}$ of CTAB extraction buffer (2\% CTAB, $0.1 \mathrm{M}$ Tris- $\mathrm{HCl}, 1.4 \mathrm{M} \mathrm{NaCl}, 20 \mathrm{mM}$ EDTA, 1\% PEG $8000)$ with $2 \mu \mathrm{L}$ RNAase A (100mg/mL).

The ITS2 sequences were amplified using a PTC-100 (Programmable Thermal Controller, MJ Research Inc) PCR machine, and the primers KG4 (CTTTTCCTCCGCTTAGTTA TATG) and KP5 (ACAACGATGAAGAACGCAG) (Invitrogen). The PCR conditions were an initial $94^{\circ} \mathrm{C}$ for 4 minutes, followed by 5 cycles of $\left[1\right.$ minute at $94^{\circ} ; 1$ minute $59^{\circ} ; 1$ minute $\left.72^{\circ}\right]$ with the annealing temperature decreased by $1^{\circ} \mathrm{C}$ each cycle. Then 30 cycles of $\left[45\right.$ seconds $94^{\circ} \mathrm{C} ; 45$ seconds $53^{\circ} \mathrm{C} ; 45$ seconds $72^{\circ} \mathrm{C}$ ] followed by ten minutes at $72^{\circ} \mathrm{C}$. Sequencing was done commercially (Macrogen Inc, Korea). The chromatograms were visually examined and individuals identified as either a parental species or a heterozygous hybrid (where double peaks were present).

\section{Morphometric Data Analysis}

The morphometric data contained a large number of missing values. Scatterplots showed no difference between the character traits measurements at 5, 10, 15 and 20 cm down the axis, so the measurements on each individual were averaged. There 
were some missing data for lamina characteristics after this averaging, as many laminae were excluded from measurement due to herbivory damage. The missing values were not randomly distributed, and C. maschalocarpum averages were based on fewer data points than the others due to greater levels of herbivory and exposure damage. Randomly removing data points to an equivalent level in C. angustifolium and hybrid data made little or no change to overall group averages $(0.002 \%$ to $0.03 \%$ change). This suggests no bias in accuracy due to variation in the number of data points averaged between the species.

Cluster analysis finds natural groupings or clusters within the data (Fielding, 2007). These were conducted first with genetically confirmed data and type specimens, and then with all individuals, using the software NTSYSpc version 2.11 software (Rohlf, 2000). The unweighted pair-groups method average (UPGMA) clustering method was used (Fielding, 2007). Boxplots were used to identify morphological traits which showed divergence. These diverged characters were incorporated into a distance matrix using Gower's Index in Le Progiciel R 4.0 software (Casgrain \& Legendre, 1999). This index was used as it can cope with missing values, count data and continuous data (Montanari \& Mignani, 1994; Podani, 1999). It has also been used in other studies on macroalgae morphology (Fowler-Walker et al., 2006). Cophenetic values were calculated to test how well the cluster tree represents the data (Rohlf, 2000; Rohlf \& Sokal, 1981).

ANOVA was used to compare the morphological groups found in the cluster analysis. Non-normal data was log transformed prior to analysis with ANOVA. Log transformed data that still did not meet ANOVA assumptions was analysed using the 
non-parametric Kruskal-Wallis test. Chi-squared tests were used to test for associations between wave exposure zones and the presence of vesicles and branches. Significance was determined at the 0.05 probability level.

\subsection{Results}

\section{ITS2 sequences and morphological identification}

Morphological identifications matched with genetic sequences in $93.8 \%$ of a random sub-sample of individuals $(\mathrm{n}=80)$. All C. maschalocarpum $(\mathrm{n}=25)$ and hybrid $(\mathrm{n}=27)$ morphological assignments were supported by the ITS2 sequences. $82.1 \%$ of the random sub-sample $(\mathrm{n}=28)$ of morphologically identified $C$. angustifolium had matching $C$. angustifolium ITS sequences. The remaining $17.9 \%$ were five individuals with hybrid sequences; these will be described from here on in as 'putative backcrosses'.

\section{Morphology of clusters}

Stipe width, lamina length and lamina width were identified as divergent morphological traits with boxplots and used in the cluster analyses. The first cluster analysis was of the random sub-sample of genetically identified individuals and the type specimens. This had a cophenetic correlation of 0.84 , indicating a 'good fit' (Rohlf, 2000). This cluster tree is shown in Figure 2.

Genetically identified individuals clustered into four main morphological groups. Group I contained all of the genetically confirmed $C$. angustifolium $(\mathrm{n}=23)$, two hybrids, and the putative backcrosses $(n=5)$. Group II included all of the other hybrids (n=25), and a C. maschalocarpum individual. Closer examination of this $C$. maschalocarpum individual reveals it was only just long enough to be considered 
'adult' ( $>20 \mathrm{~cm}$ long) and therefore included in this study. Groups III and IV were composed of C. maschalocarpum only (III n=19, IV n=6). Hereafter Group I will be referred to as $C$. angustifolium, Group II as the hybrids, Groups III and IV combined as C. maschalocarpum. A major subdivision between the morphology of $C$. angustifolium and hybrid individuals, and the C. maschalocarpum individuals, was revealed in the cluster analysis. The hybrid cluster had a higher similarity coefficient with the C. angustifolium cluster (0.75) than with the C. maschalocarpum clusters (0.49).

The second cluster analysis was of all morphologically identified individuals, including the genetically identified individuals and type specimens. This had a cophenetic correlation of greater than 0.90 , indicating the cluster tree is a 'very good fit' of the data (Rohlf, 2000). This second cluster tree had the same group structure and membership of genetically identified individuals as the cluster tree of only genetically identified individuals (see Appendix 1). 
Identity of individuals

C. angustifolium

Putative backcrosses

Hybrids

C. maschalocarpum

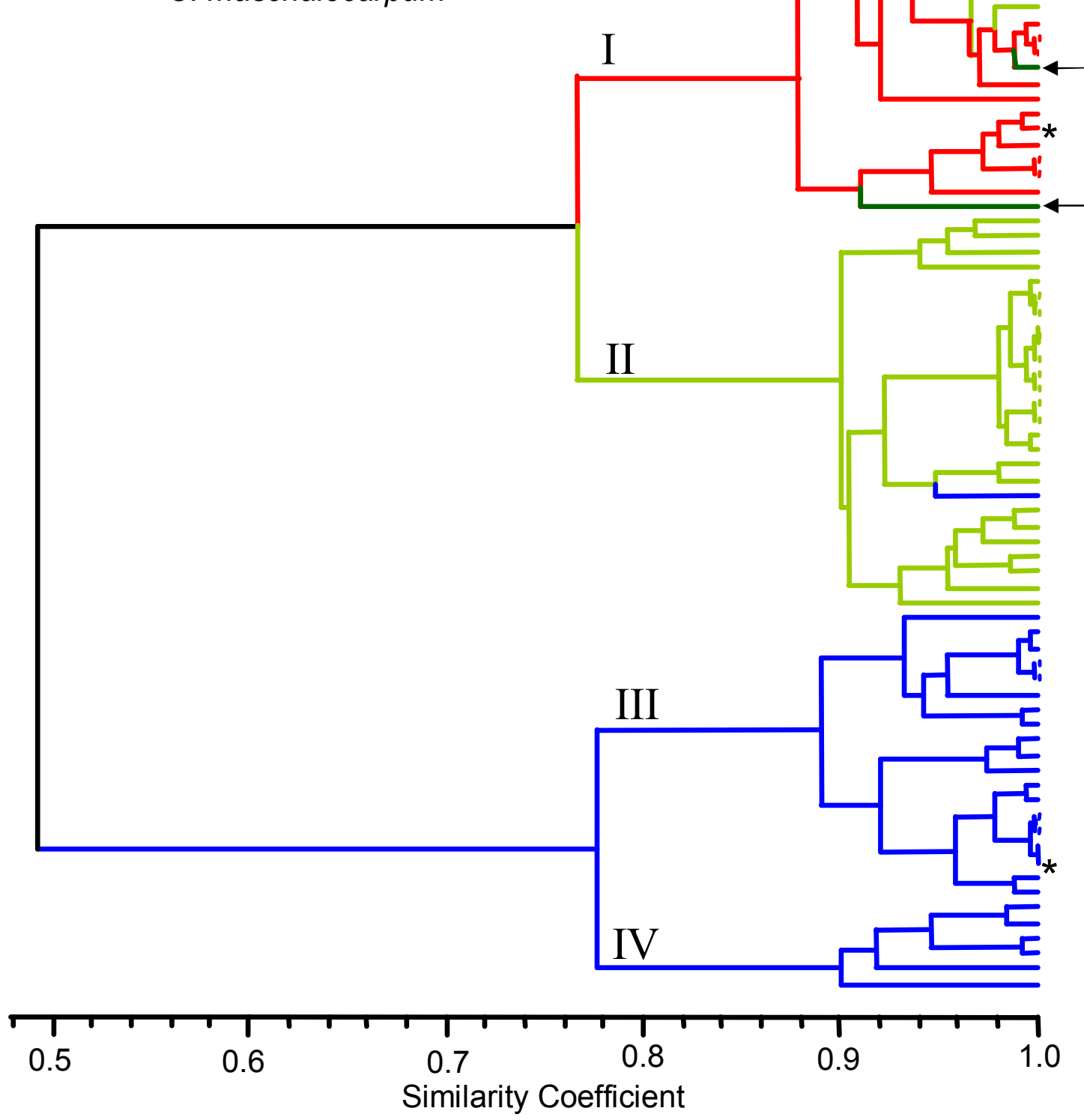

Figure 3: Cluster analysis showing the morphology of a random sub-sample of genetically identified individuals, and the type specimens for the parental species (shown by asterisks). Individuals cluster into four morphological groups as labelled I to IV. Colours represent the identity of the individuals (see legend). Putative backcrosses are those morphologically identified as $C$. angustifolium but with hybrid ITS sequences, as shown in with arrows. The coenphetic value of this tree is $\mathrm{r}=0.84486$. 


\section{Comparing morphologies}

Comparisons of the morphologies of the C. angustifolium group (I), the hybrid group (II) and the pooled C. maschalocarpum groups (III \& IV) found a range of differences between them (Table 1). Log stipe width $(\mathrm{p}<0.001)$, lamina length $(\mathrm{p}<0.001)$, and lamina width $(\mathrm{p}<0.001)$ were different between the three groups (all pairwise Tukey Tests were $\mathrm{p}<0.05$ ) (Fig. 3). The pooled C. maschalocarpum group had a wider stipe, and a shorter and wider lamina than the C. angustifolium group. The hybrid group exhibited traits intermediate to the parents for each of these traits. There was no overlap in logged stipe width for the three groups (Fig. 3a).

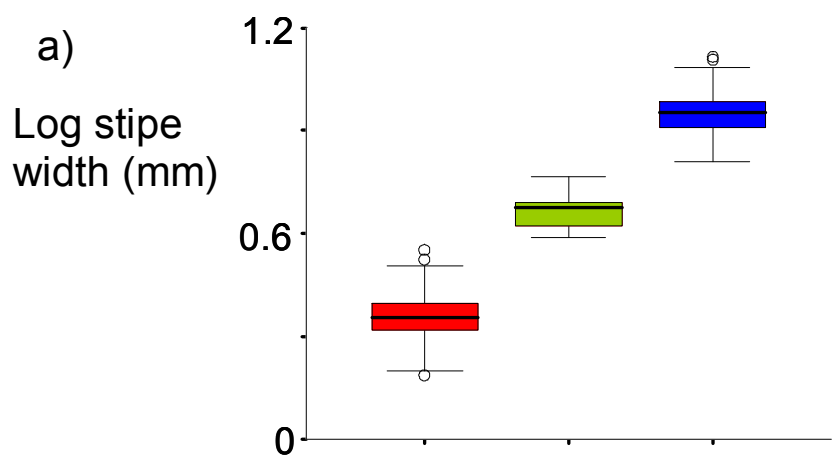

b)

\section{Lamina length $(\mathrm{mm})$}

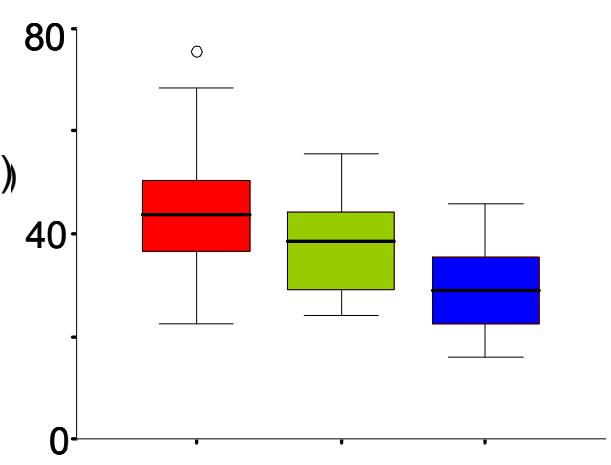

c)
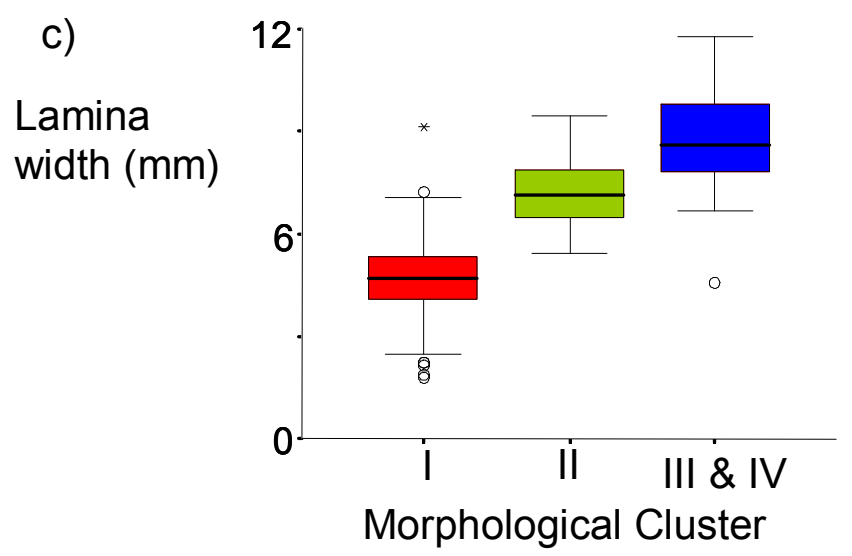

Figure 4: The three groups had significant different a) log stipe widths, b) lamina lengths and c) lamina widths. The boxplots show the spread of data with outliers marked by circles and extreme outliers marked with asterisks. Colours represent the general composition of groups (red for $C$. angustifolium, green for hybrids, and blue for $C$. maschalocarpum). 
Stipe thickness was also different between the three groups $(\mathrm{p}<0.001)$ with median stipe thickness being thickest for the C. angustifolium group (I), and thinnest for the hybrid group (II). Lamina thickness was also found to be non-uniform $(\mathrm{p}<0.00)$. The $C$. angustifolium group (I) had significantly thicker lamina than the hybrids (II), and the pooled C. maschalocarpum group (III \& IV) (Tukey tests: $\mathrm{p}<0.05$ ). The lamina thickness of the hybrid group (II) and the pooled C. maschalocarpum group (III \& IV) were not significantly different (Tukey test: $\mathrm{p}=0.952$ ).

There were differences between the groups in the proportion of individuals with secondary axes $\left(\mathrm{X}_{2}=13.529, \mathrm{df}=2, \mathrm{n}=461, \mathrm{p}=0.001\right)$. The $C$. angustifolium group (I) had the lowest proportion of individuals with branches, while the hybrid group (II) and pooled C. maschalocarpum group (III \& IV) had a similar proportion of individuals with secondary axes. The proportion of individuals with vesicles present also differed between the three groups $(\mathrm{p}=0.001)$. No individuals in the $C$. angustifolium group (I) had vesicles, compared to $9.4 \%$ of the hybrid group (II), and $47.9 \%$ of the pooled $C$. maschalocarpum group (III \& IV). 
Table 1: Relative morphological differences between the three groups (tested with ANOVA and Kruskal-Wallis tests at the 5\% significance level)

\begin{tabular}{|l|l|l|l|l|}
\hline Character trait & Group I & Group II & Group III \& & Statistics \\
\hline Stipe width & Narrow & Intermediate & Wide & $\mathrm{F}=4843.291, \mathrm{df}=2$, \\
\hline Lamina length & Long & Intermediate & Short & $\mathrm{F}=43.275, \mathrm{df}=2$, \\
\hline Lamina width & Narrow & Intermediate & Wide & $\mathrm{F}=247.230, \mathrm{df}=2$, \\
\hline Stipe thickness & Thick & Thin & Intermediate & $\mathrm{X}_{2}=23.134, \mathrm{df}=2$, \\
\hline Lamina & Thick & Thin & Thin & $\mathrm{F}=21.22, \mathrm{df}=2$, \\
\hline $\begin{array}{l}\text { Proportion with } \\
\text { secondary axes } \\
\text { present }\end{array}$ & Low & High & High & $\begin{array}{l}\mathrm{X}_{2}=13.529, \mathrm{df}=2, \\
\mathrm{n}=461, \mathrm{p}=0.001\end{array}$ \\
\hline $\begin{array}{l}\text { Proportion with } \\
\text { vesicles present }\end{array}$ & Absent & Low & High & $\begin{array}{l}\mathrm{X}_{2}=167.196, \mathrm{df}=2, \\
\mathrm{n}=461, \mathrm{p}=0.001\end{array}$ \\
\hline
\end{tabular}

There were significant differences in total length, stipe width, stipe thickness, presence of vesicles between the two groups (III and IV) of C. maschalocarpum (Table 2). Group IV was generally longer in total length, had a wider and thicker stipe, and had a greater proportion of individuals with vesicles present than Group III. There were also nonsignificant trends $(0.10>\mathrm{p}>0.05)$ of Group IV having wider and thicker lamina, and more frequently having secondary branches. There was no difference between the lamina length of the two groups. There was no difference in the distributions between the two C. maschalocarpum groups, either between sites $\left(\mathrm{X}_{2}=3.146, \mathrm{df}=1, \mathrm{n}=146, \mathrm{p}=0.076\right)$ or exposure zones $\left(\mathrm{X}_{2}=5.162, \mathrm{df}=3, \mathrm{n}=146, \mathrm{p}=0.160\right)$. 
Table 2: Relative morphological differences between the C. maschalocarpum clusters III \& IV.

\begin{tabular}{|c|c|c|c|c|}
\hline Significance & $\begin{array}{l}\text { Morphological } \\
\text { trait }\end{array}$ & $\begin{array}{l}\text { Group } \\
\text { III }\end{array}$ & $\begin{array}{l}\text { Group } \\
\text { IV }\end{array}$ & Statistics \\
\hline \multirow{4}{*}{$\begin{array}{l}\text { Statistically } \\
\text { significant at } \\
5 \% \text { level }\end{array}$} & Total length & Shorter & Longer & $\mathrm{F}=6.803, \mathrm{df}=1, \mathrm{n}=146, \mathrm{p}=0.010$ \\
\hline & Stipe width & Narrower & Wider & $\mathrm{F}=250.906, \mathrm{df}=1, \mathrm{n}=146, \mathrm{p}<0.001$ \\
\hline & Stipe thickness & Thinner & Thicker & $\mathrm{F}=14.188, \mathrm{df}=1, \mathrm{n}=146, \mathrm{p}<0.001$ \\
\hline & $\begin{array}{l}\text { Proportion with } \\
\text { vesicles }\end{array}$ & Low & High & $X_{2}=11.026, d f=1, n=146, p=0.001$ \\
\hline \multirow{3}{*}{$\begin{array}{l}\text { Trends in the } \\
\text { data } \\
\text { (significant at } \\
\text { the } 10 \% \text { level) }\end{array}$} & Lamina width & Narrower & Wider & $\mathrm{F}=2.885, \mathrm{df}=1, \mathrm{n}=49, \mathrm{p}=0.096$ \\
\hline & $\begin{array}{l}\text { Lamina } \\
\text { thickness }\end{array}$ & Thinner & Thicker & $\mathrm{F}=3.837, \mathrm{df}=1, \mathrm{n}=49, \mathrm{p}=0.056$ \\
\hline & $\begin{array}{l}\text { Proportion with } \\
\text { secondary axes } \\
\text { present }\end{array}$ & Low & High & $X_{2}=3.161, d f=1, n=146, p=0.075$ \\
\hline $\begin{array}{l}\text { Not significant } \\
\text { and no trends }\end{array}$ & Lamina length & Same & Same & $\mathrm{F}=1.517, \mathrm{df}=\mathrm{a}, \mathrm{n}=49, \mathrm{p}=0.224$ \\
\hline
\end{tabular}

\subsection{Discussion}

Carpophyllum angustifolium, C. maschalocarpum and their hybrids have distinct and distinguishable morphologies. Identifiable hybrid and parental morphotypes have been found within many Fucus hybrid species complexes; however morphologically ambiguous individuals are often present as well (Coyer et al., 2002a; Kucera \& Saunders, 2008; Scott \& Hardy, 1994). No other detailed morphometric analysis of randomly sampled and molecularly identified individuals has been done in a Fucalean hybrid system. Subsequently the range and degree of overlap of parental and hybrid morphologies are unknown in other Fucalean hybrid systems. 
Stipe width alone can distinguish between C. angustifolium, C. maschalocarpum and their hybrids, and provides a useful taxonomic character for field identification. Stipe width meets three requirements described for a useful macroalgal taxonomic character in macro-algae; it is constant, easy to observe and non-destructive (Mathieson et al., 1981). Stipe width of the parent species and hybrids was easy to measure and rarely affected by herbivory or exposure damage (pers. obs.). Stipe width was concluded to be a particularly valuable taxonomic trait for identification of Fucus spp. after an investigation into the spatial variability of $F$. spiralis and $F$. vesiculosus (Coleman \& Muhlin, 2008).

Carpophyllum angustifolium $\times$ C. maschalocarpum hybrids generally had an intermediate morphology to the parent species. Hybrids had intermediate stipe width, lamina length, lamina width and vesicle presence. However, the thickness of hybrid lamina was novel, being thinner than both parents. Furthermore the proportion of hybrid individuals with secondary branching was indistinguishable from C. maschalocarpum. Intermediate hybrid morphologies are usually found in hybrid systems although not necessarily in all cases (Coyer et al., 2006b; Rieseberg \& Ellstrand, 1993; Seehausen, 2004). Intermediate morphology is used to identify putative hybrid individuals for further investigation in Fucus, a genus of Fucalean algae (Coyer et al., 2002a; Scott \& Hardy, 1994). Despite this there are examples of morphological traits in hybrids being aligned to one of the parental species. For example, hybridisation between the dioecious Fucus vesiculosus and the hermaphroditic Fucus spiralis results in hybrids with both maternal and paternal sexual phenotypes (Billard et al., 2005b). In salt marsh habitat the 
same $F$. vesiculosus $\times F$. spiralis hybrids are morphologically indistinguishable from polyploid $F$. vesiculosus individuals also found in salt marshes (Coyer et al., 2006b).

The presence of hybrid genotypes with $C$. angustifolium morphotypes suggests introgression is occurring. Hybrid ITS genotypes with parental morphology were found in the $F$. vesiculosus $\times F$. spiralis species complex, and were also cautiously interpreted as possibly due to introgression (Kucera \& Saunders, 2008). Introgression is an important evolutionary process that has the potential to integrate genetic material from one species into another (Coyer et al., 2007). Introgression has been identified in Fucus hybrid complexes, and is considered a significant factor in the evolution of Fucus lineages (Coyer et al., 2006a; Coyer et al., 2007; Wallace et al., 2004).

Fucus species seem to have maintained their genetic integrity despite extensive hybridisation. For example, hybrids made up 13\% of Fucus serratus and Fucus evanescens in one population; however nuclear DNA introgression was only $1.5 \%$ in the two species, and both species maintain different distributions and morphologies (Coyer et al., 2007; Coyer et al., 2002a). Coyer (2006a) suggested different parental mating systems might act as a barrier to extensive introgression, and protect the parental species integrity. Hybridisation in Fucus appears to only occur between dioecious (having separate male and female individuals) and hermaphroditic species (e.g. Billard et al., 2005a; Coyer et al., 2007; Mathieson et al., 2006; Wallace et al., 2004). All members of the Carpophyllum genus are dioecious (Lindauer et al., 1961). Extensive introgression, and the loss of parental species genetic integrity, could be more likely in Carpophyllum hybrid systems if Coyer et al. (2006a) hypothesis about mating systems is correct. 
The absence of individuals with C. maschalocarpum morphology and hybrid genotypes suggests introgression may be asymmetrical, with backcrossing only between hybrids and $C$. angustifolium. Asymmetries in angiosperm reproduction are thought to be common in a broad range of taxa (Tiffin et al., 2000). Asymmetrical hybridisation and introgression has been found in Fucus spp. (Coyer et al., 2007; Coyer et al., 2002a). Determining the symmetry of introgression is important for predicting its implications on parental species integrity (Coyer et al., 2007).

The value of ITS for confirming and determining the extent of introgression is limited due to homogenisation of ITS (Alvarez \& Wendel, 2003). Microsatellites have a high mutation rate and large variability, and have been used successfully to resolve relationships in a Fucus hybrid complex (Coyer et al., 2006b; Coyer et al., 2007; Engel et al., 2005; Wallace et al., 2004). Introgression can also be identified by comparing maternally inherited DNA, such as mtDNA or cpDNA, with nuclear DNA in the putative hybrids and introgressed individuals (Coyer et al., 2007; Coyer et al., 2002a).

The morphometric analysis distinguished variation within C. maschalocarpum, which could be correlated to recruitment. The differences between the two C. maschalocarpum clusters (i.e. total length, stipe width, stipe thickness, vesicles) were characteristics thought to be associated with maturity (Dromgoole, 1965). Carpophyllum maschalocarpum has pulsed peak recruitment, and has been shown to recruit in cohorts after bare rock is opened up by disturbance (Schiel, 1980; Schiel, 1988). 
This work on Carpophyllum combined morphometric data with molecular ITS2 identifications found generally distinct and distinguishable parental and hybrid morphologies. Further investigation needs to be done using microsatellites and maternally inherited DNA in conjunction with morphology to confirm and determine the extent and symmetry of introgression, and identify backcrosses, $\mathrm{F}_{2}$ and later hybrids. 


\section{Chapter 3: Wave exposure and morphology in Carpophyllum angustifolium and Carpophyllum maschalocarpum}

\subsection{Abstract}

Environmental conditions can influence the morphology of local biota through phenotypic plasticity or local adaptation. Macroalgal morphologies are often associated with wave exposure conditions. This study investigated the relationship between morphology and wave exposure in two common endemic subtidal macroalgae, Carpophyllum angustifolium and Carpophyllum maschalocarpum, from the East Cape of New Zealand. Morphological comparisons were made between individuals from four different wave exposure zones, as defined by fetch and barnacle composition. Carpophyllum angustifolium individuals were longer in more wave exposed environments. Carpophyllum maschalocarpum were shorter with thinner stipes, and fewer individuals had vesicles, in more wave exposed zones. Morphological traits also varied between sites for both species suggesting that other influences are important in determining the species morphology. Further study is needed to investigate the role of phenotypic plasticity and genetic variability in driving morphological variation in $C$. angustifolium and C. maschalocarpum.

\subsection{Introduction}

Local environmental conditions can influence the morphology of organisms as a result of selection or phenotypic plasticity. This has been shown in a range of taxa and environments (Hochkirch et al., 2008; Mboumba \& Ward, 2008; Trussell, 2000). In coastal environments the morphology of local biota is significantly affected by wave 
exposure (Denny, 2006; Stewart, 2006). For example Arsenault (2001) found the length of the legs of the barnacle Balanus glandula declined with increasing wave exposure.

Phaeophyceae, the brown macroalgae, have been found to be significantly affected by wave exposure (Engelen et al., 2005; Fowler-Walker et al., 2006; Tuya \& Haroun, 2006). Water motion around macroalgae affects their nutrient acquisition, creates mechanical fatigue, and can result in the loss of biomass or dislodgement of entire individuals (Hurd, 2000; Kawamata, 2001). Phaeophyceae are highly plastic organisms, with numerous examples of environmentally induced forms (Mathieson et al., 2006; Mathieson et al., 1981). There are optimal morphologies for Phaeophyceae in different wave exposure regimes. Traits which reduce drag (i.e. small size, streamlined shape, flexibility) and increase strength (i.e. thickness, aggregation) are favoured in high wave exposed areas (Puijalon \& Bornette, 2004; Ruuskanen \& Nappu, 2005; Stewart, 2006; Stewart \& Carpenter, 2003; Thomsen et al., 2004; Wernberg, 2005). Johnson and Koehl (1994) found the blade morphology of the kelp Nereocystis luetkeana to be longer and thinner in more wave exposed areas, and to experience less drag than the sheltered blade form.

Carpophyllum angustifolium and Carpophyllum maschalocarpum dominate the high subtidal of north-eastern New Zealand (Schiel, 1990). The two species have different morphologies and wave exposure distributions. Carpophyllum angustifolium is streamlined, flexible, with strong aggregating holdfasts, and is distributed in exposed to moderately wave exposed areas (Chapters 2 \& 4. Adams, 1994). Carpophyllum maschalocarpum has vesicles, is larger, has wide flat stipes and occurs in sheltered to 
moderately exposed areas (Chapters $2 \& 4$. Adams, 1994). Determining how the morphology of these species is affected by wave exposure will provide insight into environmental selection and plasticity in Carpophyllum. It will also allow hypotheses to be generated about the fitness and distribution of their morphologically intermediate hybrids relative to wave exposure.

One of the major barriers in studying relationships between morphology and wave exposure is measuring the wave exposure component. Measuring wave exposure on rocky shores is difficult due to its spatial and temporal variability (Denny, 1988; Eckman et al., 2003). Direct measurements of water motion can be done using a range of equipment including dynamometers and plaster of paris clod cards (Carrington Bell \& Denny, 1994; Thompson \& Glenn, 1994). All of these methods have limitations (Lindegarth \& Gamfeldt, 2005; Porter et al., 2000). One serious obstacle to deploying sensitive and expensive equipment is its attachment and survival in high wave exposure environments. Subsequently direct measurements often rely on short term data collected in calm water (Arsenault et al., 2001; Stewart \& Carpenter, 2003). For example Coleman et al. (2008) only measured water motion on days of 'low to moderate water motion'. Short term measurements can be misleading if extrapolated over long periods and varying environmental conditions (Gaylord, 1999).

The difficulties associated with direct measurement have led many researchers to infer water motion from fetch or biological information (Ballantine, 1961; Engelen et al., 2005; McQuaid et al., 2000). In two major journals approximately half of the papers on wave exposure over a recent ten year period developed categorical definitions of 
exposure using fetch or local biota (Lindegarth \& Gamfeldt, 2005). Fetch and local biota can provide information about wave exposure over a relatively long time frame. However, both have their limitations. Fetch data have low spatial resolution, while geographically specific information on the distribution or morphology of local biota might not be available (Arsenault et al., 2001; Gaylord, 1999; Lindegarth \& Gamfeldt, 2005). The distribution of barnacles by wave exposure in New Zealand has been well described (Foster, 1967; Foster, 1978). Barnacles were one of the first taxa to be considered for defining wave exposure, and are a useful guide due to their immobility and dominance on rocky shores (Ballantine, 1961; Heaven \& Scrosati, 2008).

This study will compare the morphology of $C$. angustifolium and C. maschalocarpum between four wave exposure zones defined by fetch and barnacle distribution. Does the morphology of C. angustifolium, and C. maschalocarpum individuals change in areas of different wave exposure? Is the relationship between wave exposure and morphology the same in both species?

\subsection{Methods}

\section{Sampling locations}

Samples were collected from two sites on the East Cape of the North Island, New Zealand (Fig. 1). The two sites were both within the greater Whanarua Bay, which faces north-west and contains a number of smaller sandy bays divided by large rocky islands or outcrops. The first site is located at the south-eastern end of Maraehako Bay (S37 $\left.40.4^{\prime} \mathrm{E} 177^{\circ} 47.8^{\prime}\right)$. The second site was on the rock walls located at Uncles Bay (S37 


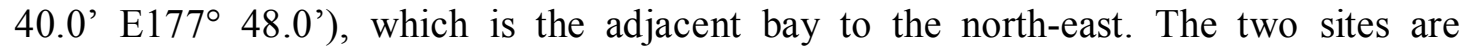
approximately $500 \mathrm{~m}$ apart, and are separated by Motu Kaimeanui Island and two deep inlets. Sampling was conducted during the 2007-2008 summer.

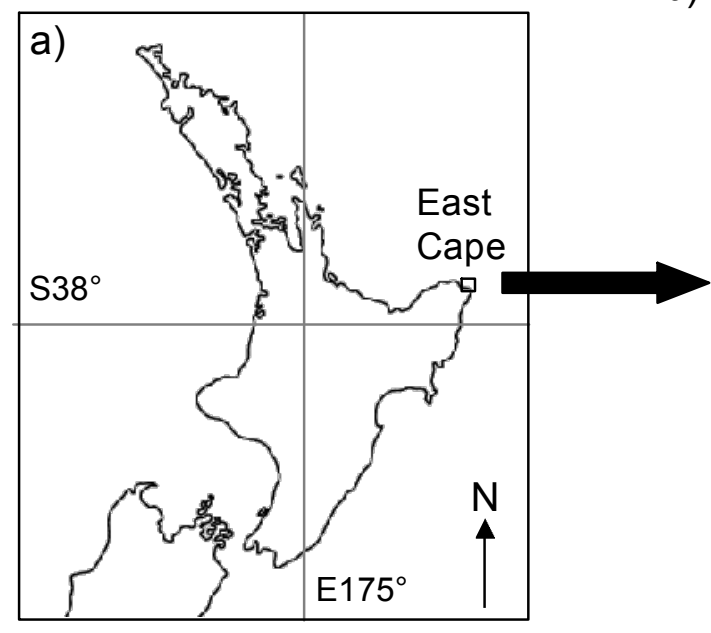

\section{Whanarua Bay}

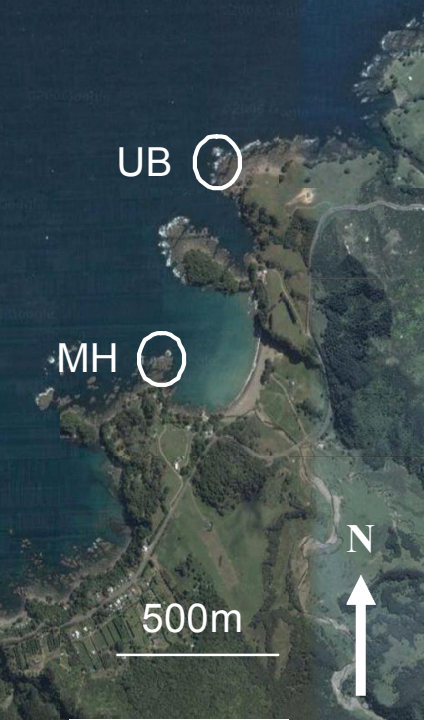

Figure 2: The location of sampling a) on the East Cape of the North Island of New Zealand, and b) the two sites in the greater Whanarua Bay: Maraehako Bay (MH) and Uncles Bay (UB) (Google Earth 5.0).

\section{Assessing wave exposure}

Four wave exposure zones were selected from each of the two sites. These zones were determined based on fetch and barnacle distributions. Firstly sites were divided using an estimate of fetch based on a modified Baardseth Index. The Baardseth Index is calculated by placing a transparent circular disc with a radius equivalent to $7.5 \mathrm{~km}$ on a point in a map and determining the number of $9^{\circ}$ segments containing no land or islands (Baardseth, 1970). In this study the angle of open segments was summed in situ to incorporate small-scale disruptions to oncoming waves such as rocky outcrops. This sum was over $120^{\circ}$ for the most exposed zone (zone 1), up to $60^{\circ}$ in the second most exposed 
zone (zone 2), and $0^{\circ}$ in the two most sheltered zones. The two most sheltered zones were distinguished by the direction rock walls were facing. The rock walls in the moderately sheltered exposure zone (zone 3) faced the opposite side of the bay, whilst those in the most sheltered exposure zone faced the shore (zone 4) (Fig. 2).

Transect lines were laid in each zone, and quadrat locations were selected randomly from the top $0.5 \mathrm{~m}$ of the Carpophyllum depth distribution. The intertidal barnacle fauna was checked for consistency with wave exposure prior to sampling each quadrat. The expected barnacle fauna for the four exposure zones was determined based on work by Foster $(1967 ; 1978)$, and is summarised in Figure 2. Quadrats were rejected if barnacle fauna did not match the expected fauna in the exposure zone, the rock face was not vertical, fewer than three individuals were present, or the quadrat was less than $0.5 \mathrm{~m}$ from a previously sampled quadrat. All Carpophyllum individuals with holdfasts inside the 20 by $20 \mathrm{~cm}$ quadrats were collected. Sixty nine quadrats were sampled in the two sites, with 280 C. angustifolium and 152 C. maschalocarpum adults collected in total. Collected material was frozen at $-4^{\circ} \mathrm{C}$ within a week of collection, and thawed in seawater prior to morphometric analysis. 


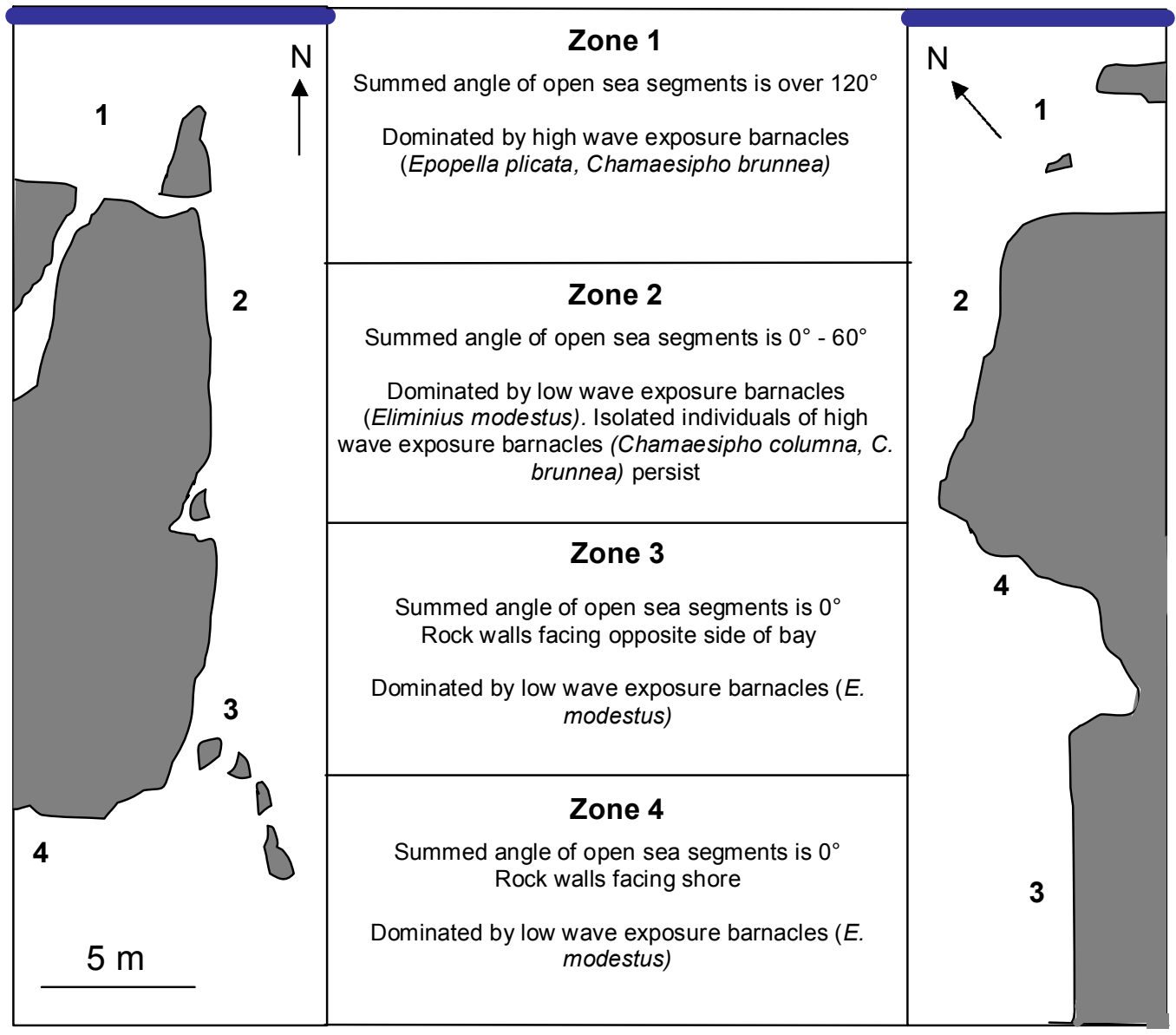

Figure 2: The wave exposure zones were defined by the degree of exposure to the open sea, orientation of the rock walls, and the barnacles in the intertidal portion of the rock wall. On the left and right simplified illustrations of the two study sites are shown with the general locations of the zones marked. The blue line represents the open sea.

\section{Morphometrics}

Adults were morphologically identified, and cleared of any epiphytes. Individuals longer than $20 \mathrm{~cm}$ were considered adults. Only those with complete haptera were used in morphometrics so as to avoid pseudo-replication (i.e. the doubling up of measurements from the same individual). Individuals were measured using digital callipers and a metre rule. 
The morphometric characteristics selected for measurement were stipe width and thickness; and lamina length, width and thickness (Fig. 3). This study focused on the stipe and lamina characteristics of the primary axes (defined as the dominant axis which arises directly from the holdfast). The stipe and lamina measurements were taken from approximately $5,10,15$, and $20 \mathrm{~cm}$ from the apex of the primary axis. Lamina length was measured from the edge of the stipe where the lamina forms to its tip. Lamina and stipe width were measured at the widest point, perpendicular to an imagined mid-line. Thicknesses were measured at the thickest point. In some places herbivory had altered morphology of the stipe and lamina; these could be detected by sudden and distinct changes in lamina or stipe outline. Measurements of stipe and lamina that were affected by herbivory were excluded, and if possible replaced by measurements by the nearest intact equivalent with $3 \mathrm{~cm}$. The total length of the individual, presence of vesicles longer than $8 \mathrm{~mm}$, and presence of secondary branches longer than $20 \mathrm{~cm}$ were also recorded. 


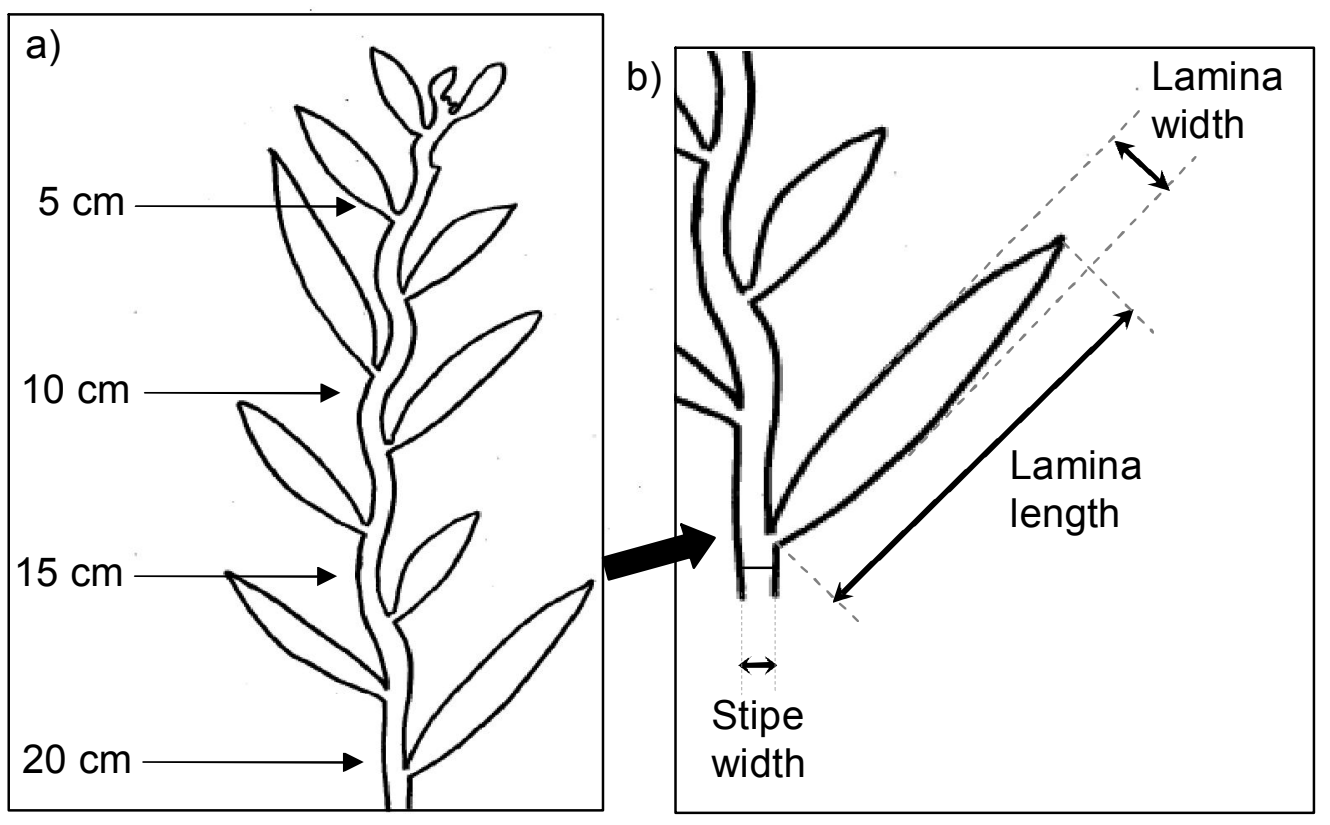

Figure 3: The location of the measurements taken at from each individual 5, 10, 15, 20 $\mathrm{cm}$ are shown with arrows on a stylised axis in a). Stipe width, lamina length and width are illustrated at $20 \mathrm{~cm}$ from the apex in b).

\section{Data Analysis}

The morphometric data contained missing values due to herbivory and wave exposure damage on some parts of individuals. There was no difference between the measurements taken at the different locations down the apex of individuals. Consequently these measurements were averaged for each individual. This resolved the missing values problem as most individuals had at least one measurement for each morphological trait. For example stipe width on an individual was an average from the measurements at $5,10,15$, and $20 \mathrm{~cm}$ from the apex.

Morphological characters from individuals in different wave exposure zones were compared for each species. Data from the two sites were combined. ANOVA and Tukey 
post-hoc comparisons were conducted where data were normally distributed and variances equal. Data were log transformed where ANOVA assumptions were not met. Log transformed data which still did not meet assumptions was analysed nonparametrically with Kruskal-Wallis tests. Chi-squared tests were used to investigate the presence data on vesicles and branching. The level of significance for all statistical tests conducted was determined using the value $\alpha=0.05$.

\subsection{Results}

\section{Wave exposure and morphology}

Carpophyllum angustifolium was found only in the two most wave exposed zones $\left(\mathrm{n}_{\text {zone1 }}=165, \mathrm{n}_{\text {zone2 }}=115\right)$ whilst $C$. maschalocarpum was found in all four wave exposure zones $\left(\mathrm{n}_{\text {zone } 1}=7, \mathrm{n}_{\text {zone } 2}=31, \mathrm{n}_{\text {zone } 3}=62, \mathrm{n}_{\text {zone } 4}=52\right)$. Some morphological traits were found to differ between exposure zones (Table 1). Total length for both species varied by wave exposure zone (Fig. 4). However the two species showed opposite trends for total length. Carpophyllum angustifolium individuals were shorter in the more sheltered zone of their distribution. By comparison C. maschalocarpum tended to be longer in the more sheltered zones, with individuals in exposure zones 3 and 4 significantly longer than those in zone 2 (Tukey Tests: $p<0.001, p=0.024$ ). There was no significant difference in C. maschalocarpum length between the two most sheltered zones (Tukey Test: $\mathrm{p}=0.344)$. Furthermore the seven $C$. maschalocarpum individuals in the most exposed zone had highly variable total lengths, and subsequently could not be differentiated from any other zone (Tukey Test: $\mathrm{p}=0.807, \mathrm{p}=0.452, \mathrm{p}=0.902$ ). 


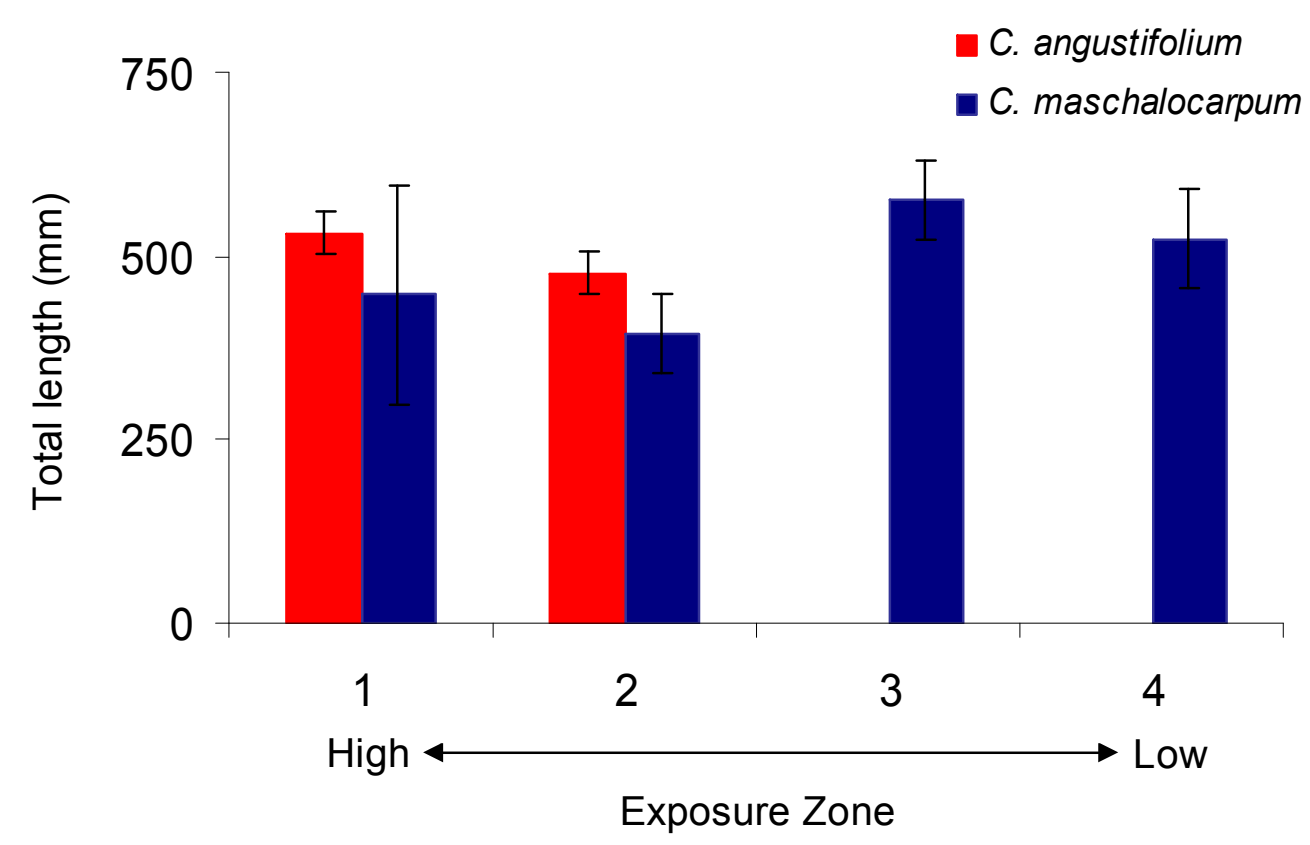

Figure 4: The average length of individuals in each sample differed between exposure zones in both species. The bars show average total length, with $95 \%$ confidence intervals as error bars.

None of the other morphological traits measured significantly varied, or showed nonsignificant trends of variation, by wave exposure zone in C. angustifolium (e.g. stipe width, stipe thickness, lamina length, lamina width, lamina thickness, presence of vesicles) (Table 1). Stipe thickness and vesicle presence varied in C. maschalocarpum from the different wave exposure zones. There were also non-significant trends of lamina thickness and the presence of branching varying between wave exposure zones.

The average Carpophyllum maschalocarpum stipe thickness increased as wave exposure decreased (Fig. 5a). Stipes were significantly thinner in exposure zone 2 than zones 3 and 4 at both sites (Tukey tests: $\mathrm{p}=0.026$ ). The presence of vesicles in $C$. maschalocarpum individuals varied between the different exposure zones. The 
proportion of individuals with vesicles was lowest in the most exposed zone, highest in the moderately exposed zone, and intermediate in the two most sheltered zones (Fig. $5 b)$.

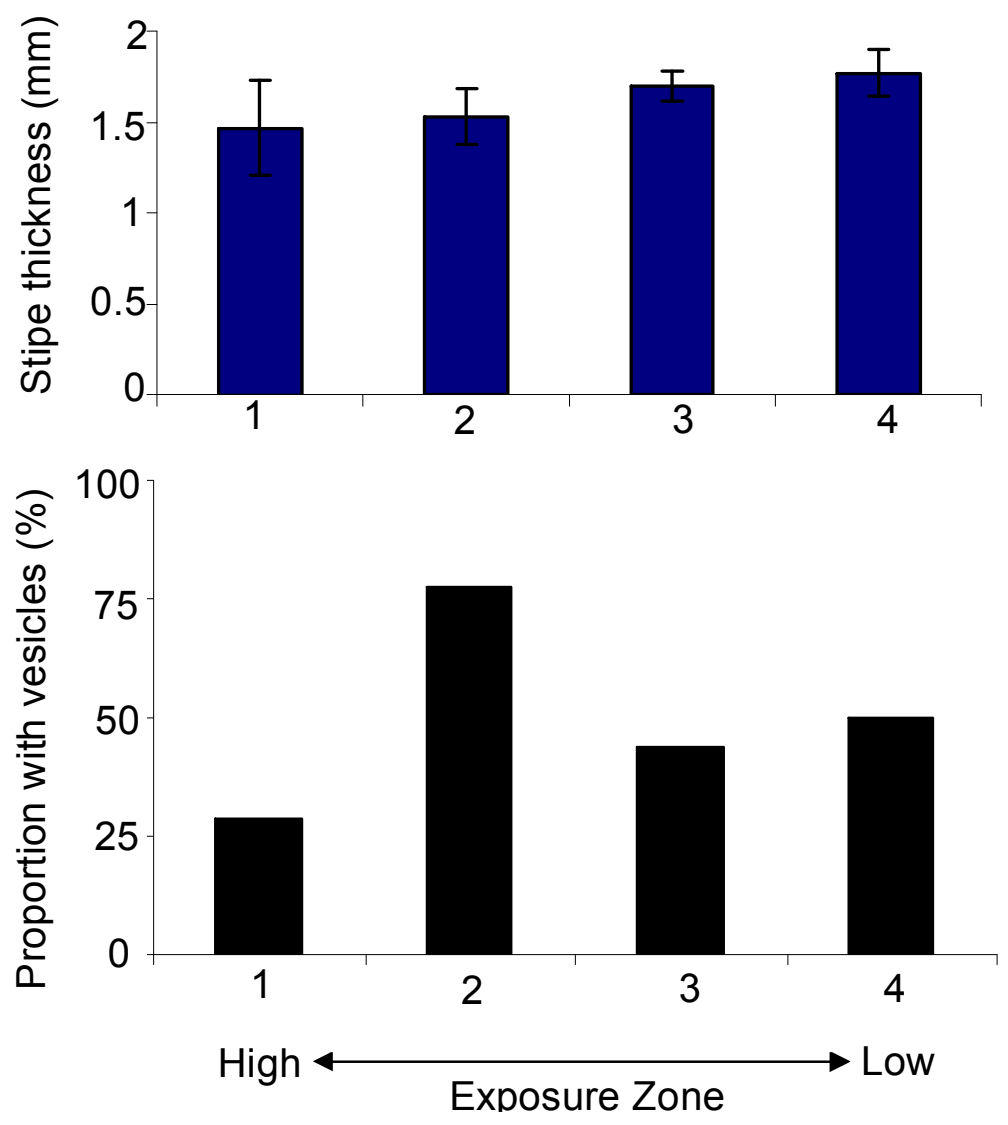

Figure 5: The variation in a) stipe thickness and b) vesicle presence between exposure zones for C. maschalocarpum. Error bars show 95\% confidence intervals.

There was a non-significant trend of lamina thickness in C. maschalocarpum differing between exposure sites, being thinner in more exposed zones. Another non-significant trend in C. maschalocarpum was in branching; there appeared to be fewer individuals with major branches in more exposed zones (Table 1). 
Table 1: Variation in morphological traits between exposure zones for C. angustifolium and C. maschalocarpum.

\begin{tabular}{|c|c|c|c|c|}
\hline Species & Significance & $\begin{array}{l}\text { Character } \\
\text { trait }\end{array}$ & $\begin{array}{l}\text { In more } \\
\text { exposed } \\
\text { zones }\end{array}$ & Statistics \\
\hline \multirow[t]{7}{*}{ C. angustifolium } & Significant & Total length & Longer & $\begin{array}{l}\mathrm{X}_{2}=5.980, \mathrm{df}=1, \mathrm{n}=280 \\
\mathrm{p}=0.014\end{array}$ \\
\hline & \multirow[t]{6}{*}{$\begin{array}{l}\text { Not } \\
\text { significant }\end{array}$} & Stipe width & & $\begin{array}{l}\mathrm{F}=0.883, \mathrm{df}=1, \mathrm{n}=280, \\
\mathrm{p}=0.348\end{array}$ \\
\hline & & Stipe thickness & & $\begin{array}{l}F=1.944, d f=1, n=280 \\
p=0.164\end{array}$ \\
\hline & & Lamina length & & $\begin{array}{l}\mathrm{X}_{2}=0.009, \mathrm{df}=1, \mathrm{n}=280 \\
\mathrm{p}=0.927\end{array}$ \\
\hline & & Lamina width & & $\begin{array}{l}F=1.137, d f=1, n=173, \\
p=0.288\end{array}$ \\
\hline & & $\begin{array}{l}\text { Lamina } \\
\text { thickness }\end{array}$ & & $\begin{array}{l}\mathrm{X}_{2}=0.010, \mathrm{df}=1, \mathrm{n}=173 \\
\mathrm{p}=0.919\end{array}$ \\
\hline & & \begin{tabular}{|l|}
$\begin{array}{l}\text { Proportion with } \\
\text { vesicles }\end{array}$ \\
\end{tabular} & & $\begin{array}{l}\mathrm{X}_{2}=0.529, \mathrm{df}=1, \mathrm{n}=280 \\
\mathrm{p}=0.467\end{array}$ \\
\hline \multirow[t]{8}{*}{\begin{tabular}{|l} 
C. \\
maschalocarpum
\end{tabular}} & \multirow[t]{3}{*}{ Significant } & Total length & Shorter & $\begin{array}{l}F=6.063, d f=3, n=152 \\
p=0.001\end{array}$ \\
\hline & & Stipe thickness & Thinner & $\begin{array}{l}F=6.981, d f=4, n=149, \\
p<0.001\end{array}$ \\
\hline & & $\begin{array}{l}\text { Proportion of } \\
\text { individuals } \\
\text { with vesicles }\end{array}$ & Lower & $\begin{array}{l}\mathrm{X}_{2}=11.491, \mathrm{df}=3, \mathrm{n}=152, \\
\mathrm{p}=0.009\end{array}$ \\
\hline & \multirow{2}{*}{$\begin{array}{l}\text { Non- } \\
\text { significant } \\
\text { trends }\end{array}$} & $\begin{array}{l}\text { Lamina } \\
\text { thickness }\end{array}$ & Thinner & $\begin{array}{l}F=2.689, d f=2, n=49 \\
p=0.079\end{array}$ \\
\hline & & $\begin{array}{l}\text { Proportion with } \\
\text { branches }\end{array}$ & Lower & $\begin{array}{l}X_{2}=6.159, d f=3, n=152 \\
p=0.104\end{array}$ \\
\hline & \multirow{3}{*}{$\begin{array}{l}\text { Not } \\
\text { significant }\end{array}$} & Stipe width & & $\begin{array}{l}F=1.874, d f=1, n=149, \\
p=0.137\end{array}$ \\
\hline & & Lamina length & & $\begin{array}{l}F=1.461, d f=3, n=49 \\
p=0.289\end{array}$ \\
\hline & & Lamina width & & $\begin{array}{l}\mathrm{F}=0.458, \mathrm{df}=3, \mathrm{n}=49 \\
\mathrm{p}=0.713\end{array}$ \\
\hline
\end{tabular}




\section{Site effect}

Carpophyllum morphological traits also varied between sites (Table 3). Stipe thickness and lamina thickness were significantly different between the two sites for $C$. angustifolium and C. maschalocarpum. Carpophyllum angustifolium stipe width and lamina width also varied between the two sites. Carpophyllum maschalocarpum lamina length varied between the two sites.

Table 1: Relative differences and statistics for character traits that significantly differed between the two sites (at the 5\% significance level).

\begin{tabular}{|l|l|l|l|}
\hline Species & Character trait & $\begin{array}{l}\text { At } \\
\text { Maraehako } \\
\text { Bay }\end{array}$ & Statistics \\
\hline \multirow{4}{*}{ C. angustifolium } & Stipe width & Wider & $\mathrm{F}=23.917, \mathrm{df}=1, \mathrm{n}=280, \mathrm{p}<0.000$ \\
\cline { 2 - 4 } & Stipe thickness & Thicker & $\mathrm{F}=6.848, \mathrm{df}=1, \mathrm{n}=280, \mathrm{p}=0.009$ \\
\cline { 2 - 4 } & Lamina width & Wider & $\mathrm{F}=1.137, \mathrm{df}=1, \mathrm{n}=173, \mathrm{p}<0.000$ \\
\cline { 2 - 4 } & Lamina thickness & Thinner & $\mathrm{F}=7.371, \mathrm{df}=1, \mathrm{n}=173, \mathrm{p}=0.007$ \\
\hline \multirow{2}{*}{$\begin{array}{l}\text { C. } \\
\text { maschalocarpum }\end{array}$} & Stipe thickness & Thinner & $\mathrm{F}=42.163, \mathrm{df}=1, \mathrm{n}=149, \mathrm{p}<0.000$ \\
\cline { 2 - 4 } & Lamina length & Thinner & $\mathrm{F}=4.782, \mathrm{df}=1, \mathrm{n}=49, \mathrm{p}=0.034$ \\
\cline { 2 - 4 } & Lamina thickness & Longer & $\mathrm{F}=23.979, \mathrm{df}=1, \mathrm{n}=49, \mathrm{p}<0.000$ \\
\hline
\end{tabular}

\subsection{Discussion}

Morphological traits differed between exposure zones, which suggests that $C$. angustifolium and C. maschalocarpum morphologies are affected by wave exposure. Previous studies have found algae in more wave exposed areas tend to be shorter with narrower and thicker lamina and stipes, and fewer or no vesicles (Fowler-Walker et al., 2006; Johnson \& Koehl, 1994; Kawamata, 2001; Stewart \& Carpenter, 2003). These relationships have been detected in another species in the Carpophyllum genus: Carpophyllum flexulosum (Cole et al., 2001). Some of these patterns were found in $C$. maschalocarpum; individuals were shorter, and a lower proportion had vesicles in the 
more wave exposed zones. There was also a non-significant trend of $C$. maschalocarpum being less branched in the more wave exposed zones. However opposing patterns were also found, with $C$. angustifolium being longer, and $C$. maschalocarpum stipes being thinner in more wave exposed zones. A non-significant trend was also found for $C$. maschalocarpum lamina being thinner in more wave exposed zones.

Carpophyllum angustifolium individuals were marginally, but significantly, longer in the most wave exposed zone, going against the trends found in other macroalgae. High wave exposures can prevent macroalgae from reaching large sizes, and smaller sized macroalgae experience less drag and wave damage (Blanchette, 1997; Hurd, 2000). The results found in our study could reflect different strategies to dealing with mechanical stress from wave exposure. Carpophyllum angustifolium grows in higher densities than C. maschalocarpum (Hodge, pers. obs.). The wave exposure that individuals are subjected to can be modified and reduced in dense macroalgal stands (Eckman, 1983), potentially reducing the selection pressure on morphology. Also, C. angustifolium appears to be very flexible (Hodge, pers. obs.). Flexibility can allow morphological reconfiguration in situ which can reduce the drag forces a macroalga is exposed to (Carrington, 1990; Denny, 2006). Flexibility in some macroalgae can result in reduced drag in higher flows (Carrington, 1990; Gaylord et al., 1994).

Another opposing trend to what has been found in other macroalgae was in the thickness of $C$. maschalocarpum stipes and lamina. Stipes were significantly thinner in $C$. maschalocarpum from more exposed zones, and C. maschalocarpum laminae showed a 
similar non-significant trend. This pattern could be a reflection of the relationship between age and thickness. Laminae and stipes get thicker with age, and individuals and their components are often younger in more exposed areas due to wave damage (Dudgeon \& Johnson, 1992). Carpophyllum maschalocarpum stipes and laminae might be thinner in more exposed areas because they are younger.

The relationships between wave exposure and morphology differed between the two species. The only trait that varied by wave exposure in both species was total length, which showed opposing trends in the two species. Also more morphological traits differed by wave exposure in C. maschalocarpum than in $C$. angustifolium. This could be due to their different wave exposure distributions. High levels of phenotypic plasticity has been hypothesised as being associated with generalist species, as opposed to specialist species (Sultan, 2000). Carpophyllum maschalocarpum had a much broader wave exposure distribution than C. angustifolium. Carpophyllum angustifolium was only found in the two most exposed zones, suggesting specialisation to high wave exposure. Carpophyllum maschalocarpum was found in all four wave exposure zones, which indicates that it is a generalist species (see also Dromgoole, 1973).

Differences in wave exposure - morphological relationships between the species could also be a reflection of the different strategies for dealing with wave exposure. The consequences of wave exposure on an individual are influenced by drag, and attachment strength (Kawamata, 2001). Changes in length, stipe and lamina dimensions can alter drag; but not attachment strength. Higher attachment strengths have been found in individuals with aggregating or larger holdfasts, and individuals from exposed locations 
(Dudgeon \& Johnson, 1992; Thomsen et al., 2004; Wernberg, 2005). The relative importance of reducing drag, and increasing attachment strength could differ between the two species, with a greater emphasis on reducing drag in C. maschalocarpum and increasing attachment strength in C. angustifolium. Attachment strength, holdfast biomass, or holdfast aggregation, were not measured in this study but are hypothesised to vary between wave exposure zones and species. During sampling it was noted that in the most exposed zone individuals were strongly attached, often having to be cut off or prised off the rocks with scissors. Empirical testing of attachment strength could help in interpretation in the relationships between morphology and wave exposure found in this study. Differing emphasis on drag and attachment strength was concluded in a similar study which found a lack of correlation between the morphological changes of two aquatic angiosperm species, Berula erecta and Mentha aquatica, along a water flow gradient (Puijalon \& Bornette, 2004).

The relationship between morphology and wave exposure was consistent between the two sites, but morphology differed between the sites. Morphological variation between sites has been found in a previous study on Fucus (Coleman \& Muhlin, 2008). Morphological variation could be due to environmental variability between the two sites, although these were thought to be very similar and only $500 \mathrm{~m}$ apart. Alternatively variation could be due to genetic differences between the two populations. Carpophyllum has low dispersal capacity; the majority of recruits settle within metres of parental plants (Schiel, 1980). Such low dispersal capacity could allow genetic differentiation between the two populations. Previous studies have found fucoid algae to have genetic differentiation at very low spatial scales; populations just 10m apart 
showed genetic differentiation in Fucus vesiculosus (Coyer et al., 1997; Engelen et al., 2001; Tatarenkov et al., 2007; Williams \& Di Fiori, 1996).

It should be noted that this study investigated wave exposure categorically, which has disadvantages. First relationships between wave exposure and morphology can be obscured or confused by small scale wave exposure variability. In a study aimed to compare algal morphology in exposed, semi-exposed and protected sites, Eckman (2003) found $30-50 \%$ of variation in water flow occurred between replicates at the same site. Secondly non-linear relationships between morphology and wave exposure can be distorted and misinterpreted when it is categorised (Kitzes \& Denny, 2005, see Fig. 5).

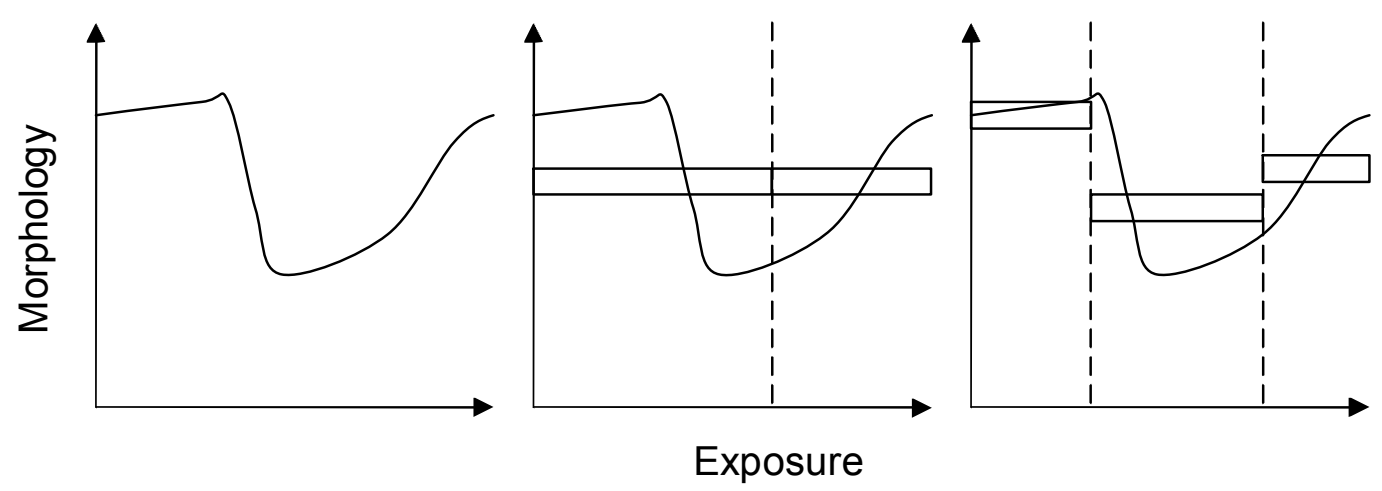

Figure 5: A hypothetical non-linear relationship between morphology and wave exposure, showing the different interpretations gained from a continuous measure, and two different categorical measures of wave exposure.

Further investigation of $C$. angustifolium and $C$. maschalocarpum is needed to understand the pattern of morphological variation found in this study. In particular analysis of morphology relative to a continuous measure of wave exposure could reveal finer scale trends, and non-linear relationships. Also investigation of attachment strength 
and flexibility is required to determine the importance of morphology on the effects of wave exposure for the two species. The drivers of the morphological variations observed are unknown. Exploration of the role of the environment and genetic variation is required. Transplant experiments, and an understanding of the genetic structuring of Carpophyllum populations could provide further insight. 


\section{Chapter 4: Distribution of $C$. angustifolium, $C$. maschalocarpum, and their hybrids with regard to wave exposure}

\subsection{Abstract}

An understanding of what shapes the distribution of species is one of the core questions in ecology. Wave exposure is one factor that affects the distribution of brown algae in the high subtidal. In north-east New Zealand Carpophyllum angustifolium and Carpophyllum maschalocarpum are major components of the shallow subtidal. The two species have different morphologies, which are each thought to be optimal in different wave exposure environments. Carpophyllum hybrids with intermediate morphology have been found in the wild. This study investigated the distributions of $C$. angustifolium, C. maschalocarpum and their hybrids relative to wave exposure in the high subtidal. Four wave exposure zones were defined within each site based on fetch and barnacle distribution. It was found that $C$. angustifolium was associated with high wave exposure while Carpophyllum maschalocarpum was associated with low wave exposure. Hybrids occurred in the intermediate wave exposure zones where parental distributions overlapped. Investigation of the distributions by depth is required to determine whether the hybrid distribution is environmentally selected or dispersal limited. 


\subsection{Introduction}

Environmental conditions can structure species distributions locally. Factors such as temperature, desiccation stress, salinity and wave exposure have been found to influence species distributions in marine systems (Harley, 2003; Heaven \& Scrosati, 2008; Pennings et al., 2005). Exposure to water motion has been found to have significant effects on the distribution of macroalgae in the shallow subtidal (Engelen et al., 2005) (Tuya \& Haroun, 2006). Water motion around macroalgae affects nutrient acquisition, creates mechanical fatigue, and can result in the loss of biomass or dislodgement of entire individuals (Hurd, 2000; Kawamata, 2001).

Certain morphologies are more successful in avoiding damage in areas of high wave exposure. In macroalgae, traits which reduce drag (i.e. small size, more streamlined shape, increased flexibility) or increase strength (i.e. thickness, aggregation) are favoured in high wave exposed areas (Puijalon \& Bornette, 2004; Ruuskanen \& Nappu, 2005; Stewart, 2006; Thomsen et al., 2004; Wernberg \& Thomsen, 2005). For example the kelp Nereocystis luetkeana has narrower and longer blades in high wave exposed areas, which Johnson et al. (1994) found significantly reduced drag.

Water motion on rocky shores is difficult to measure due to its spatial and temporal variability (Denny, 1988; Eckman et al., 2003). Direct measurements of water motion can be done using a range of equipment including dynamometers and plaster of paris clod cards (Carrington Bell \& Denny, 1994; Thompson \& Glenn, 1994). However, these methods have limitations (Lindegarth \& Gamfeldt, 2005; Porter et al., 2000). One major obstacle is the attachment and survival of equipment in high wave exposure 
environments. Subsequently direct measurements often rely on short term data that is collected in calm water (Arsenault et al., 2001; Stewart \& Carpenter, 2003). For example, Coleman et al. (2008) only measured wave exposure on days of 'low to moderate water motion' to 'gauge water motion'. Short term calm water measurements can be misleading if extrapolated over long periods, and varying sea conditions (Gaylord, 1999).

The difficulties associated with direct measurement have led many researchers to infer water motion from fetch or biological information (Ballantine, 1961; Engelen et al., 2005; McQuaid et al., 2000). In two major journals approximately half of the papers on wave exposure over a recent ten year period developed categorical definitions of exposure using fetch or local biota (Lindegarth \& Gamfeldt, 2005). Fetch and local biota can provide information about water motion over a relatively long time frame. However both have their limitations. Fetch data has low spatial resolution, while geographically specific information on the distribution or morphology of local biota might not be available (Arsenault et al., 2001; Gaylord, 1999; Lindegarth \& Gamfeldt, 2005). The distribution of barnacles by wave exposure in New Zealand has been well described (Foster, 1967; Foster 1978). Barnacles were one of the first taxa to be considered for defining wave exposure, and are a useful guide due to their immobility and dominance on rocky shores (Ballantine, 1961; Heaven \& Scrosati, 2008).

Carpophyllum angustifolium J. Agardh and Carpophyllum maschalocarpum Turner (Sargassaceae) are two species of macroalgae which dominate the high subtidal in New Zealand (Schiel, 1990). Their distributions are thought to be structured by wave 
exposure with C. angustifolium described as occurring in more wave exposed areas, and C. maschalocarpum in less wave exposed areas (Dromgoole, 1965; Lindauer et al., 1961). However, this is based solely on observations; their distributions have never been thoroughly investigated with regard to wave exposure. The two species have distinct morphology (Adams, 1994), with characters that appear suited to their hypothesised distribution. Carpophyllum angustifolium has been described as streamlined, flexible, with strong aggregating holdfasts, while C. maschalocarpum has been described as large, with vesicles and wide flat stipes (Dromgoole, 1965; Lindauer et al., 1961). The two species hybridise in the wild, producing hybrids with intermediate morphologies (see Chapter 2). Based on the intermediate morphology of the hybrids it could be hypothesised that they might be distributed in areas of intermediate wave exposure relative to the parents.

There is support for the distribution of hybrids being dependent on environmental factors (Fritsche \& Kaltz, 2000; Wang et al., 1997). This is a reflection of the relative fitness of hybrids in certain environments (Arnold \& Hodges, 1995). Hybrids are often found in intermediate or novel environments from the parental species (Arnold, 1997). The hybrids between the brown algae Fucus spiralis and Fucus vesiculosus have been identified as having both intermediate and novel distributions relative to the parental species (Coyer et al., 2006; Scott \& Hardy, 1994). Fucus spiralis and Fucus vesiculosus hybrids were distributed at intermediate shore heights to the parents on rocky shores (Scott \& Hardy, 1994). Fucus spiralis $\times$ F. vesiculosus hybrids were also found with a dwarf morphology in a salt marsh which is a novel habitat from their diploid parents (Coyer et al., 2006). 
This study will investigate the distributions of $C$. angustifolium, C. maschalocarpum and their hybrids in the high subtidal with regard to wave exposure. Wave exposure zones will be defined within sites using fetch and barnacle distributions. Do the two parents occupy different wave exposure zones, with C. angustifolium in the more exposed and C. maschalocarpum in the more sheltered? Are the morphologically intermediate hybrids found in intermediate wave exposure zones?

\subsection{Methods}

\section{Sampling locations}

Samples were collected from two sites on the East Cape of the North Island of New Zealand, where C. angustifolium, C. maschalocarpum and their hybrids were known to be present (Fig. 1). The two sites were both in the greater Whanarua Bay, which faces north-west and contains a number of smaller sandy bays divided by large rocky islands. The first site was located at the south-eastern end of Maraehako Bay (S37 $40.4^{\prime}$ E177

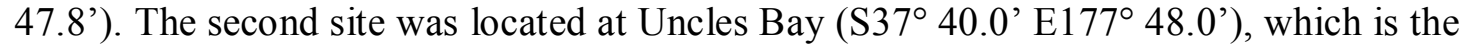
adjacent bay to the north-east. The two sites are approximately $500 \mathrm{~m}$ apart, separated by Motu Kaimeanui Island and two deep inlets (Fig. 1). Sampling was conducted during the 2007-2008 summer season. 

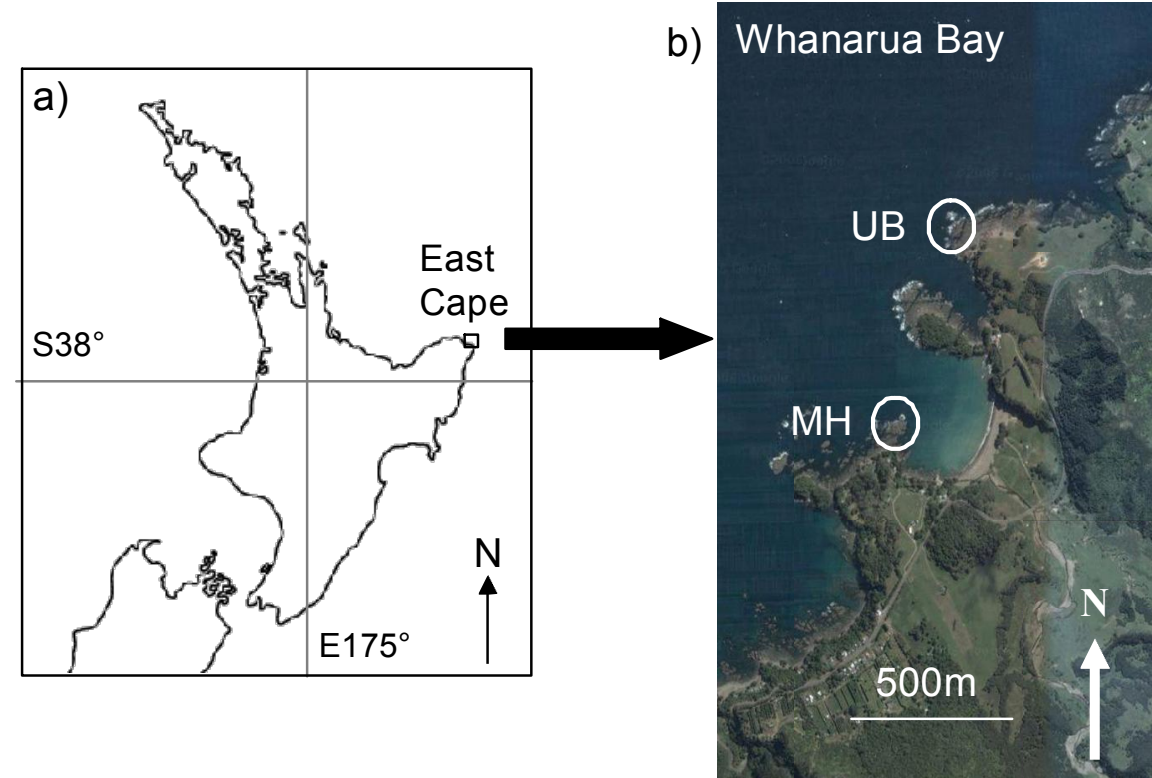

Figure 1: The location of the sampling sites a) on the East Cape of the North Island of New Zealand, and b) the two sites in the greater Whanarua Bay: Maraehako Bay (MH), and Uncles Bay (UB).

\section{Assessing wave exposure}

Four wave exposure zones were selected from each of the two sites. These zones were determined based on fetch and barnacle distributions. Firstly sites were divided using an estimate of fetch based on a modified Baardseth Index. The Baardseth Index is calculated by placing a transparent circular disc with a radius of $7.5 \mathrm{~km}$ on a point in a map and determining the number of $9^{\circ}$ segments containing no land, small islands, or rocky outcrops (Baardseth, 1970). In this study the angle of open segments was summed in-situ to incorporate small scale disruptions to oncoming waves such as rocky outcrops. This sum was over $120^{\circ}$ for the most exposed zone, up to $60^{\circ}$ in the second most exposed zone, and $0^{\circ}$ in the two most sheltered zones. The two most sheltered zones were distinguished by the direction rock walls were facing. The rock walls in the 
moderately sheltered exposure zone faced the opposite side of the bay, whilst those in the most sheltered exposure zone faced the shore.

\section{Sampling}

Transect lines were laid in each zone, and quadrat locations were selected randomly for the top $0.5 \mathrm{~m}$ of the Carpophyllum depth distribution. The intertidal barnacle fauna was checked for consistency with wave exposure prior to sampling each quadrat. The expected barnacle fauna for the four wave exposure zones was determined based on work by Foster (1967 and 1978), and is illustrated in Figure 2. Quadrats were rejected if barnacle fauna did not match the expected fauna in the wave exposure zone, the rock face was not vertical, less than three Carpophyllum individuals were present, or the quadrat was less than $0.5 \mathrm{~m}$ from a previously sampled quadrat. All Carpophyllum individuals with holdfasts inside the $20 \mathrm{~cm}$ by $20 \mathrm{~cm}$ quadrats were collected. Sixty nine quadrats were sampled in the two sites, with six to eight quadrats from each zone. Six additional quadrats were sampled from zones where hybrids were found in more than one of the original quadrats. Collected material was frozen at $-4^{\circ} \mathrm{C}$ within a week of collection, and thawed in seawater prior to drying and weighing. 


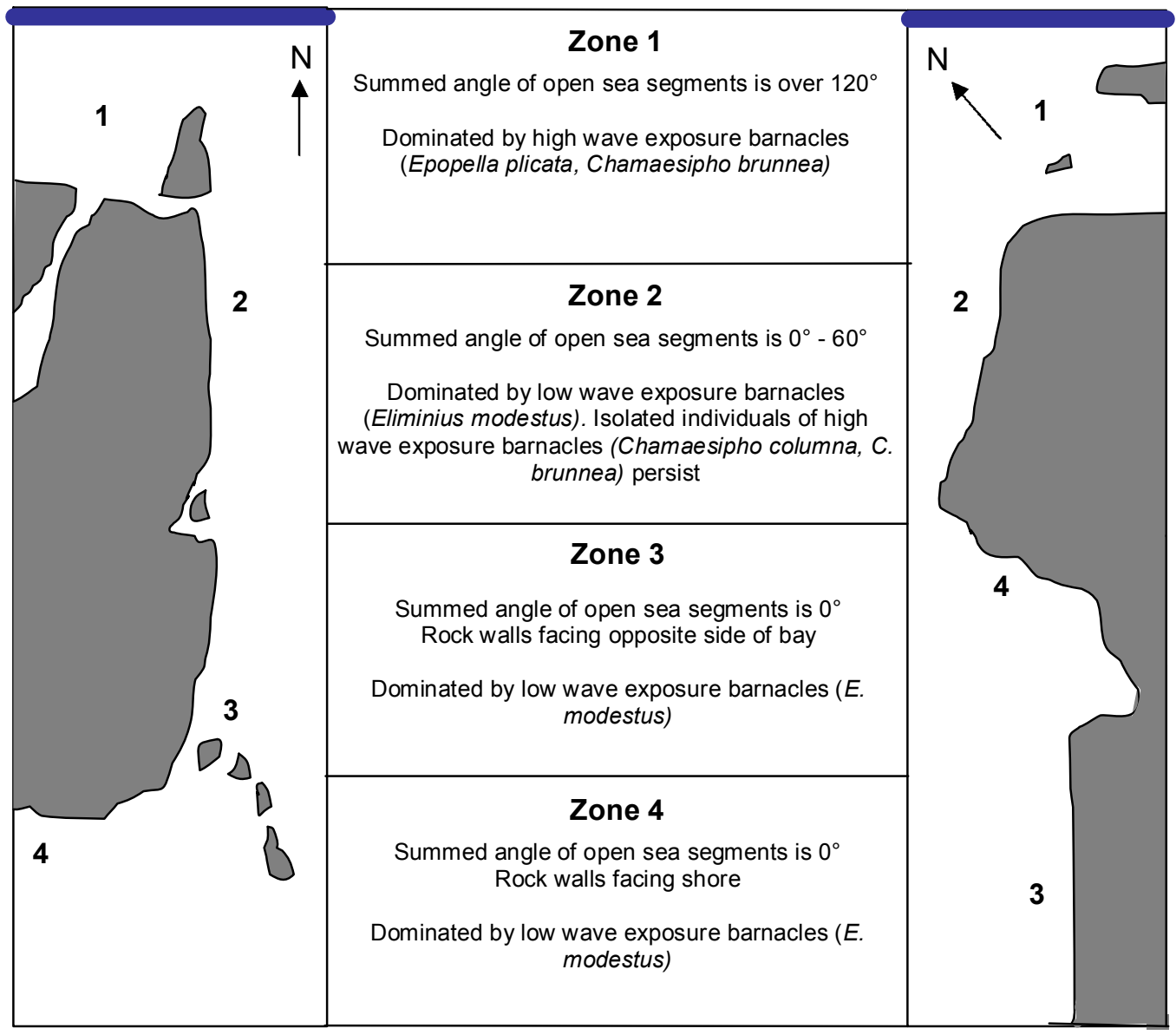

Figure 2: The wave exposure zones were defined by the degree of exposure to the open sea, orientation of the rock walls, and the barnacles in the intertidal portion of the rock wall. On the left and right simplified illustrations of the two study sites are shown with the general locations of the zones marked. The blue line represents the open sea.

\section{Laboratory analysis}

Adults were morphologically identified, cleared of epiphytes, dried and weighed. Individuals longer than $20 \mathrm{~cm}$ were considered adults. All holdfasts were removed as the amount of rock and non-algal biomass stuck in them was variable. Algae were dried at $50^{\circ} \mathrm{C}$ for $24 \mathrm{hrs}$ or longer (in a Clayson Incubator) until thoroughly dry and then weighed using a balance accurate to $0.01 \mathrm{~g}$. 


\section{Data analysis}

Carpophyllum distribution data were analysed in SPSS 17.0. The distributions of biomass were not normally distributed due to the large number of zeros from the absence data. Transformations were unable to normalise data, so data were analysed non-parametrically. The chi-squared test was used to test for distributional overlap between species, and non-random distribution across wave exposure zones and sites. Differences in biomass between the different zones were tested with the non-parametric Kruskal-Wallis and Mann Whitney tests. Statistical significance was inferred at the 5\% level.

\subsection{Results}

\section{Distribution of parent species}

Carpophyllum angustifolium was distributed in different wave exposure zones from $C$. maschalocarpum (Chi squared test: $\chi_{2}=33.051, \mathrm{df}=3, \mathrm{n}=79, \mathrm{p}<0.000$ ) (Fig. 3). Carpophyllum angustifolium was found only in the relatively high wave exposed zones 1 and 2. Carpophyllum maschalocarpum was found mostly in the relatively low wave exposed zones 3 and 4 . 


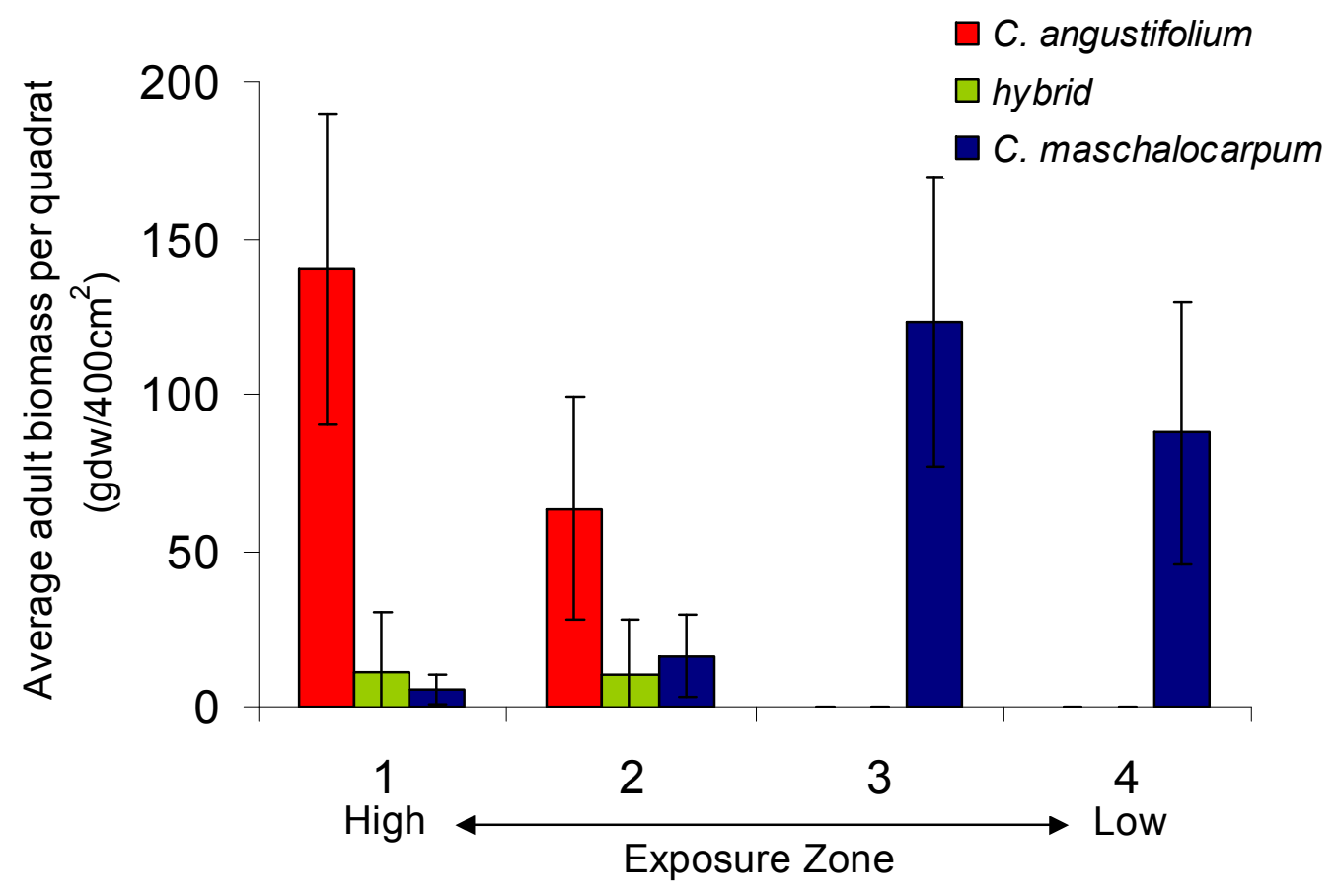

Figure 3: Average biomass of C. angustifolium and C. maschalocarpum and their hybrids in the $20 \mathrm{~cm}$ by $20 \mathrm{~cm}$ quadrats from each wave exposure zone. The error bars represent $95 \%$ confidence intervals.

\section{Distribution of hybrids}

The $C$. angustifolium $\times C$. maschalocarpum hybrids were rare in comparison to the parent species (Fig. 3), and were found in only 9 out of the 69 quadrats. Wave exposure was a significant factor in adult hybrid distribution (Kruskal-Wallis $\mathrm{X}_{2}=7.970, \mathrm{df}=3$, $\mathrm{n}=69, \mathrm{p}=0.047$ ). Adult hybrids were found only in the relatively sheltered wave exposure zones 1 and 2, with no significant differences in hybrid adult biomass between these two zones (Mann-Whitney $U=187.000, Z=-0.794, n=41, p=0.427$ ). The wave exposure zones where hybrids were found were only those where both parental species were also present. Furthermore eight of the nine $400 \mathrm{~cm}^{2}$ quadrats containing adult 
hybrids also contained one or both of the parental species. The other quadrat without adult parental species contained less than 2 gdw (grams dry weight) of adult hybrid. There was no significant difference in the total Carpophyllum biomass contained in the quadrats with and without hybrids $(\mathrm{F}=0.444, \mathrm{df}=1, \mathrm{n}=69 \mathrm{p}=0.507)$.

\section{Site differences}

The composition of C. angustifolium, C. maschalocarpum and their hybrids in the high wave exposure zone 1 differed between the two sites. In this wave exposure zone both species and hybrids were found at Uncles Bay. In contrast only C. angustifolium was found in this zone at Maraehako Bay.

\subsection{Discussion}

The distributions of $C$. angustifolium, C. maschalocarpum and their hybrids were correlated with wave exposure. Carpophyllum angustifolium was distributed in the relatively exposed zones, while $C$. maschalocarpum was distributed mainly in the sheltered zones. This was consistent with the hypotheses and descriptions of Dromgoole (1973), Lindaeur (1961) and Adams (1994). Hybrids were distributed in the relatively exposed zones.

Hybrids are most commonly found in environmental conditions intermediate between the parental distributions (Arnold et al., 2001; Campbell \& Waser, 2007; Harrison, 1986; Wang et al., 1998). Hybrids often have environmentally dependent fitness, and the importance of this forms the basis of two important hybrid distribution models: the 
Bounded Hybrid Superiority model and the Evolutionary Novelty model (Arnold, 1997; Arnold \& Hodges, 1995; Moore, 1977). However this pattern has not been confirmed for Fucalean hybrids due to a lack of study. In this literature review only two studies on Fucalean hybrid distribution were found, and both were based on only two plots or transects. In one of these studies the spatial distribution of hybrids could not be distinguished from the parental species (Coyer et al., 2007). In the other study distributions were structured by shore height with hybrids having an intermediate distribution (Scott \& Hardy, 1994). The intermediate wave exposure zones where Carpophyllum hybrids were found were also the zones where both parental species were present. Eight out of the nine quadrats where hybrids were found contained individuals of one or both the parental species. This pattern was also found in the two studies previously mentioned, where hybrid individuals were all within five metres of individuals from both parental species (Coyer et al., 2007; Scott \& Hardy, 1994).

The distribution pattern found could be a reflection of environmentally dependent selection in different wave exposures. This is concordant with what is known about their adult morphology. Carpophyllum angustifolium is more streamlined than $C$. maschalocarpum and hybrids are intermediate (Chapter 2; Adams 1994). More streamlined morphologies significantly reduce drag in high wave exposure, and as such are likely to reduce wave damage and confer fitness advantages in high wave exposure environments (Johnson \& Koehl, 1994; Wernberg \& Thomsen, 2005). Greater attachment strength and flexibility can also be selected for in high wave exposures, and could be more important than morphology in determining drag forces (Carrington, 1990; Denny, 2006). These characters have not been fully investigated in the two parental 
species, although $C$. angustifolium is thought to have greater attachment strength (Dromgoole 1973; Hodge, pers. obs.).

Zygote attachment and settler survival in different wave exposures could also be structuring adult Carpophyllum distributions. The majority of mortality in Fucalean algae occurs in microscopic stages (Schiel \& Foster, 2006). Only 2\% of $C$. maschalocarpum settlers survive to reproductive age (Schiel, 1985). Distributions of $C$. angustifolium, C. maschalocarpum and their hybrids might be structured by selection acting on zygotes and settlers. Settlement of zygotes can be affected by wave exposure (Vadas et al., 1992). Attachment of zygotes to the substrate has been described as one of the most important events in the life cycle of an intertidal alga (Hardy \& Moss, 1979). One small wave is able to remove $90 \%$ of settlers in some Fucalean species (Vadas et al., 1990). The effect of wave exposure on the attachment ability of zygotes to the substratum varies between species (Taylor \& Schiel, 2003; Vadas et al., 1992). Taylor and Schiel (2003) found that the variations in attachment ability of three Fucalean algae (Hormosira banksii, Cystophora torulosa, Durvillaea antarctica) under different water flow conditions correlated with their adult distribution. They suggest early environmentally dependent selection on zygotes structures adult distribution patterns (Taylor \& Schiel, 2003). The attachment ability of $C$. angustifolium, $C$. maschalocarpum and hybrid zygotes is largely unknown (Schiel \& Foster, 2006). No study has yet investigated the effects of wave exposure on zygote attachment in Carpophyllum, and the zygotes of Carpophyllum hybrids have never been observed at all. 
Hybrid distribution could be a reflection of the contact zone - the area where parental species distributions overlap. The extent of the contact zone is determined by parental species distribution, as well as parental gamete and hybrid zygote dispersal capacities. Dispersal capacity in the order Fucales is limited, as their eggs are relatively large, nonmotile and often coated in mucus. Consequently the settlement of zygotes tends to occur within metres of parents (Chapman 1995, Schiel \& Foster 2006). Schiel (1980) found three quarters of C. angustifolium and C. maschalocarpum recruits settled within four metres of parent plants. Such a low dispersal capacity results in a narrow contact zone, and makes it likely hybrid zygotes will settle in areas close to an individual of both parental species.

This extent of the contact zone in this study is not known, as only the top $0.5 \mathrm{~m}$ of Carpophyllum distribution were investigated. Distributions of $C$. angustifolium and $C$. maschalocarpum extend to $7 \mathrm{~m}$ depth (Schiel, 1990). In high wave exposed areas $C$. angustifolium is distributed in a belt of varying thickness above C. maschalocarpum (Dromgoole, 1973; Hodge, unpubl. data). That no hybrids were found in the top $0.5 \mathrm{~m}$ in the most exposed zone at Maraehako Bay despite both $C$. angustifolium and $C$. maschalocarpum individuals being only one metre apart by depth (Hodge, unpubl. Data), suggests environmental factors and not dispersal are limiting hybrid distributions.

This study found a pattern of distributions being correlated with wave exposure. Further work is required to investigate if and how wave exposure selection pressures create the distributions of C. angustifolium, C. maschalocarpum, and their hybrids. Previous studies have used field and laboratory experiments and field transplants to determine the 
drivers of different species distributions relative to wave exposure environments (Correa et al., 2006; Kawamata, 2001; Ladah et al., 2003). Determining whether attachment strength differs between the two species and their hybrid, and experimentally comparing zygote attachment and adult morphology in different flow regimes in the laboratory are important next steps (Taylor \& Schiel, 2003). Field transplants in this system would be difficult and involve high loss rates; however if possible it is a good way of comparing fitness. Previous attempts transplanting the sister species Carpophyllum flexulosum were not particularly successful (Travers, 1996). Further work should be done investigating $C$. angustifolium, C. maschalocarpum and hybrid distributions by depth. Are the hybrids distributed at intermediate depths relative to the parents? 


\section{Chapter 5: Morphological evidence of hybridisation in Carpophyllum angustifolium and Carpophyllum maschalocarpum populations from Leigh}

\subsection{Abstract}

Hybridisation is a common and important evolutionary process. The future and genetic diversity of the parent species involved can be significantly affected by hybridisation. A previous study revealed hybridisation between the subtidal brown algae Carpophyllum angustifolium and Carpophyllum maschalocarpum at the East Cape of the North Island, New Zealand. This previous research used the molecular marker ITS2 but was unable to resolve hybrids at Leigh in northern New Zealand as shared ITS2 ribotypes were present in the parental species. In the present study the morphologies of individuals at Leigh were compared with the genetically identified individuals from the East Cape to investigate whether hybridisation is also occurring at Leigh. Individuals at Leigh were found to form morphological clusters similar to those at the East Cape, which suggests that hybridisation is occurring. Carpophyllum angustifolium and hybrid morphology differed between the Leigh and East Cape populations. This could be due to environmental differences, a lack of genetic connectivity, or differences in the level of introgression between the sites.

\subsection{Introduction}

Recent reviews have concluded hybridisation is more important and prevalent than previously thought (Grant et al., 2005; Mallet, 2005). Hybridisation can affect biodiversity through hybrid speciation, parental species extinctions, and transfers of 
genetic information between parental species (Seehausen, 2004). Twenty-five percent of plant and ten percent of animal species are estimated to be currently hybridising (Mallet, 2005). Hybridisation also occurs in the kingdom Chromista, although the extent of hybridisation is unknown. This kingdom contains the diverse and highly plastic brown macroalgae in the phylum Phaeophyceae. Detecting hybridisation in the phylum Phaeophyceae is particularly challenging due to the high levels of plasticity exhibited (Scott \& Hardy, 1994).

Morphological methods have been used to identify wild hybrids. The assumption of hybrid morphological intermediacy underpins most morphological analyses (Estabrook et al., 1996). Hybrid indices, for example, create a morphological continuum between two parent species, and identify hybrids as those lying in the intermediate region of the continuum (Anderson, 1953; Estabrook et al., 1996; Wilson, 1992). However, identifying hybrids based on intermediate morphologies has limitations. First hybrids can have morphologies similar to, novel from, or more extreme than the parental species (Coyer et al., 2002a; Lihova et al., 2007; Seehausen, 2004). Secondly, problems arise in highly plastic and variable taxa such as macroalgae (Rieseberg \& Ellstrand, 1993; Scott \& Hardy, 1994). Finally morphological differences might merely reflect patterns of plasticity or environmental variation (Mathieson et al., 1981).

Molecular techniques using variation in nuclear DNA have also been used to identify hybrids. The assumption in molecular analyses is that species specific markers from both parent species will be found in hybrids (Hegarty \& Hiscock, 2005). The internal transcribed spacer (ITS) sequence is part of the ribosomal region in the nuclear DNA, 
and is one of the most widely used sequences in plant evolutionary studies (Feliner \& Rossello, 2007). ITS has been used in a variety of taxa to identify hybrids (Casteleyn et al., 2009; Coyer et al., 2008; Kauserud et al., 2007). It is biparentally inherited, so hybrids are ITS heterozygotes where parental species have distinct ITS sequences. The heterozygosity of hybrids has been confirmed with artificially produced $F_{1}$ hybrids in macroalgae (Coyer et al., 2002b). However ITS has limitations. It is part of a multi-gene family that can undergo concerted evolution (Alvarez \& Wendel, 2003). Concerted evolution has the effect of homogenising all ITS gene copies, converting heterozygotes to homozygotes. Subsequently ITS can only detect recent hybridisation (Alvarez \& Wendel, 2003).

Hybridisation between two subtidal brown seaweeds, Carpophyllum angustifolium J. Agardh and Carpophyllum maschalocarpum Turner (Sargassaceae), is occurring in New Zealand (Buchanan, unpubl. data). Intermediate 'hybrid' morphologies have been recorded in the literature since the 1960s (Dromgoole, 1965; Lindauer et al., 1961), and molecular work has confirmed these to be hybrids in East Cape populations (Chapter 2). Buchanan (unpubl) found in the East Cape populations the two parental species each had a single distinct ITS2 ribotype, which allowed the ITS2 heterozygotes to be identified as hybrids. In populations further north at Leigh both parental species had multiple ITS2 ribotypes, and some ITS2 ribotypes were shared between species (Buchanan, unpubl.). The presence of shared ITS2 ribotypes means ITS2 heterozygotes are not necessarily hybrids. Consequently ITS2 cannot be used to identify hybrids. The presence of shared ITS2 ribotypes might be due to introgression, or alternatively to incomplete lineage sorting of the ancestral ribotypes in this population. 
Recent work investigating the morphology of genetically identified individuals in the East Cape populations found the morphologies of parents and hybrids to be distinct (see Chapter 2). This study used an identical morphometric analysis to investigate the morphologies in the northern Leigh populations of $C$. angustifolium, $C$. maschalocarpum and their hybrids. Do the morphologies of individuals in the $C$. angustifolium $\times$ C. maschalocarpum hybrid system in Leigh populations form distinct morphological groups? How does the morphology of Leigh individuals compare with the genetically identified East Cape individuals?

\subsection{Methods}

\section{Sampling locations}

Samples were collected from two sites in Leigh on the North Island of New Zealand (Fig. 1). The first site was located around Surge Rock (S36 $\left.{ }^{\circ} 16.3^{\prime}, \mathrm{E} 174^{\circ} 48.1^{\prime}\right)$, and the second site was found at the Ray Rock area (S $36^{\circ} 16.3^{\prime}$, E174 $\left.48.2^{\prime}\right)$. The two sites are approximately $500 \mathrm{~m}$ apart and are separated by rocky islands. Sampling was conducted in mid February 2008 in the summer season. The genetically identified individuals used for comparison were collected from the East Cape in Chapter 2. 


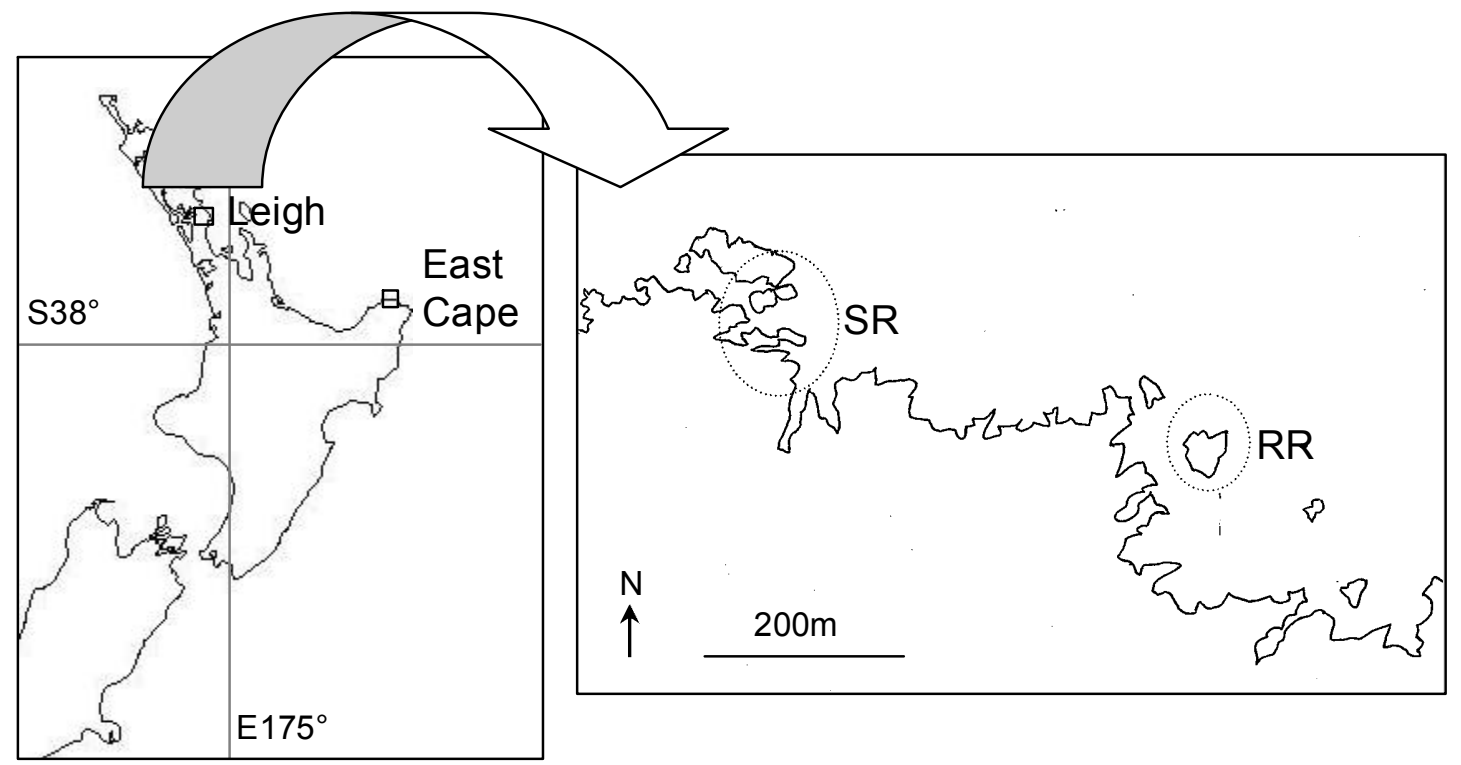

Figure 1: The location of sampling a) for the Leigh individuals and the East Cape reference individuals in New Zealand, and b) the two Leigh Sites: Surge Rock (SR), and Ray Reef (RR)

\section{Sampling}

Transect lines were laid along rock walls in the high subtidal, and quadrat locations were selected randomly for the top $0.5 \mathrm{~m}$ of Carpophyllum depth distribution. Quadrats were rejected if the rock face was not vertical, less than three individuals were present, or if the quadrat was less than $0.5 \mathrm{~m}$ from a previously sampled quadrat. All Carpophyllum individuals with holdfasts inside the $20 \mathrm{~cm}$ by $20 \mathrm{~cm}$ quadrats were collected. Thirty eight quadrats were sampled in the two sites, with 38 C. angustifolium, $41 C$. maschalocarpum and 24 hybrid adults collected in total. Collected material was frozen at $-4^{\circ} \mathrm{C}$ within a week of collection, and thawed in unfiltered seawater prior to morphometric analysis. 


\section{Morphometrics}

Adults (longer than $20 \mathrm{~cm}$ ) were morphologically identified, cleared of epiphytes, and measured using digital callipers. Only those individuals with complete haptera were used in morphometrics so as to avoid pseudo-replication (i.e. the doubling up of measurements from the same individual). Individuals were measured using digital callipers and a metre rule.

The morphometric characteristics selected for measurement were stipe width, lamina length and lamina width (Fig. 2). These were the characters which best distinguished between East Cape parent species and hybrids in Chapter 2. This study focused on the stipe and lamina characteristics of the primary axis (defined as the axis which arises directly from the holdfast). The stipe and lamina measurements were taken from approximately $5 \mathrm{~cm}$ from the tip of the axis. Lamina length was measured from the edge of the stipe to the tip of the lamina. Lamina and stipe width were measured at the widest point, perpendicular to an imagined mid-line. In some places herbivory had altered the morphology of the stipe and lamina; these could be detected by sudden and distinct changes in lamina or stipe outline. Measurements of stipe and lamina that were affected by herbivory were excluded, and if possible replaced by measurements from the nearest intact equivalent within $10 \mathrm{~cm}$. 


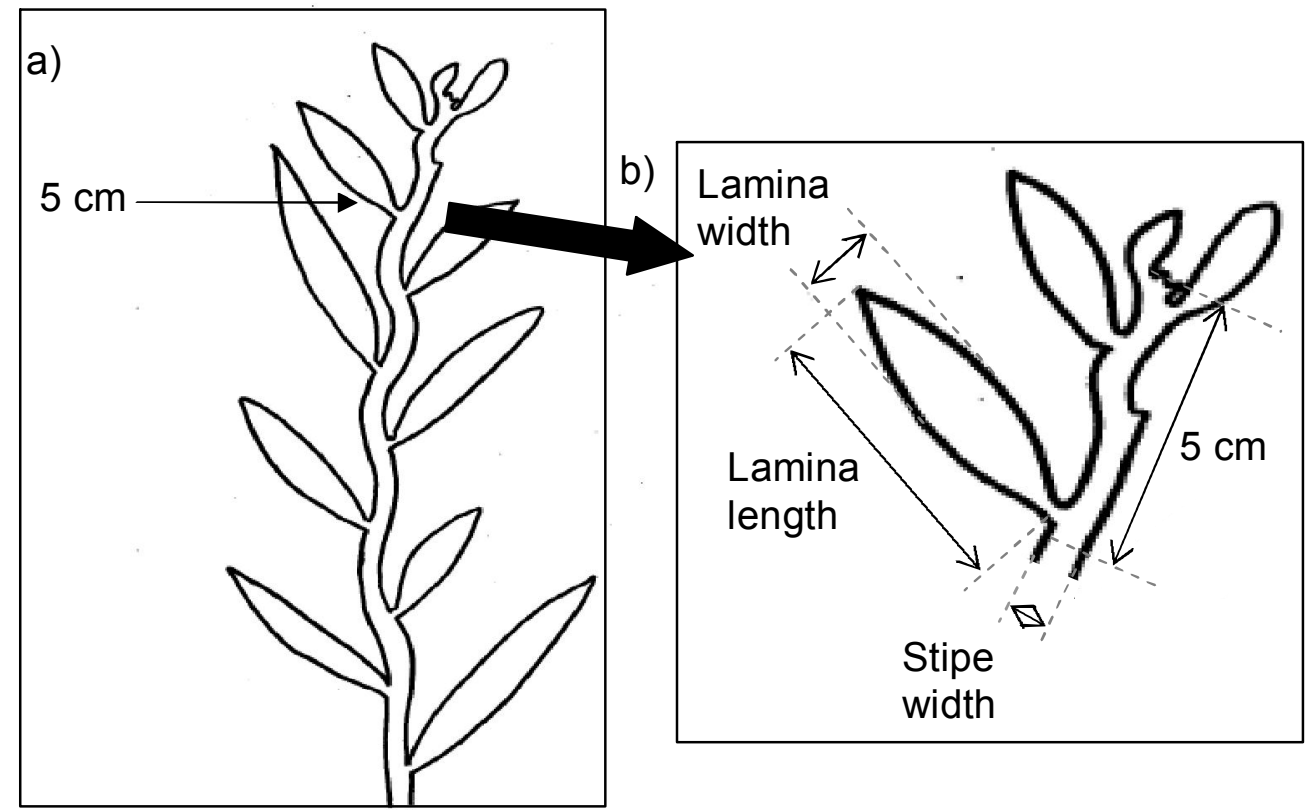

Figure 2: The location of the measurements taken from each individual a) on a stylised axis, and b) a close up of stipe width, lamina length and lamina width measurements.

\section{Data Analysis}

Cluster analysis finds natural groupings or clusters within the data (Fielding, 2007).

These were done with the Leigh individuals using the software NTSYSpc, version 2.11(Rohlf, 2000). The unweighted pair-groups method average (UPGMA) clustering method was used, which is the most common and accepted method (Fielding, 2007), and also produced the highest cophenetic correlation. Boxplots were used to confirm divergence for the three morphological traits. The data were incorporated into a distance matrix using Gower's Index in Le Progiciel R 4.0 software (Casgrain \& Legendre, 1999). This index was used as it can cope with missing values, and has been used in other studies on macroalgae morphology (Fowler-Walker et al., 2006; Montanari \& Mignani, 1994; Podani, 1999). Coenphetic values were calculated to test the fit of the cluster tree to the distance matrix (Rohlf, 2000; Rohlf \& Sokal, 1981). The resulting 
cluster tree was compared to the cluster analysis done on genetically identified individuals from the East Cape in Chapter 2.

The morphology of the Leigh clusters was compared with the genetically identified individuals from the East Cape. Stipe width, lamina length and lamina width were analysed with MANOVA where assumptions were met, and npMANOVA where assumptions were not met using SPSS 17.0 and PAST software (Hammer et al., 2001). Assumptions of normality, equal variances and equality of covariance matrices were checked respectively with box plots, Levene's Test and Box's Test.

\subsection{Results}

\section{Leigh morphologies}

The cluster analysis of Leigh individuals revealed a tree with four distinct morphological clusters. This cluster tree was similar in structure to one produced for individuals genetically identified from the East Cape (Fig. 3). However, the clusters were more morphologically similar to each other at Leigh than at the East Cape, with an overall similarity coefficient of 0.60 compared to 0.49 . 


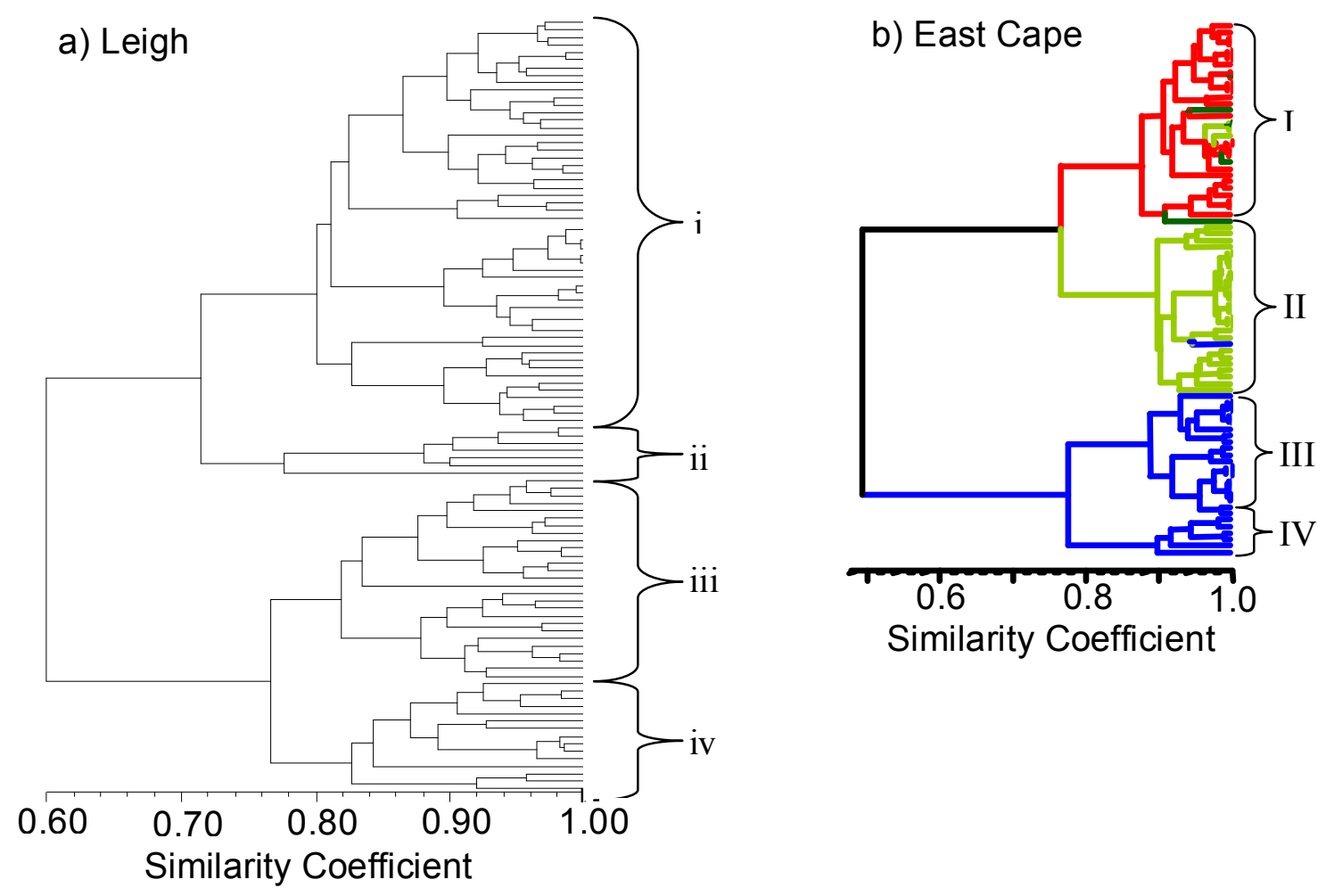

Figure 3: The morphological cluster trees of a) randomly sampled individuals from Leigh, and b) genetically identified individuals from the East Cape. Individuals cluster into four different groups on both trees as labelled i to iv at Leigh and I to IV at the East Cape. Colours on b) represent the identity of the individuals. Carpophyllum angustifolium is shown in red, C. maschalocarpum in blue, hybrids in light green, and putative backcrosses in dark green. The coenphetic value for the trees are 0.76 for Leigh, and 0.84 at the East Cape.

The four morphological clusters identified at Leigh were analogous to the clusters of genetically identified East Cape individuals, which allowed hypotheses of the identity of Leigh clusters. There were differences in the multivariate morphologies between Leigh clusters and their hypothesised taxa from the East Cape (Fig. 4). Leigh individuals in cluster I had different multivariate morphologies from the genetically identified $C$. angustifolium individuals from the East Cape $(\mathrm{n}=64, \mathrm{~F}=8.531, \mathrm{p}=0.0033)$. The multivariate morphologies of Leigh individuals in cluster II differed from the confirmed 
hybrids from the East Cape $(\mathrm{n}=18, \mathrm{~F}=14.11, \mathrm{p}=0.0019)$. The multivariate morphology of clusters III and IV did not differ from that of C. maschalocarpum in the East Cape $(\mathrm{n}=52, \mathrm{~F}=0.05, \mathrm{p}=0.985)$.

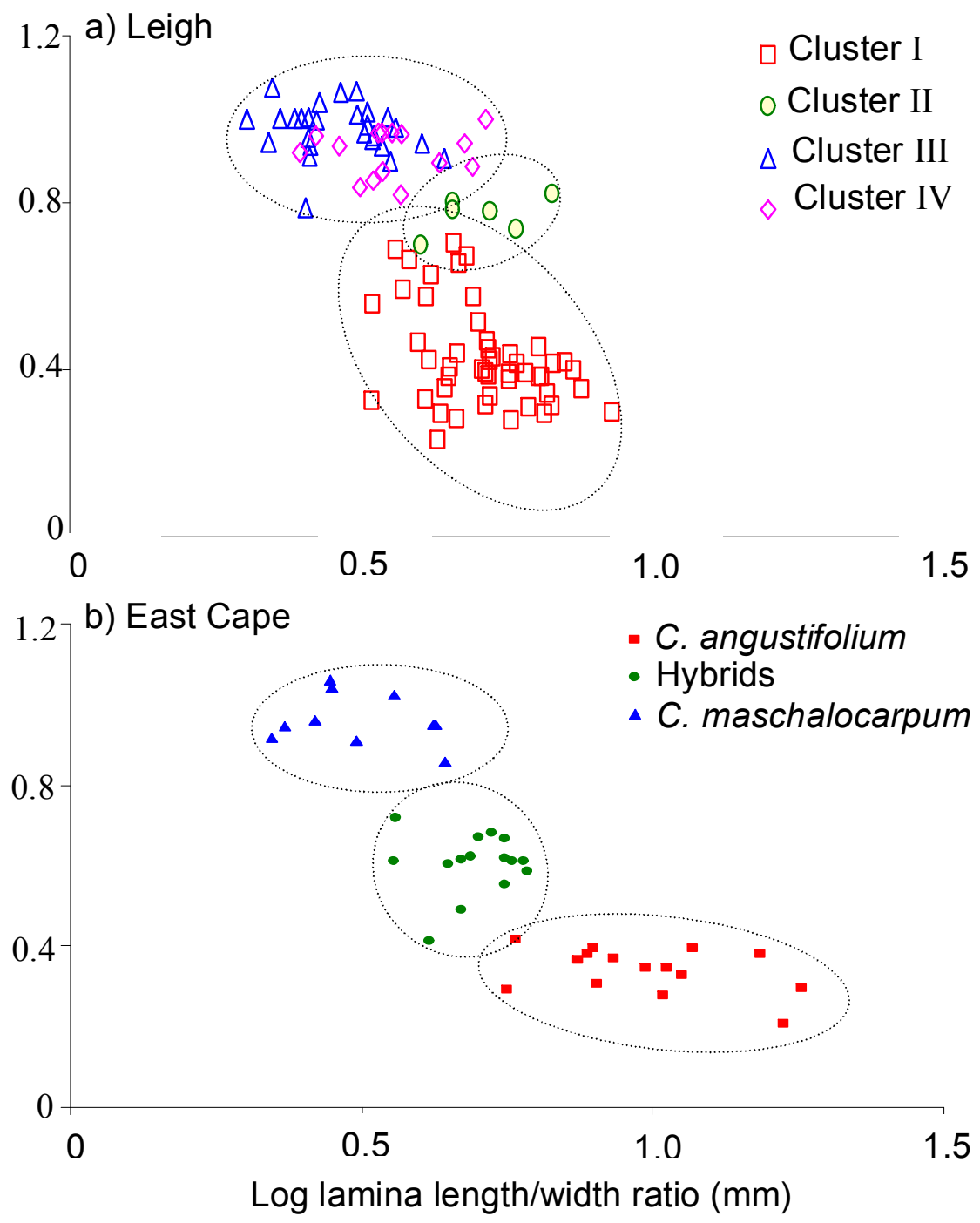

Figure 4: The multivariate morphology of a) the individuals from Leigh, and b) the genetically identified individuals from the East Cape. Circles with dashed borders show the general distributions of species and hybrids. Leigh individuals are plotted according to assigned cluster, and the dashed borders surrounds hypothesised identities based on the East Cape tree. NB clusters III and IV were both genetically C. maschalocarpum in East Cape cluster analysis. 


\subsection{Discussion}

The individuals from Leigh formed a cluster tree with the same branching and shape as the cluster tree of individuals with known hybrids from the East Cape. Carpophyllum angustifolium and C. maschalocarpum produce hybrids with intermediate morphology at the East Cape, which form a morphological cluster related to C. angustifolium (Chapter 2). The presence of a similar shaped tree, and a comparable 'hybrid' morphological cluster in the Leigh cluster tree strongly suggests that hybridisation is also occurring at Leigh.

The C. angustifolium and hybrid morphological clusters at Leigh significantly differed from their genetically identified equivalents at the East Cape site $300 \mathrm{~km}$ away. Differences in Carpophyllum morphology have previously been found between sites less than a kilometre apart (Chapter 3). The variation found in between Leigh and East Cape morphological clusters could be due to several reasons. First environmental differences between the two sites could result in morphological differences through phenotypic plasticity. Secondly the morphological differences could reflect genetic divergence between the populations. Thirdly differing levels of introgression could be affecting $C$. angustifolium and hybrid morphologies at the two sites.

Macroalgae are highly plastic organisms whose morphologies are influenced by environmental conditions (Fowler-Walker et al., 2006; Hurd, 2000; Johnson \& Koehl, 1994; Kawamata, 2001). Leigh and the East Cape are located approximately $300 \mathrm{~km}$ apart, and are likely to experience different local environmental conditions. One major environmental difference between the two locations is their fetch, and consequently 
wave exposure. Leigh is sheltered by the Coromandel Peninsula and a range of offshore islands (including Great Barrier Island). By comparison, the East Cape is completely open to the Pacific Ocean. The extent of wave exposure is likely to be much lower at Leigh. Wave exposure has been found to affect total length, stipe thickness and the presence of vesicles in C. angustifolium, C. maschalocarpum and their hybrids (Chapter 3). However, none of these traits were measured in this study. This study investigated only stipe width, lamina width and lamina length; none of which showed significant or non-significant trends in variation between wave exposure zones (Chapter 3). Reduced wave exposure would affect $C$. angustifolium and the hybrids more than $C$. maschalocarpum because of their relative wave exposure distributions. Carpophyllum angustifolium and the hybrids tend to be distributed in moderately exposed to exposed areas, while C. maschalocarpum is distributed in more sheltered areas (Chapter 4). The lack of difference between Leigh and East Cape C. maschalocarpum morphology could be explained by the presence of similarly sheltered areas at Leigh and the East Cape (see Chapter 4).

Morphological differences between Leigh and East Cape individuals could reflect the level of genetic connectivity between populations, and the different dispersal capacities of the two species. Leigh and the East Cape are separated by approximately $500 \mathrm{~km}$ of coastline. Carpophyllum have low dispersal capacity due to their large non-motile eggs, which in some cases are fertilised in situ on the maternal plant (Delf, 1939). Schiel (1980) found that three quarters of recruits settled within four metres of parent $C$. angustifolium and C. maschalocarpum plants. Rafting can allow long distance dispersal in some macroalgae. The potential for rafting differs between $C$. angustifolium and $C$. 
maschalocarpum due to morphological differences. Vesicles can provide the buoyancy required for rafting, and are present in some C. maschalocarpum individuals but are completely absent in C. angustifolium (Chapter 2, Adams, 1994; Dromgoole, 1990). Rafting has the potential to move genetic material large distances, and could explain the morphological similarity between C. maschalocarpum individuals from Leigh and the East Cape.

Alternatively C. angustifolium and hybrid morphology could differ between Leigh and the East Cape because of differing levels of introgression, i.e. the backcrossing of hybrids with parental species. Introgression can facilitate the transfer of genetic information from one parental species to another (Seehausen, 2004), and therefore can affect the morphologies of parental species (Gammon et al., 2007; Grant et al., 2004; Lihova et al., 2007). Eggs and sperm have been found in the hybrids, during the reproductive period of both parental species (Buchanan \& Hodge, pers. obs.). East Cape individuals have been found with $C$. angustifolium morphology and hybrid ITS2 ribotype suggesting introgression (Chapter 2). That only $C$. angustifolium and not $C$. maschalocarpum backcrosses were found in the previous study suggests introgression could be one way, resulting in genetic modification of C. angustifolium only.

This study finds morphological support for hybridisation between C. angustifolium and C. maschalocarpum at Leigh. Further study needs to be done to investigate the morphological differences found in C. angustifolium and the hybrids between Leigh and the East Cape. Laboratory and field experiments need to be conducted to investigate the role of the environment on Carpophyllum morphology. Knowledge of the genetic 
structure of populations at different spatial scales would add significantly to the existing information on egg and zygote dispersal. The presence and extent of introgression in this hybrid system needs to be explored with microsatellite data, or by comparing patterns in uniparental and biparental markers. 


\section{Chapter 6: General Discussion}

The process of hybridisation has been identified as a common and important evolutionary force (Arnold, 1997; Morgan-Richards et al., 2009; Seehausen, 2004). However, the vast majority of research into the topic is based on terrestrial plant and animal systems (Gardner, 1997). A New Zealand recent review made no mention of hybridisation outside the plant and animal kingdoms (Morgan-Richards et al., 2009). The presence of hybridisation between the brown algae Carpophyllum angustifolium and Carpophyllum maschalocarpum provided an opportunity to investigate hybridisation in a marine system, and in species from the kingdom Chromista. Hybrids have been identified in other species of brown algae, in particular within the order Fucales (Billard et al., 2005; Coyer et al., 2006b; Wallace et al., 2004). However, previous study on hybridisation in the order Fucales has not included a detailed morphometric analysis combined with molecular data, nor a detailed study of distribution (Coyer et al., 2007; Scott \& Hardy, 1994). In this case hybridisation resulted in morphologically intermediate hybrids which were distributed in intermediate wave exposure zones.

\section{Morphology}

Carpophyllum angustifolium, C. maschalocarpum and their hybrids had distinct and intermediate morphologies in this study. Hybrids have generally been found to have intermediate morphologies; although novel, similar and more extreme morphologies have also been found (Arnold \& Hodges, 1995; Rieseberg \& Ellstrand, 1993; Seehausen, 2004). Identifiable hybrid and parental morphotypes have been found within many Fucus hybrid species complexes but morphologically ambiguous individuals also 
exist (Coyer et al., 2002; Kucera \& Saunders, 2008; Scott \& Hardy, 1994). The presence of hybrid genotypes with distinctive C. angustifolium morphotypes suggests that asymmetrical introgression is occurring. Introgression has been identified in Fucus hybrid complexes, and determined as a significant factor in the evolution of Fucus lineages (Coyer et al., 2006a; Coyer et al., 2007; Wallace et al., 2004).

\section{Morphology and wave exposure}

Some aspects of Carpophyllum angustifolium and C. maschalocarpum morphology were found to be correlated with wave exposure. In the more wave exposed zones Carpophyllum angustifolium individuals were longer, while C. maschalocarpum individuals were shorter, had thinner stipes and less frequent vesicle presence. There were also trends of $C$. maschalocarpum individuals having thinner lamina, and lower branch presence in higher wave exposures. Some of the patterns were as expected, namely that morphological traits which reduced drag would be present in high wave exposure zones. Some of these patterns, namely total length in C. angustifolium and stipe and lamina width in C. maschalocarpum were the opposite of those generally found in macroalgae with regard to wave exposure (Fowler-Walker et al., 2006; Johnson \& Koehl, 1994; Kawamata, 2001; Stewart \& Carpenter, 2003). It is hypothesised that these patterns could be a result of flexibility reducing the importance of morphological traits in high wave exposures. Flexibility can allow morphological reconfiguration, which can reduce the drag forces macroalgae are exposed to (Carrington, 1990; Denny, 2006). Some flexible macroalgae can have reduced drag in higher flows (Carrington, 1990; Gaylord et al., 1994). The patterns of thinner laminae and stipes in $C$. maschalocarpum could be a reflection of the age of these components in different wave 
exposure zones. Laminae and stipes get thicker with age, and individuals and individuals and their components are often younger in more exposed areas due to wave damage (Dudgeon \& Johnson, 1992).

That the relationships between wave exposure and morphology differed between the two species could be due to their different wave exposure distributions. High levels of phenotypic plasticity have been hypothesised as being associated with generalist species, as opposed to specialist species (Sultan, 2000). Carpophyllum maschalocarpum had a

much broader wave exposure distribution than C. angustifolium. Carpophyllum angustifolium was only found in the two most exposed zones, which suggests specialisation to high wave exposure. Carpophyllum maschalocarpum was found in all four wave exposure zones, which indicates it is more of a generalist species.

\section{Distribution}

The distributions of C. angustifolium, C. maschalocarpum and their hybrids were found to be correlated with wave exposure. Carpophyllum angustifolium was only distributed in the relatively high wave exposed zones, while C. maschalocarpum was distributed mainly in the more sheltered zones, as hypothesised by Dromgoole (1973), Lindaeur (1961) and Adams (1994). Hybrids were distributed in intermediate wave exposure zones where both parental species were present. The presence of an intermediate hybrid distribution relative to environmental conditions in parental species' distributions has been found in other species, and is often a result of environmentally dependent hybrid fitness (Campbell \& Waser, 2001; Campbell \& Waser, 2007; Fritsche \& Kaltz, 2000; Miglia et al., 2005). Carpophyllum hybrids with their intermediate morphology could be 
more successful in intermediate wave exposures. In the only other studies on Fucalean hybrid distribution the hybrid with extreme morphology occurred in extreme environments, and the hybrid with intermediate morphology was distributed in intermediate environments, (Coyer et al., 2007; Scott \& Hardy, 1994).

The intermediate wave exposure zones where Carpophyllum hybrids were found were also the zones with parental species overlap: the contact zone. The intermediate distribution could be a reflection of contact zones, parental gamete dispersal capacity and hybrid zygote dispersal. Difficulties arise in teasing apart dispersal limitation from environmental selection in this study, as the true extent of the contact zone was not determined. Parental species occur below the top $0.5 \mathrm{~m}$ depth investigated, and subsequently the contact zone could extend beyond this depth.

\section{Hybridisation at Leigh}

The individuals from Leigh formed a cluster tree with the same branching and shape as the cluster tree of individuals with known hybrids from the East Cape. This strongly suggests that hybridisation is also occurring at Leigh. That C. angustifolium and hybrid morphological clusters at Leigh significantly differed from their genetically identified equivalents at the East Cape site could be due to environmental differences, genetic divergence or differing levels of introgression between the two sites. Leigh and the East Cape are located approximately $300 \mathrm{~km}$ apart, and are likely to experience different local environmental conditions. One major environmental difference between the two locations is their fetch, and consequently wave exposure. The extent of wave exposure is likely to be much lower at Leigh. However, none of the traits measured on individuals at 
Leigh were found to be affected by wave exposure in Chapter 3. Morphological differences between Leigh and East Cape individuals could reflect the level of genetic connectivity between populations, and the different dispersal capacities of the two species. Leigh and the East Cape are separated by approximately $500 \mathrm{~km}$ of coastline. Carpophyllum have low dispersal capacity, with recruits typically settling within metres of parent plants (Schiel, 1980). However, rafting can allow long distance dispersal in $C$. maschalocarpum due to the presence of vesicles (Chapter 2, Adams, 1994; Dromgoole, 1990). Rafting has the potential to move genetic material large distances, and could explain the presence of morphological differentiation between Leigh and the East Cape in C. angustifolium and not C. maschalocarpum. Alternatively C. angustifolium and hybrid morphology could differ between Leigh and the East Cape because of differing levels of introgression, i.e. the backcrossing of hybrids with parental species. Introgression facilitates transfer of genetic information from one parental species to another (Seehausen, 2004), which can affect the morphologies of parental species (Gammon et al., 2007; Grant et al., 2004; Lihova et al., 2007). Eggs and sperm have been found in the hybrids during the reproductive period of both parental species (Buchanan \& Hodge, pers. obs.). East Cape individuals have been found with $C$. angustifolium morphology and hybrid ITS2 ribotype suggesting introgression (Chapter 2). That only C. angustifolium and not C. maschalocarpum backcrosses were found in the previous study suggests introgression could be one way, resulting in genetic modification of C. angustifolium only. 


\section{Limitations of this study}

This study investigated wave exposure categorically, which has several flaws. First nonlinear relationships between morphology and wave exposure can be distorted and misinterpreted when exposure is categorised (Kitzes \& Denny, 2005). Secondly relationships between wave exposure and morphology could be obscured or confused by small scale wave exposure variability. In a study aimed to compare algal morphology in exposed, semi-exposed and protected sites; Eckman (2003) found 30-50\% of variation in water flow occurred between replicates at the same site. Attempts in this study to deploy dynamometers to measure maximum velocities were unsuccessful. Research with continuous measures of wave exposure could be limited by the lack of a comprehensive method for such measurements in the high wave exposed zones.

\section{Future directions}

The value of ITS for confirming and determining the extent of introgression is limited due to homogenisation of ITS (Alvarez \& Wendel, 2003). Microsatellites have a high mutation rate and large variability, and have been used successfully to resolve relationships in a Fucus hybrid complex (Coyer et al., 2006b; Coyer et al., 2007; Engel et al., 2005; Wallace et al., 2004). Introgression can also be identified by comparing uniparentally inherited DNA, such as mtDNA or cpDNA, with nuclear DNA in the putative hybrids and introgressed individuals (Coyer et al., 2007; Coyer et al., 2002). Further investigation of this hybrid system using microsatellites and maternally inherited DNA in conjunction with morphology will have greater power to confirm and determine the extent and symmetry of introgression, and identify backcrosses, $F_{2}$ and later hybrids. Research investigating the attachment strength and tenacity of holdfasts for the parent 
species and hybrids would provide insight into fitness in different wave exposure environments. Furthermore laboratory experiments investigating drag on different Carpophyllum morphologies in different flow regimes would also help resolve the importance of morphology in Carpophyllum distribution. Laboratory studies also need to be conducted to investigate how wave exposure affects zygote attachment, whether it differs between the two species and hybrids, and whether it could be structuring adult distributions. No study has yet fully investigated the reproductive potential of Carpophyllum hybrids; determining the quality and quantity of eggs and sperm produced will provide information on the potential for introgression in this species complex.

\section{Conclusions}

This study found C. angustifolium $\times$ C. maschalocarpum hybrids to have intermediate and distinct morphology from the parent species, as well as evidence which suggests introgression is occurring. Also some morphological traits in the parental species were found to be correlated with wave exposure. The distributions of the parental species and hybrids were also correlated with wave exposure, with hybrids occurring in intermediate areas. Hybrids were only distributed in wave exposure zones with parental species overlap. Finally the study found morphological evidence of hybridisation in northern populations where parental species have overlapping ITS2 sequences. 


\section{References}

Adams, N.M. 1994. Seaweeds of New Zealand: an illustrated guide. Christchurch: Canterbury University Press.

Albert, M.E., Dantonio, C.M. and Schierenbeck, K.A. 1997. Hybridization and introgression in Carpobrotus spp. (Aizoaceae) in California .1. Morphological evidence. American Journal of Botany, 84: 896-904.

Alvarez, I. and Wendel, J.F. 2003. Ribosomal ITS sequences and plant phylogenetic inference. Molecular Phylogenetics and Evolution, 29: 417-434.

Anderson, E. 1953. Introgressive Hybridization. Biological Reviews of the Cambridge Philosophical Society, 28: 280-307.

Arnold, M.L. 1997. Natural hybridization and evolution. Oxford: Oxford University Press.

Arnold, M.L. and Hodges, S.A. 1995a. Are natural hybrids fit or unfit relative to their parents. Trends in Ecology \& Evolution, 10: 67-71.

Arnold, M.L. and Hodges, S.A. 1995b. The Fitness of Hybrids - Reply. Trends in Ecology \& Evolution, 10: 289-289.

Arnold, M.L., Kentner, E.K., Johnston, J.A., Cornman, S. and Bouck, A.C. 2001. Natural hybridisation and fitness. Taxon, 50: 93-104.

Arsenault, D.J., Marchinko, K.B. and Palmer, A.R. 2001. Precise tuning of barnacle leg length to coastal wave action. Proceedings of the Royal Society of London Series B-Biological Sciences, 268: 2149-2154.

Baack, E.J. and Rieseberg, L.H. 2007. A genomic view of introgression and hybrid speciation. Current Opinion in Genetics \& Development, 17: 513-518.

Baardseth, E. 1970. A square-scanning, two stage sampling method of estimating seaweed quantities. Norwegian Institude of Seaweed Research Report, 33: 1-40.

Ballantine, W.J. 1961. A biologically defined exposure scale for the comparative description of rocky shores. Field Studies, 1: 1 - 18.

Barton, N.H. and Hewett, G.M. 1985. Analysis of hybrid zones. Annual reveiw of ecology and systematics, 16: 113-148.

Billard, E., Daguin, C., Pearson, G., Serrao, E., Engel, C. and Valero, M. 2005a. Genetic isolation between three closely related taxa: Fucus vesiculosus, $F$. spiralis, and F. ceranoides (Phaophyceae). Journal of Phycology, 41: 900-905.

Billard, E., Serrao, E.A., Pearson, G.A., Engel, C.R., Destombe, C. and Valero, M. 2005b. Analysis of sexual phenotype and prezygotic fertility in natural populations of Fucus spiralis, F. vesiculosus (Fucaceae, Phaeophyceae) and their putative hybrids. European Journal of Phycology, 40: 397-407.

Blanchette, C.A. 1997. Size and survival of intertidal plants in response to wave action: A case study with Fucus gardneri. Ecology, 78: 1563-1578.

Buchanan, J. unpubl. data. Hybridisation in the genus Carpophyllum. Wellington: Victoria University of Wellington

Campbell, D.R. and Waser, N.M. 2001. Genotype-by-environment interaction and the fitness of plant hybrids in the wild. Evolution, 55: 669-676.

Campbell, D.R. and Waser, N.M. 2007. Evolutionary dynamics of an Ipomopsis hybrid zone: Confronting models with lifetime fitness data. American Naturalist, 169: 298-310. 
Carrington Bell, E. and Denny, M.W. 1994. Quantifying wave exposure - A simple device for recording maximum velocity and results of its use at several field sites. Journal of Experimental Marine Biology and Ecology, 181: 9-29.

Carrington, E. 1990. Drag and dislodgment of an intertidal macroalga: consequences of morphological variation in Mastocarpus papillatus Kutzing. Journal of Experimental Marine Biology and Ecology, 139: 185-200.

Casgrain, P. and Legendre, P. 1999. The R Package, version 4.0.

Casteleyn, G., Adams, N.G., Vanormelingen, P., Debeer, A.E., Sabbe, K. and Vyverman, W. 2009. Natural hybrids in the marine diatom Pseudo-nitzschia pungens (Bacillariophyceae): Genetic and morphological evidence. Protist: in press (doi:10.1016/j.protis.2008.1011.1002).

Chapman, A.R.O. 1995. Functional ecology of fucoid algae - 23 years of progress. Phycologia, 34: 1-32.

Chen, J.W., Tauer, C.G., Bai, G.H., Huang, Y.H., Payton, M.E. and Holley, A.G. 2004. Bidirectional introgression between Pinus taeda and Pinus echinata: evidence from morphological and molecular data. Canadian Journal of Forest ResearchRevue Canadienne De Recherche Forestiere, 34: 2508-2516.

Clayton, M.N. 1984. Evolution of the Phaeophyta with particular reference to the Fucales. Progress in Phycological Researh, 3: 11.

Cole, R.G., Babcock, R.C. and Travers, V. 2001. Distributional expansion of Carpophyllum flexuosum onto wave-exposed reefs in north-eastern New Zealand. New Zealand Journal of Marine and Freshwater Research, 35: 17-32.

Coleman, M.A. and Muhlin, J.F. 2008. Patterns of spatial variability in the morphology of sympatric fucoids. Northeastern Naturalist, 15: 111-122.

Correa, J.A., Lagos, N.A., Medina, M.H., Castilla, J.C., Cerda, M., Ramirez, M., Martinez, E., Faugeron, S., Andrade, S., Pinto, R. and Contreras, L. 2006. Experimental transplants of the large kelp Lessonia nigrescens (Phaeophyceae) in high-energy wave exposed rocky intertidal habitats of northern Chile: Experimental, restoration and management applications. Journal of Experimental Marine Biology and Ecology, 335: 13-18.

Coyer, J.A., Hoarau, G., Oudot-Le Secq, M.-P., Stam, W.T. and Olsen, J.L. 2006a. A mtDNA-based phylogeny of the brown algal genus Fucus (Heterokontophyta; Phaeophyta). Molecular Phylogenetics and Evolution, 39: 209-222.

Coyer, J.A., Hoarau, G., Pearson, G.A., Serrao, E.A., Stam, W.T. and Olsen, J.L. 2006b. Convergent adaptation to a marginal habitat by homoploid hybrids and polyploid ecads in the seaweed genus Fucus. Biology Letters, 2: 405-408.

Coyer, J.A., Hoarau, G., Stam, W.T. and Olsen, J.L. 2007. Hybridization and introgression in a mixed population of the intertidal seaweeds Fucus evanescens and $F$. serratus. Journal of Evolutionary Biology, 20: 2322-2333.

Coyer, J.A., Miller, K.A., Engle, J.M., Veldsink, J., Cabello-Pasini, A., Stam, W.T. and Olsen, J.L. 2008. Eelgrass meadows in the California Channel Islands and adjacent coast reveal a mosaic of two species, evidence for introgression and variable clonality. Annals of Botany, 101: 73-87.

Coyer, J.A., Olsen, J.L. and Stam, W.T. 1997. Genetic variability and spatial separation in the sea palm kelp Postelsia palmaeformis (Phaeophyceae) as assesed with M13 fingerprints and RAPDs. Journal of Phycology, 33: 561-568. 
Coyer, J.A., Peters, A.F., Hoarau, G., Stam, W.T. and Olsen, J.L. 2002a. Hybridization of the marine seaweeds, Fucus serratus and Fucus evanescens (Heterokontophyta: Phaeophyceae) in a 100-year-old zone of secondary contact. Proceedings of the Royal Society - Biological Sciences (Series B), 269: 18291834.

Coyer, J.A., Peters, A.F., Hoarau, G., Stam, W.T. and Olsen, J.L. 2002b. Inheritance patterns of ITS1, chloroplasts and mitochondria in artificial hybrids of the seaweeds Fucus serratus and F. evanescens (Phaeophyceae). European Journal of Phycology, 37: 173-178.

Crapon de Caprona, M.D. and Fritzsch, B. 1984. Interspecific fertile hybrids of haplochromine Cichlidae (Teleostei) and their possible importance for speciation Netherlands Journal of Zoology, 34: 503-538.

Delf, E.M. 1939. Studies in the Fucales of New Zealand I. The genus Carpophyllum Grev. The Journal of Botany, 77: 129 - 138.

Denny, M. 1988. Biology and the Mechanics of the Wave-Swept Environment. Princeton, USA: Princeton University Press.

Denny, M.W. 2006. Ocean waves, nearshore ecology, and natural selection. Aquatic Ecology, 40: 439-461.

Dromgoole, F.I. 1965. Contribution to the ecology of Carpophyllum maschalocarpum (Turn.) Grev.: Unpublished MSc thesis, University of Auckland.

Dromgoole, F.I. 1973. A contribution to the biology of the genus Carpophyllum Grev.: Unpublished Phd thesis, University of Auckland.

Dromgoole, F.I. 1990. Gas-filled structures, bouyancy and support in marine macroalgae. Progress in Phycological Research: 169-211.

Dudgeon, S.R. and Johnson, A.S. 1992. Thick vs thin - Thallus morphology and tissue mechanics influence differential drag and dislodgment of 2 codominant seaweeds. Journal of Experimental Marine Biology and Ecology, 165: 23-43.

Eckman, J.E. 1983. Hydrodynamic Processes Affecting Benthic Recruitment. Limnology and Oceanography, 28: 241-257.

Eckman, J.E., Duggins, D.O. and Siddon, C.E. 2003. Current and wave dynamics in the shallow subtidal: implications to the ecology of understory and surface-canopy kelps. Marine Ecology-Progress Series, 265: 45-56.

Ellstrand, N.C. and Schierenbeck, K.A. 2000. Hybridization as a stimulus for the evolution of invasiveness in plants? Paper presented at the Colloquium on Variation and Evolution in Plants and Micro-organisms - Toward a New Synthesis 50 Years after Stebbins, Irvine, California, 2000.

Emms, S.K. and Arnold, M.L. 1997. The effect of habitat on parental and hybrid fitness: Transplant experiments with Louisiana irises. Evolution, 51: 1112-1119.

Engel, C.R., Daguin, C. and Serrao, E. 2005. Genetic entities and mating system in hermaphroditic Fucus spiralis and its close dioecious relative $F$. vesiculosus (Fucaceae, Phaeophyceae). Molecular Ecology, 14: 2033-2046.

Engelen, A.H., Aberg, P., Olsen, J.L., Stam, W.T. and Breeman, A.M. 2005. Effects of wave exposure and depth on biomass, density and fertility of the fucoid seaweed Sargassum polyceratium (Phaeophyta, Sargassaceae). European Journal of Phycology, 40: 149-158. 
Engelen, A.H., Olsen, J.L., Breeman, A.M. and Stam, W.T. 2001. Genetic differentiation in Sargassum polyceratium (Fuclaes: Phaeophyceae) around the island of Curacao (Netherlands Antilles). Marine Biology, 139: 267-277.

Estabrook, G.F., Gil-ad, N.L. and Reznicek, A.A. 1996. Hypothesizing hybrids and parents using character intermediacy, parental distance, and equality. Taxon, 45: 647-662.

Feliner, G.N. and Rossello, J.A. 2007. Better the devil you know? Guidelines for insightful utilization of nrDNA ITS in species-level evolutionary studies in plants. Molecular Phylogenetics and Evolution, 44: 97-919.

Fielding, A.H. 2007. Cluster and classification techniques for the biosciences. Cambridge: Cambridge University Press.

Fishman, L. and Willis, J.H. 2006. A cytonuclear incompatibility causes anther sterility in Mimulus hybrids. Evolution, 60: 1372-1381.

Foster, B.A. 1967. A guide to the littoral balanomorph barnacles of New Zealand. Tuatara, 15: 75-86.

Foster, B.A. 1978. The marine fauna of New Zealand: Barnacles (Cirripedia: Thoracica). New Zealand Oceanographic Institute, 69: 1-160.

Fowler-Walker, M.J., Wernberg, T. and Connell, S.D. 2006. Differences in kelp morphology between wave sheltered and exposed localities: morphologically plastic or fixed traits? Marine Biology, 148: 755-767.

Fritsche, F. and Kaltz, O. 2000. Is the Prunella (Lamiaceae) hybrid zone structured by an environmental gradient? Evidence from a reciprocal transplant experiment. American Journal of Botany, 87: 995-1003.

Fritz, R.S. 1999. Resistance of hybrid plants to herbivores: Genes, environment, or both? Ecology, 80: 382-391.

Gammon, M.A., Grimsby, J.L., Tsfrelson, D. and Kesseli, R. 2007. Molecular and morphological evidence reveals introgression in swarms of the invasive taxa Fallopia japonica, F. sachalinensis, and F. X bohemica (Polygonaceae) in the United States. American Journal of Botany, 94: 948-956.

Gardner, J.P.A. 1997. Hybridization in the sea. In Advances in Marine Biology, Vol 31, Advances in Marine Biology, pp. 1-78.

Gaylord, B. 1999. Detailing agents of physical disturbance: wave-induced velocities and accelerations on a rocky shore. Journal of Experimental Marine Biology and Ecology, 239: 85-124.

Gaylord, B., Blanchette, C.A. and Denny, M.W. 1994. Mechanical Consequences of Size in Wave-Swept Algae. Ecological Monographs, 64: 287-313.

Graham, L.E. and Wilcox, L.W. 2000. Algae. Sydney: Prentice-Hall

Grant, P.R., Grant, B.R., Markert, J.A., Keller, L.F. and Petren, K. 2004. Convergent evolution of Darwin's finches caused by introgressive hybridization and selection. Evolution, 58: 1588-1599.

Grant, P.R., Grant, B.R. and Petren, K. 2005. Hybridization in the recent past. American Naturalist, 166: 56-67.

Greene, B. 1999. Genetic variation and hybridisation of black stilts (Himantopus novaezelandiae) and pied stilts (H. leucocephalus), Order Charadriiformes. New Zealand Journal of Zoology, 26: 271-277.

Hammer, O., Harper, D.A.T. and Ryan, P.D. 2001. PAST: Paleontological Statistics Software Package for Education and Data Analysis. In Palaeontologia 
Electronica,

pp. electronica.org/2001_2001/past/issue2001_2001.htm

http://palaeo-

Hardig, T.M., Brunsfeld, S.J., Fritz, R.S., Morgan, M. and Orians, C.M. 2000. Morphological and molecular evidence for hybridization and introgression in a willow (Salix) hybrid zone. Molecular Ecology, 9: 9-24.

Hardy, F.G. and Moss, B.L. 1979. The effects of substratum on the mophology of the rhizoids of Fucus germlings. Estuarine and Coastal Marine Science, 9: 577-584.

Harley, C.D.G. 2003. Abiotic stress and herbivory interact to set range limits across a two-dimensional stress gradient. Ecology, 84: 1477-1488.

Harrison, R.G. 1986. Pattern and process in a narrow hybrid zone. Heredity, 56: 337349.

Harrison, R.G. 1993. Hybrid zones and the evolution process.

Heaven, C.S. and Scrosati, R.A. 2008. Benthic community composition across gradients of intertidal elevation, wave exposure, and ice scour in Atlantic Canada. Marine Ecology-Progress Series, 369: 13-23.

Hegarty, M.J. and Hiscock, S.J. 2005. Hybrid speciation in plants: new insights from molecular studies. New Phytologist, 165: 411-423.

Hochkirch, A., Deppermann, J. and Groning, J. 2008. Phenotypic plasticity in insects: the effects of substrate color on the coloration of two ground-hopper species. Evolution \& Development, 10: 350-359.

Hurd, C.L. 2000. Water motion, marine macroalgal physiology, and production. Journal of Phycology, 36: 453-472.

Johansen-Morris, A.D. and Latta, R.G. 2008. Genotype by environment interactions for fitness in hybrid genotypes of Avena barbata. Evolution, 62: 573-585.

Johnson, A.S. and Koehl, M.A.R. 1994. Maintenance of dynamic strain similarity and environmental-stress factor in different flow habitats - thallus allometry and material properties of a giant kelp. Journal of Experimental Biology, 195: 381410.

Kauserud, H., Svegarden, I.B., Decock, C. and Hallenberg, N. 2007. Hybridization among cryptic species of the cellar fungus Coniophora puteana (Basidiomycota). Molecular Ecology, 16: 389-399.

Kawamata, S. 2001. Adaptive mechanical tolerance and dislodgement velocity of the kelp Laminaria japonica in wave-induced water motion. Marine EcologyProgress Series, 211: 89-104.

Kitzes, J.A. and Denny, M.W. 2005. Red algae respond to waves: Morphological and mechanical variation in Mastocarpus papillatus along a gradient of force. Biological Bulletin, 208: 114-119.

Kucera, H. and Saunders, G.W. 2008. Assigning morphological variants of Fucus (Fucales, Phaeophyceae) in Canadian waters to recognized species using DNA barcoding. Botany-Botanique, 86: 1065-1079.

Ladah, L., Bermudez, R., Pearson, G. and Serrao, E. 2003. Fertilization success and recruitment of dioecious and hermaphroditic fucoid seaweeds with contrasting distributions near their southern limit. Marine Ecology-Progress Series, 262: 173-183.

Landry, C.R., Hartl, D.L. and Ranz, J.M. 2007. Genome clashes in hybrids: insights from gene expression. Heredity, 99: 483-493. 
Landry, C.R., Wittkopp, P.J., Taubes, C.H., Ranz, J.M., Clark, A.G. and Hartl, D.L. 2005. Compensatory cis-trans evolution and the dysregulation of gene expression in interspecific hybrids of Drosophila. Genetics, 171: 1813-1822.

Levin, D.A. 2002. Nucleocytopiasmic incompatibility fosters speciation. Paper presented at the International Workshop on Plant Adaptation - Molecular Genetics and Ecology, Vancouver, Canada, 2002.

Lewis, R.J. 1996. Hybridization of brown algae: compatibility and speciation. In Cytology, genetics and molecular biology of algae (B.R. Chaudhary and S.B. Agrawal, eds), pp. 275-289. Amsterdam: SPB Academic Publishing.

Lewis, R.J. and Neushul, M. 1995. Intergeneric hybridization among five genera of the family lessoniaceae (Phaeophyceae) and evidence for polyploidy in a fertile Pelagophycus X Macrocystis hybrid. Journal of Phycology, 31: 1012-1017.

Lihova, J., Kucera, J., Perny, M. and Marhold, K. 2007. Hybridization between two polyploid Cardamine (Brassicaceae) species in north-western Spain: Discordance between morphological and genetic variation patterns. Annals of Botany, 99: 1083-1096.

Lindauer, V.W., Chapman, V.J. and Aiken, M. 1961. The marine algae of New Zealand: Phaeophyceae Nova Hedwigia, 3: 307-309.

Lindegarth, M. and Gamfeldt, L. 2005. Comparing categorical and continuous ecological analyses: Effects of "wave exposure" on rocky shores. Ecology, 86: 1346-1357.

Mach, K.J., Hale, B.B., Denny, M.W. and Nelson, D.V. 2007. Death by small forces: a fracture and fatigue analysis of wave-swept macroalgae. Journal of Experimental Biology, 210: 2231-2243.

Mallet, J. 2005. Hybridization as an invasion of the genome. Trends in Ecology \& Evolution, 20: 229-237.

Mathieson, A.C., Dawes, C.J., Wallace, A.L. and Klein, A.S. 2006. Distribution, morphology, and genetic affinities of dwarf embedded Fucus populations from the Northwest Atlantic Ocean. Botanica Marina, 49: 283-303.

Mathieson, A.C., Norton, T.A. and Neushul, M. 1981. The taxonomic implications of genetic and environmentally induced variations in seaweed morphology. Botanical Review, 47: 313-347.

Mboumba, G.B. and Ward, D. 2008. Phenotypic plasticity and local adaptation in two extreme populations of Acacia karroo. African Journal of Range \& Forage Science, 25: 121-130.

McQuaid, C.D., Lindsay, J.R. and Lindsay, T.L. 2000. Interactive effects of wave exposure and tidal height on population structure of the mussel Perna perna. Marine Biology, 137: 925-932.

Miglia, K.J., McArthur, E.D., Moore, W.S., Wang, H., Graham, J.H. and Freeman, D.C. 2005. Nine-year reciprocal transplant experiment in the gardens of the basin and mountain big sagebrush (Artemisia tridentata: Asteraceae) hybrid zone of Salt Creek Canyon: the importance of multiple-year tracking of fitness. Biological Journal of the Linnean Society, 86: 213-225.

Montanari, A. and Mignani, S. 1994. Notes on the bias of dissimilarity indices: the case of archaeological classification. Questiio, 18: 39-49.

Moore, W.S. 1977. Evaluation of narrow hybrid zones in vertebrates. Quarterly Review of Biology, 52: 263-277. 
Morgan-Richards, M., Smissen, R.D., Shepherd, L.D., Wallis, G.P., Hayward, J.J., Chan, C., Chambers, G.K. and Chapman, H.M. 2009. A review of genetic analyses of hybridisation in New Zealand. Journal of the Royal Society of New Zealand, 39: 15-34.

Nelson, W.A. 1994. Distribution of macroalgae in New Zealand - an archipelago in space in time. Botanica Marina, 37: 221-233.

Nybakken, J.W. and Bertness, M.D. 2004. Marine biology: an ecological approach. San Francisco: Pearson Education Inc.

Pennings, S.C., Grant, M.B. and Bertness, M.D. 2005. Plant zonation in low-latitude salt marshes: disentangling the roles of flooding, salinity and competition. Journal of Ecology, 93: 159-167.

Perrie, L.R., Shepherd, L.D. and Brownsey, P.J. 2005. Asplenium xlucrosum nothosp nov.: a sterile hybrid widely and erroneously cultivated as "Asplenium bulbiferum". Plant Systematics and Evolution, 250: 243-257.

Phillips, J.A. 2007. Heterokontophyta: Phaeophyceae. In Algae of Australia: Introduction (P.M. McCarthy and A.E. Orchard, eds), pp. 264-287. Melbourne: CSIRO Publishing.

Podani, J. 1999. Extending Gower's general coefficient of similarity to ordinal characters. Taxon, 48: 331-340.

Porter, E.T., Sanford, L.P. and Suttles, S.E. 2000. Gypsum dissolution is not a universal integrator of 'water motion'. Limnology and Oceanography, 45: 145-158.

Puijalon, S. and Bornette, G. 2004. Morphological variation of two taxonomically distant plant species along a natural flow velocity gradient. New Phytologist, 163: 651-660.

Repplinger, M., Johannesen, J., Seitz, A. and Comes, H.P. 2007. Morphological and molecular evidence for hybridization and introgression in Central European Arctium (Asteraceae). Plant Systematics and Evolution, 268: 75-95.

Rieseberg, L.H. 1998. Molecular ecology of hybridization. In Advances in Molecular Ecology (G.R. Carvalho, ed), pp. 459-487. Amsterdam: NATO Science Series.

Rieseberg, L.H. and Ellstrand, N.C. 1993. What can molecular and morphological markers tell us about plant hybridization? Critical Reviews in Plant Sciences, 12: 213-241.

Rohlf, F.J. 2000. NTSYS-pc: Numerical Taxonomy and Multivariate Analysis System, version 2.11. New York: Exeter Software.

Rohlf, F.J. and Sokal, R.R. 1981. Comparing numerical taxonomic studies. Systematic Zoology, 30: 459-490.

Ruuskanen, A.T. and Nappu, N.P. 2005. Morphological differences in Fucus gardneri between two shores with equal cartographic exposure values but different levels of wave action. Annales Botanici Fennici, 42: 27-33.

Sambatti, J.B.M., Ortiz-Barrientos, D., Baack, E.J. and Rieseberg, L.H. 2008. Ecological selection maintains cytonuclear incompatibilities in hybridizing sunflowers. Ecology Letters, 11: 1082-1091.

Schiel, D.R. 1980. A demographic and experimental evaluation of plant and herbivore interactions in subtidal algal stands: Unpublished Phd thesis, University of Auckland.

Schiel, D.R. 1985. Growth, survival and reproduction of two species of marine-algae at different densities in natural stands. Journal of Ecology, 73: 199-217. 
Schiel, D.R. 1988. Algal interactions on shallow subtidal reefs in northern New Zealand - a review. New Zealand Journal of Marine and Freshwater Research, 22: 481489.

Schiel, D.R. 1990. Macroalgal assemblages in New Zealand - structure, interactions and demography. Hydrobiologia, 192: 59-76.

Schiel, D.R. and Foster, M.S. 2006. The population biology of large brown seaweeds: Ecological consequences of multiphase life histories in dynamic coastal environments. Annual Review of Ecology Evolution and Systematics, 37: 343372.

Schneider, K.R., Wethey, D.S., Helmuth, B.S.T. and Hilbish, T.J. 2005. Implications of movement behavior on mussel dislodgement: exogenous selection in a Mytilus spp. hybrid zone. Marine Biology, 146: 333-343.

Scott, G.W. and Hardy, F.G. 1994. Observations of the occurrence of hybrids between two sympatric species of Fucoid algae. Cryptogamie Algologie, 15: 297-305.

Seehausen, O. 2004. Hybridization and adaptive radiation. Trends in Ecology \& Evolution, 19: 198-207.

Stewart, H.L. 2006. Morphological variation and phenotypic plasticity of buoyancy in the macroalga Turbinaria ornata across a barrier reef. Marine Biology, 149: 721730 .

Stewart, H.L. and Carpenter, R.C. 2003. The effects of morphology and water flow on photosynthesis of marine macroalgae. Ecology, 84: 2999-3012.

Sultan, S.E. 2000. Phenotypic plasticity for plant development, function and life history. Trends in Plant Science, 5: 537-542.

Tatarenkov, A., Jonsson, R.B., Kautsky, L. and Johannesson, K. 2007. Genetic structure in populations of Fucus vesiculosus (Phaeophyceae) over spatial scales from 10 $\mathrm{m}$ to $800 \mathrm{~km}$. Journal of Phycology, 43: 675-685.

Taylor, D.I. and Schiel, D.R. 2003. Wave-related mortality in zygotes of habitat-forming algae from different exposures in southern New Zealand: the importance of 'stickability'. Journal of Experimental Marine Biology and Ecology, 290: 229245.

Thompson, T.L. and Glenn, E.P. 1994. Plaster standards to measure water motion. Limnology and Oceanography, 39: 1768-1779.

Thomsen, M.S., Wernberg, T. and Kendrick, G.A. 2004. The effect of thallus size, life stage, aggregation, wave exposure and substratum conditions on the forces required to break or dislodge the small kelp Ecklonia radiata. Botanica Marina, 47: 454-460.

Thorsson, A., Palsson, S.P., Sigurgeirsson, A. and Anamthawat-Jonsson, K. 2007. Morphological variation among Betula nana (diploid), B-pubescens (tetraploid) and their triploid hybrids in Iceland. Annals of Botany, 99: 1183-1193.

Thuret, G. 1854. Recherches sur la fecondation des Fucacees. Annales des Sciences Naturelles (Botanique), 4: 197-214.

Tiebre, M.S., Bizoux, J.P., Hardy, O.J., Bailey, J.P. and Mahy, G. 2007. Hybridization and morphogenetic variation in the invasive alien Fallopia (Polygonaceae) complex in Belgium. American Journal of Botany, 94: 1900-1910.

Tiffin, P., Olsen, M.S. and Moyle, L.C. 2000. Asymmetrical crossing barriers in angiosperms. Proceedings of the Royal Society B-Biological Sciences, 268: 861867. 
Travers, V. 1996. Morphological variation in Carpophyllum flexulosum: Auckland University.

Trussell, G.C. 2000. Phenotypic clines, plasticity, and morphological trade-offs in an intertidal snail. Evolution, 54: 151-166.

Tuya, F. and Haroun, R.J. 2006. Spatial patterns and response to wave exposure of shallow water algal assemblages across the Canarian Archipelago: a multi-scaled approach. Marine Ecology-Progress Series, 311: 15-28.

Vadas, R.L., Johnson, S. and Norton, T.A. 1992. Recruitment and mortality of early post-settlement stages of benthic algae. British Phycological Journal, 27: 331351.

Vadas, R.L., Wright, W.A. and Miller, S.L. 1990. Recruitment of Ascophyllum nodosum: wave action as a source of mortality. Marine Ecology-Progress Series, 61: 263-272.

Wallace, A.L., Klein, A.S. and Mathieson, A.C. 2004. Determining the affinities of salt marsh fucoids using microsatellite markers: Evidence of hybridization and introgression between two species of Fucus (Phaeophyta) in a Maine estuary. Journal of Phycology, 40: 1013-1027.

Wang, H., Byrd, D.W., Howard, J.L., McArthur, E.D., Graham, J.H. and Freeman, D.C. 1998. Narrow hybrid zone between two subspecies of big sagebrush (Artemisia tridentata : Asteraceae). V. Soil properties. International Journal of Plant Sciences, 159: 139-147.

Wang, H., McArthur, E.D., Sanderson, S.C., Graham, J.H. and Freeman, D.C. 1997. Narrow hybrid zone between two subspecies of big sagebrush (Artemisia tridentata: Asteraceae) .4. Reciprocal transplant experiments. Evolution, 51: 95102.

Wernberg, T. 2005. Holdfast aggregation in relation to morphology, age, attachment and drag for the kelp Ecklonia radiata. Aquatic Botany, 82: 168-180.

Wernberg, T. and Thomsen, M.S. 2005. The effect of wave exposure on the morphology of Ecklonia radiata. Aquatic Botany, 83: 61-70.

Williams, S.L. and Di Fiori, R.E. 1996. Genetic diversity and structure in Pelvetia fastigiata (Phaeophyta: Fucales): does a small effective neighborhood size explain fine-scale genetic structure? Marine Biology, 126: 371-382.

Wilson, P. 1992. On inferring hybridity from morphological intermediacy. Taxon, 41: 11-23.

Zuccarello, G.C. and Lokhorst, G.M. 2005. Molecular phylogeny of the genus Tribonema (Xanthophyceae) using rbcL gene sequence data: monophyly of morphologically simple algal species. Phycologia, 44: 384-392. 


\title{
Appendix 1: Cluster tree of all of the morphologically identified individuals with East Cape
}

\author{
Morphological Identity \\ C. angustifolium \\ Hybrids \\ C. maschalocarpum
}

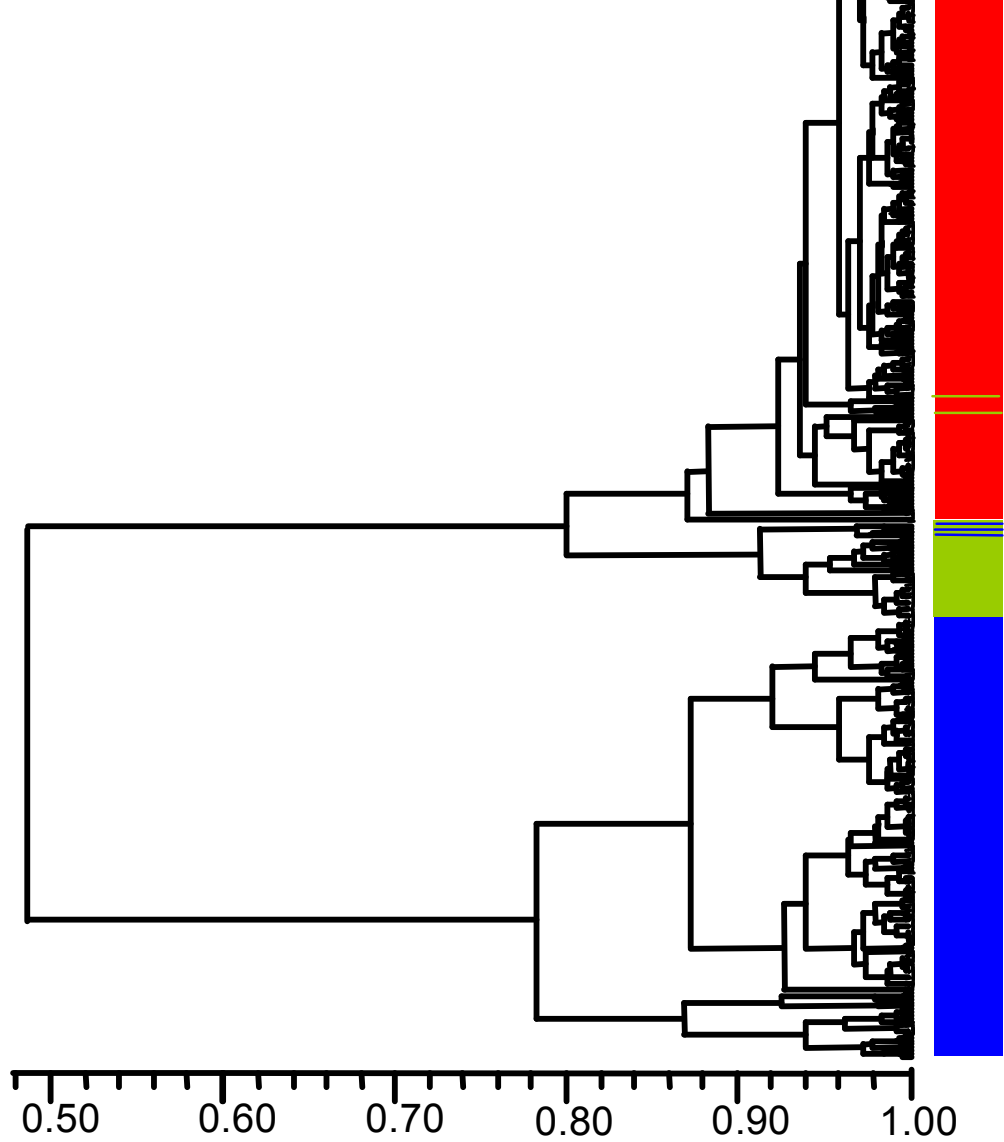

Similarity Coefficient

Figure 1: Cluster analysis of all the morphologically identified individuals from the East Cape. The coloured bars on the right of the tree show the morphological identity of individuals. The tree shows the same branching and structure as the tree of genetically identified individuals from the East Cape. The coenphenetic value of this tree is 0.90 indicating an excellent fit of the tree to the original data matrix. 


\section{Appendix 2: Herbarium specimens}

Representative specimens from this study have been deposited in the Te Papa herbarium.

The WELT numbers of each specimens are listed below:

WELT No. Identification Details

A029610

A029611

A029612

A029613

A029614

A029615

A029616

A029617

A029618

A029619

A029620

A029621

A029622

A029623

A029624

A029625

A029626

A029627

A029628

A029629

A029630

A029631

A029632

A029633

A029634

A029635

A029636

A029637/A

A029637/B

A029638/A

A029638/B
Carpophyllum angustifolium J.Agardh

Carpophyllum angustifolium J.Agardh

Carpophyllum angustifolium J.Agardh

Carpophyllum angustifolium J.Agardh

Carpophyllum angustifolium J.Agardh

Carpophyllum $\mathrm{x}$ angustifolium $\mathrm{x}$ maschalocarpum

Carpophyllum $x$ angustifolium $x$ maschalocarpum

Carpophyllum $x$ angustifolium $x$ maschalocarpum

Carpophyllum $x$ angustifolium $x$ maschalocarpum

Carpophyllum $x$ angustifolium $x$ maschalocarpum

Carpophyllum maschalocarpum (Turner) Grev.

Carpophyllum maschalocarpum (Turner) Grev.

Carpophyllum maschalocarpum (Turner) Grev.

Carpophyllum maschalocarpum (Turner) Grev.

Carpophyllum maschalocarpum (Turner) Grev.

Carpophyllum angustifolium J.Agardh

Carpophyllum angustifolium J.Agardh

Carpophyllum angustifolium J.Agardh

Carpophyllum angustifolium J.Agardh

Carpophyllum angustifolium J.Agardh

Carpophyllum $x$ angustifolium $x$ maschalocarpum

Carpophyllum $x$ angustifolium $x$ maschalocarpum

Carpophyllum $x$ angustifolium $x$ maschalocarpum

Carpophyllum $x$ angustifolium $x$ maschalocarpum

Carpophyllum $x$ angustifolium $x$ maschalocarpum

Carpophyllum maschalocarpum (Turner) Grev.

Carpophyllum maschalocarpum (Turner) Grev.

Carpophyllum maschalocarpum (Turner) Grev.

Carpophyllum maschalocarpum (Turner) Grev.

Carpophyllum maschalocarpum (Turner) Grev.

Carpophyllum maschalocarpum (Turner) Grev.

\section{Collection location}

Leigh

Leigh

Leigh

Leigh

Leigh

Leigh

Leigh

Leigh

Leigh

Leigh

Leigh

Leigh

Leigh

Leigh

Leigh

East Cape

East Cape

East Cape

East Cape

East Cape

East Cape

East Cape

East Cape

East Cape

East Cape

East Cape

East Cape

East Cape

East Cape

East Cape

East Cape 